No. 1548

\title{
Aspects of inflammation, angiogenesis and coagulation in preeclampsia
}

\author{
Roland Boij
}

\author{
FACULTY OF MEDICINE AND HEALTH SCIENCES \\ Linköping University Medical Dissertation No 1548 \\ Department of Clinical and Experimental Medicine \\ Obstetrics and Gynaecology, and Clinical Immunology \\ Linköping University \\ Department of Obstetrics and Gynaecology \\ County Hospital Ryhov, Jönköping \\ Sweden
}

\subsection{U UNKNEDNG}

Linköping 2016 
(2) Roland Boij, 2016

Published articles have been printed with the permission of the copyright holder Paper I Copyright (C) American Society for Investigative Pathology

Paper II, III (2) 2012 John Wiley \& Sons A/S

ISBN: 978-91-7685-651-2

ISSN 0345-0082

Printed by LiU-tryck. Linköping, Sweden, 2016 
to my family 
"Be warned, my son, of anything in addition to them. Of making many books there is no end, and much study wearies the body."

Ecclesiastes 12:11 


\section{ABSTRACT}

Preeclampsia is a major challenge to obstetricians, due to its impact on maternal and fetal morbidity and mortality and the lack of preventive and treatment strategies. The overall aim of this thesis is to increase the knowledge of the pathogenesis of preeclampsia including the role of inflammation, angiogenesis and coagulation, both locally at the fetomaternal interface and in the maternal circulation. Uncompensated maternal endothelial inflammatory responses to factors from stressed trophoblasts seem to be a major contributor to the syndrome, together with an imbalance in angiogenesis and an activated coagulation system. An increasing amount of data indicates an involvement of the immune system with defect tolerance to the conceptus as an integral part of the pathogenesis, at least in early-onset preeclampsia (EOP). We showed that a single administration of human preeclampsia serum in pregnant IL$10^{-/-}$mice induced the full spectrum of preeclampsia-like symptoms including hypoxic injury in uteroplacental tissues and endotheliosis in maternal kidneys. Importantly, preeclampsia serum, as early as 12 to 14 weeks of gestation, disrupted cross talk between trophoblasts and endothelial cells in an in vitro model of endovascular activity (Tube formation test). These results indicate that preeclamptic sera can be used to better understand the pathophysiology and to predict the disorder. Preeclampsia has been associated with increased inflammation, aberrant angiogenesis and activated coagulation, but their correlation and relative contribution are unknown. We found that markers for all these mechanisms were independently associated with preeclampsia. Cytokines, chemokines, and complement factors seem all to be part of a Th1-associated inflammatory reaction in preeclampsia, more pronounced in EOP than in late-onset preeclampsia (LOP), in line with a more homogeneous pathogenesis in EOP as based on placental pathology. In women with intrauterine growth restriction (IUGR), with an anticipated pathologic placentation, only differences in levels for sFlt-1 and PlGF were found in comparison with mothers without IUGR. Thus, sFlt-1 and PlGF seem to be indicators of placental pathology, 
while other biomarkers might also reflect maternal endothelial pathology. Chemokines, in contrast to cytokines, may prove to be useful markers in preeclampsia.

A deficiency in regulatory $\mathrm{T}$ (Treg) cells causing reduced immune regulatory capacity has been proposed in preeclampsia. Utilizing recent advances in flow cytometry phenotyping, we found no major alterations in circulating Treg numbers in preeclamptic women compared with normal pregnant and non-pregnant women. However, preeclampsia was associated with increased fractions of CTLA- $4^{+}$and $\mathrm{CCR} 4^{+}$cells within Treg subpopulations, which is in line with a migratory defect of Treg cells, and potentially associated with a reduced number of suppressive Treg cells at the fetomaternal interface. As we found that corticosteroid treatment affected the results, it should be accounted for in studies of EOP.

Chemokines are supposed to be part of the immune adaptation in pregnancy. We found a decreased expression of CCL18 (Th2/Treg-associated), in trophoblasts from preeclamptic compared to normal pregnant women, indicating a local regulatory defect in preeclampsia, in line with our finding of a possible migratory defect of circulating Treg cells. Due to increased expression of CCL20 (Th17) and CCL22 (Th2) in first trimester placenta and increased circulating levels of CXCL10 (Th1) and CCL20 (Th17) in third trimester preeclamptic women, we suggest that CCL20 and CCL22 may be important for implantation and early placentation while in third trimester of a preeclamptic pregnancy CXCL10 and CCL20 mainly mirror maternal increased endothelial inflammation and aberrant angiogenesis. In summary, we found that preeclampsia is associated with increased inflammation, aberrant angiogenesis and activated coagulation, caused by placental factors in maternal peripheral circulation, more pronounced in the early-onset form of preeclampsia. It also appears that there is a defective modulation of the immune system in preeclamptic pregnancies. The results provide a better understanding of the pathogenesis of preeclampsia and have given suggestions to predictive markers for preeclampsia in the future. 


\section{Sammanfattning}

Havandeskapsförgiftning (preeklampsi) har stor betydelse för sjuklighet och dödlighet för mamma och barn i samband med graviditet och förlossning. Det finns inte någon etablerad profylax och inte heller någon behandling, annat än att förlösa mamman, ofta långt före planerad förlossningstid. Det övergripande syftet med denna avhandling var att öka kunskapen om varför gravida kvinnor får preeklampsi och mekanismer för sjukdomen, med den långsiktiga målsättningen att hitta markörer för tidig upptäckt och förbättrad behandling. Inflammation i moderns blodkärl som en reaktion på faktorer i blodet som kommer från en skadad moderkaka, verkar vara en viktig bidragande orsak till preeklampsi, tillsammans med en nedsatt kärlnybildning och ett överaktivt koagulationssystem. Alltmer kunskap tyder på att mammans immunsystem i många fall bidrar till uppkomsten av preeklampsi.

Vi kunde visa i vårt första arbete att serum från kvinnor med preeklampsi, kunde överföra sjukdomen till gravida möss genom en enda injektion av serum. Graden av preeklampsi blev mycket mer omfattande hos möss där man tagit bort förmågan att producera IL-10 (en anti-inflammatorisk cytokin) hos mössen. Man kunde konstatera typiska skador både i moderkaka och njurar. En intressant observation var att serum från kvinnor med preeklampsi, så tidigt som i 12:e till 14: e graviditetsveckan, visade avvikelser i ett in vitro test där påverkan på blodkärlsceller mättes (Tube Formation test). Dessa resultat tyder på att serum från kvinnor med preeklampsi kan användas för att bättre förstå varför man får denna komplikation och hur den kan förutses och förebyggas.

Preeklampsi har förknippats med ökad inflammation, onormal kärlnybildning och aktiverad koagulation, men deras inbördes förhållande och relativa betydelse är okända. Vi fann i vårt andra arbete förhöjda nivåer i blod av markörer för alla dessa processer. Däremot var de inte kopplade till varandra, vilket talar för att det finns olika varianter av sjukdomen eller att proverna tagits vid olika tidpunkter i förloppet. Olika komponenter i immunsystemet (cytokiner, kemokiner och komplementfaktorer) verkade alla vara en del i en inflammatorisk reaktion $\mathrm{i}$ preeklampsi. Hos kvinnor med tillväxthämmat barn, med en förväntat defekt 
moderkaka, var enda skillnaderna i blodnivåer för markörerna de två faktorer som speglar kärlnybildning, nämligen sFlt-1 och PIGF, när man jämförde med kvinnor som födde normalstora barn. Således är dessa biomarkörer goda indikatorer på defekt moderkaka, medan andra markörer lika gärna kan spegla inflammation i kvinnans blodkärl. Studien gav stöd för att några etablerade markörer är lämpliga för att förutsäga sjukdomen, men även förslag på nya markörer identifierades.

Brist på regulatoriska T (Treg) celler, som kan dämpa immunsvaret, har föreslagits som förklaring till en ökad inflammation hos kvinnor med havandeskapsförgiftning. Vi använde nyutvecklade metoder för att identifiera Treg celler i vårt tredje arbete. Vi fann inga större förändringar i totala antalet Treg celler i blodcirkulationen hos kvinnor med havandeskapsförgiftning jämfört med normalt gravida och icke-gravida kvinnor. Däremot var Treg cellerna förändrade vid preeklampsi med ökat uttryck av vissa immunologiska molekyler (CTLA-4 och CCR4). Fynden är i linje med en minskad förflyttning av Treg celler till moderkakan vid havandeskapsförgiftning, vilket kan leda till ökad inflammation där.

Kemokiner är en del av immunförsvaret och borde därmed också vara en del av den immunologiska omställningen under graviditeten. Vi fann i vårt fjärde arbete en minskad förekomst av CCL18 i moderkaksceller vid havandeskapsförgiftning jämfört med förekomsten i normal graviditet. CCL18 är ett skyddande kemokin som bland annat lockar till sig Treg celler till moderkakan. Fyndet stämmer med vad vi fann i vårt tredje arbete, nämligen att det verkar vara en minskad förflyttning av Treg till moderkakan vid havandeskapsförgiftning.

Sammanfattningsvis har vi funnit att preeklampsi är förknippat med ökad inflammation, avvikande kärlnybildning och aktiverad koagulation vilket tycks bero på faktorer som är utsöndrade från moderkakan och som kan påvisas i mammans blodcirkulation. Det tycks också som en defekt omställning av immunförsvaret under graviditet bidrar till uppkomsten av preeklampsi. Resultaten ger en ökad kunskap om uppkomsten av preeklampsi och har gett förslag till markörer som i framtiden kan användas för att förutsäga havandeskapsförgiftning. 


\section{Original publications}

I. Kalkunte S, Boij R, Norris W, Friedman J, Lai Z, Kurtis J, Lim KH, Padbury JF, Matthiesen L, Sharma S. Sera from preeclampsia patients elicit symptoms of human disease in mice and provide a basis for an in vitro predictive assay. Am J Pathol. 2010; 177: 2387-98.

II. Boij R, Svensson J, Nilsson-Ekdahl K, Sandholm K, Lindahl TL, Palonek E, Garle M, Berg G, Ernerudh J, Jenmalm MC, Matthiesen L, Biomarkers of coagulation, inflammation, and angiogenesis are independently associated with preeclampsia. Am J Reprod Immunol. 2012; 68:258-70.

III. Boij R, Mjösberg J, Svensson-Arvelund J, Hjorth M, Berg G, Matthiesen L, Jenmalm MC, Ernerudh J. Regulatory T-cell subpopulations in severe or early-onset preeclampsia. Am J Reprod Immunol. 2015; 74: 368-78.

IV Boij R, Mehta R, Pavlopoulos G, Lindau R, Karlsson S, Svensson-Arvelund J, Berg G, Matthiesen L, Jenmalm MC, Ernerudh J. Local and systemic chemokines in preeclampsia: Trophoblast expression and plasma levels of CCL18, CCL20, CCL22 and CXCL10. Manuscript.

\section{Supplemental relevant publications}

1. Kalkunte S, Lai Z, Norris WE, Pietras LA, Tewari N, Boij R, Neubeck S, Markert UR, Sharma S, Novel approaches for mechanistic understanding and predicting preeclampsia. J Reprod Immunol. 2009;83: 134-8.

2. Mjösberg J, Svensson J, Johansson E, Hellström L, Casas R, Jenmalm MC, Boij R, Matthiesen L, Jönsson JI, Berg G, Ernerudh J, Systemic reduction of functionally suppressive $\mathrm{CD} 4{ }^{\mathrm{dim}} \mathrm{CD} 25^{\text {high }} \mathrm{Foxp} 3^{+}$Tregs in human second trimester pregnancy is induced by progesterone and 17beta-estradiol. J Immunol. 2009; 183:759-69. 


\section{CONTENTS}

1. Introduction

$1.1 \quad$ Relevance and definitions 15

1.2 Pathogenesis of preeclampsia 16

1.3 Immunological mechanisms in preeclampsia 25

1.3.1 Preconceptual mechanisms 25

1.3.2 Failure of immunological mechanisms 26

1.3.3 Natural killer cells (NK cells) 27

$\begin{array}{lll}\text { 1.3.4 Macrophages } & 29\end{array}$

1.3.5 Regulatory T Cells 31

1.3.6 Cytokines and chemokines 36

1.4 Increased inflammation in preeclampsia 41

1.5 Role of complement factors 45

$\begin{array}{lll}1.6 & \text { Activated coagulation in preeclampsia } & 47\end{array}$

1.7 Aberrant angiogenesis in preeclampsia $\quad 50$

1.8 Prediction and prevention $\quad 53$

2 Hypothesis and Aims 55

3 Material and methods $\quad 57$

$\begin{array}{lll}3.1 & \text { Subjects } & 57\end{array}$

3.1.1 Demographic background 57

3.1.2 Study group and control group (Paper I, II and IV) 57

3.1.3 Study group and control group (Paper III) 60

$\begin{array}{lll}3.2 & \text { Ethical considerations } & 62\end{array}$

3.2.1 Animal experiments 63

3.2.2 First trimester placental samples $\quad 64$

3.3 Material $\quad 65$

3.3.1 Blood sampling $\quad 65$

3.3.2 Placental biopsies $\quad 66$

$\begin{array}{lll}3.4 & \text { Methods } & 67\end{array}$

$\begin{array}{lll}3.4 .1 & \text { Animal experiments } & 67\end{array}$

3.4.2 Tube formation test 69

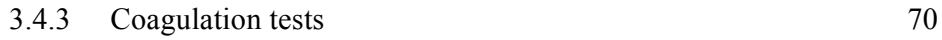

3.4.4 ELISA 71

3.4.5 Multiplex bead array $\quad 73$

3.4.6 Flow cytometry 75

3.4.7 Immunohistochemistry 78

3.5 Statistical analysis $\quad 83$

$4 \quad$ Results and discussion $\quad 85$

4.1 Paper I $\quad 85$

4.2 Paper II 93

$\begin{array}{lll}4.3 & \text { Paper III } & 104\end{array}$

4.4 Paper IV 112

$\begin{array}{lll}5 & \text { Summary and conclusions } & 121\end{array}$

6 Future perspectives 125

7 Acknowledgments 127

8 References 131 


\section{Abbreviations}

APTT Activated Pro-Thrombin Time

AT

Antithrombin

AT1-AAs Angiotensin II type 1 receptor autoantibody (AT1-AA)

C3 (a) Complement component 3 (a)

C5b-9 a complement component complex of component 5b, 6-9 (also called the membrane attack complex (MAC) or terminal complement complex (TCC))

CCL $\quad$ C-C motif Ligand

CXCL C-X-C motif Ligand

EOP Early-Onset Preeclampsia

GM-CSF Granulocyte - Macrophage Colony-Stimulating Factor

HELLP Hemolysis, Elevated Liver enzymes, Low Platelet count syndrome

IFN- $\gamma \quad$ Interferon gamma

IL Interleukin

IUGR Intra-uterine growth restriction

IUFD Intra-uterine fetal death

LMWH Low molecular weight heparin

LOP Late-Onset Preeclampsia

M-CSF Macrophage - Colony-Stimulating Factor

NK cells Natural Killer cells

NP Normal Pregnancy

PE Preeclampsia

PlGF Placental Growth Factor

PT/INR Prothrombin Time/International Normalized Ratio

PTX3 Pentraxin 3

SGA Small for Gestational Age

Th $1,2,17 \quad$ T helper $1,2,17$

Treg cells Regulatory T cells

TNF Tumour Necrosis Factor

TRAIL TNF-related apoptosis-inducing ligand

sFlt-1 Soluble Fms-like tyrosine kinase-1 


\section{Introduction}

\section{Relevance and definitions}

Gestational hypertension, intrauterine foetal growth restriction (IUGR), diabetes in pregnancy and premature delivery represent the major pregnancy complications causing maternal and foetal morbidity and mortality (2-4). Preeclampsia is clinically the most important form of gestational hypertension, sometimes combined with IUGR, and is a major cause of iatrogenic premature delivery, hence a major obstetrical problem. Preeclampsia is a leading cause of maternal and perinatal morbidity and mortality, affecting 3-10 percent of the pregnant population worldwide (3) and is a particular a problem in developing countries. In obstetrical practice, preeclampsia is one of the most challenging conditions since it is a serious threat to both the mother's and the baby's present and future health, especially when the onset is early in pregnancy. In fact, there is no treatment except to deliver the mother. There is as yet no established way to predict who will develop preeclampsia, nor is there an established and evidence-based prophylaxis. As a clinically active obstetrician I was therefore challenged to find out more about the pathophysiology of preeclampsia, by better identifying the pathogenetic mechanisms in order to contribute to identifying possible ways to predict, prevent, and hopefully treat the condition.

Preeclampsia can also be divided into early-onset (EOP) and late-onset preeclampsia (LOP), depending on debut before or after 34 weeks of gestation (5), although also 32 weeks has been used as a limit (6). In most cases, EOP means a severe preeclampsia while LOP more often is characterized by slow disease progress and less foetal impact. There is data indicating that EOP and LOP may, at least partly, represent two different conditions concerning both pathogenesis and clinical features. Whereas EOP in most cases is associated with low foetal birth weight and is probably caused by an underlying placental abnormality (placental preeclampsia), LOP may represent a syndrome with a mixture of conditions, ranging from mild preeclampsia with moderate placental affection to hypertensive conditions in pregnancy without placental dysfunction (maternal preeclampsia). A graph of foetal birth weight in LOP 
has a U-shaped form with an overrepresentation of both small and big babies mirroring the heterogeneity of that condition clinically and etiologically (7).

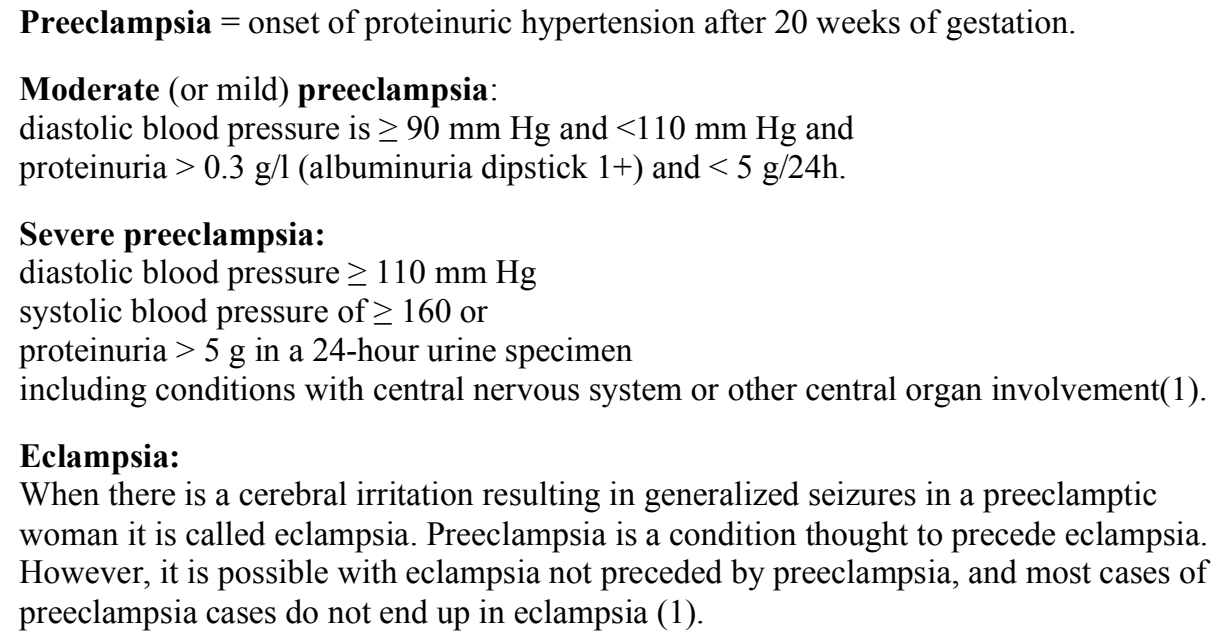

\section{Eclampsia:}

When there is a cerebral irritation resulting in generalized seizures in a preeclamptic woman it is called eclampsia. Preeclampsia is a condition thought to precede eclampsia. However, it is possible with eclampsia not preceded by preeclampsia, and most cases of preeclampsia cases do not end up in eclampsia (1).

\section{Pathogenesis of preeclampsia}

Preeclampsia is a syndrome (a pattern of clinical features), not one distinct disease, and the pathogenesis is probably as heterogeneous as the clinical presentation, and despite decades of research is still obscure and a subject of debate (8).

In this thesis I will discuss the impact of increased systemic inflammation, activated coagulation and aberrant angiogenesis on the pathogenesis of preeclampsia, as well as the immunological background to these mechanisms.

There is still no generally accepted aetiology of preeclampsia. An increasing body of evidence indicates, however, that an involvement of the immune system including maladaptation and defect tolerance to the conceptus is an integral part of the pathogenesis. This seems to be the fact for at least EOP with a placental origin, and probably some late-onset cases. Preeclampsia in general seems to be a result of imbalance between placental pro-inflammatory and anti-angiogenic factors and maternal adaptation to them. The placenta, but not the foetus, is a prerequisite for the syndrome since preeclampsia might be present in a woman with a molar pregnancy without a foetus, and delivery of the placenta is the only cure for the condition. Preeclampsia is seen more often in women with certain conditions that are related to 
an excess outflow of placental factors into the maternal circulation, such as twin pregnancies with double placentas. Moreover, it is also related to conditions with a feature of predisposing endothelial inflammation, e.g. chronic hypertension, diabetes mellitus, obesity, autoimmune diseases and renal diseases. Women with these latter conditions seem to be more sensitive to factors from the placenta that are harmful to the endothelium (9).

The pathogenesis of placental preeclampsia can be divided into three stages. The first and second stages involve a maternal maladaptation and lack of tolerance to the foetopaternal antigens. In normal pregnancy there is a deviation of the immune system towards a T helper 2 (Th2)/regulatory T cell (Treg)-like response at the foetomaternal interface. In preeclampsia, there is, however, a tendency to a local inflammation of the Th1/Th17 type in the first stage, at least in severe preeclampsia (10-13). In a normal decidua, Treg and Th2 cells predominate over Th1 and Th17 cells, while a skewing of this balance seems to be involved in complications of pregnancy (14). At the foetomaternal interface in a normal pregnancy decidua the number of Th17 cells is decreased but for Th2 cells, the number is unaltered or increased compared with the situation in peripheral circulation. Moderate Th1 and Th17 activity seems however to be a part of the early placental development during implantation, consistent with a mild inflammatory environment controlled by Treg cells (15).

In preeclampsia, an initial increased inflammation may trigger coagulation, contributing to apoptosis of trophoblasts and microthrombosis, and consequently defect trophoblast invasion of the spiral arteries with a defect remodelling These mechanisms lead to an underperfusion of the intervillous space, ending up in a shallow placentation. The result of this is local hypoxia in the placenta and oxidative and endoplasmatic reticulum (ER) stress, which represents the second stage of preeclampsia pathogenesis (9).

Early after implantation, extravillous trophoblast cells (EVT) migrate into the lumens of the spiral arteries (uterine arteries supplying the placenta). These vessels are converted into flaccid conduits, with disappearance of the smooth muscle wall 
resulting in very low resistance to blood flow. Initially, EVT occlude the spiral arteries and the embryo therefore develops in a relative hypoxic environment, where differentiating cells are protected from free potentially damaging oxygen radicals. As soon as the embryogenesis is complete, the maternal intervillous villous circulation becomes fully established, and the intraplacental oxygen concentration rises threefold. Onset of the circulation progress from the periphery to the centre of placenta, and high levels of oxidative stress in the periphery may contribute to the formation of the chorion laeve. Incomplete plugging of the spiral arteries with a premature onset of a widespread maternal intervillous circulation will be the result of a severely impaired trophoblast invasion. Extensive oxidative damage to the syncytiotrophoblast will follow, probably contributing to miscarriage. However, differing degrees of trophoblast invasion are possible with ongoing pregnancy, but conversion of the spiral arteries could be deficient with an ischemia-reperfusion-type phenomenon occurring. Impaired placental perfusion will then follow to a greater or lesser extent, and oxidative stress in the placenta will be generated contributing to preeclampsia (16).

A successful pregnancy is dependent on the conversion of the spiral arteries, involving loss of smooth muscle and the elastic lamina from the vessel wall. This conversion is associated with a 5-10-fold dilation of the vessel. Failure of this conversion is involved in pregnancy complications, like EOP and IUGR. Dilation of the spiral arteries slows the rate of flow by a factor of approximately 200. In the absence of this conversion, blood will enter the intervillous space in a turbulent way. This might damage the villous architecture and rupture anchoring villi, creating cystic lesions containing trophoblast tissue (17). 


\section{Normal}

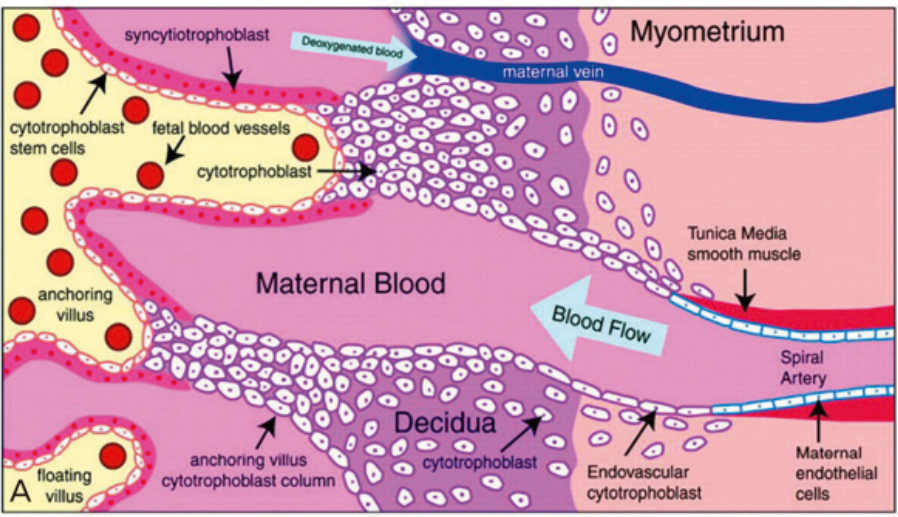

Preeclampsia

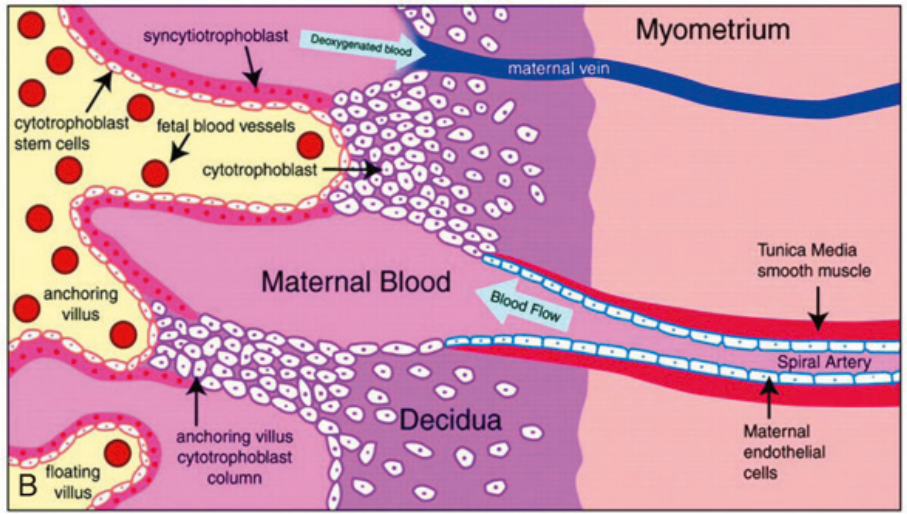

Figure 1. Abnormal placentation in preeclampsia. In normal placental development, invasive cytotrophoblasts of fetal origin invade the spiral arteries, transforming them from small-caliber resistance to high-caliber capacitance vessels capable of providing placental perfusion adequate to sustain the growing fetus. In preeclampsia (at least early-onset), cytotrophoblasts fail to adopt an invasive endothelial phenotype. Instead, invasion of the spiral arteries is shallow. Figure reproduced with permission from Lam et al (18).

This phenomenon has been has been demonstrated by ultrasound (19). Retention of smooth muscle will increase the risk of spontaneous vasoconstriction and ischemiareperfusion injury, generating oxidative stress. Incomplete remodelling of spiral arteries will change the uteroplacental perfusion from a constant low-pressure flow to a more pulsatile flow at higher pressure. This process will injure the chorionic villi, hydrodynamically and biochemically via ischemia-reperfusion $(20,21)$ (Figure 12). However, dilation has a modest impact on total blood flow. Hence, both rheological damage and chronic hypoxia with oxidative stress seem to be the result of a deficient conversion of the spiral arteries (22). 


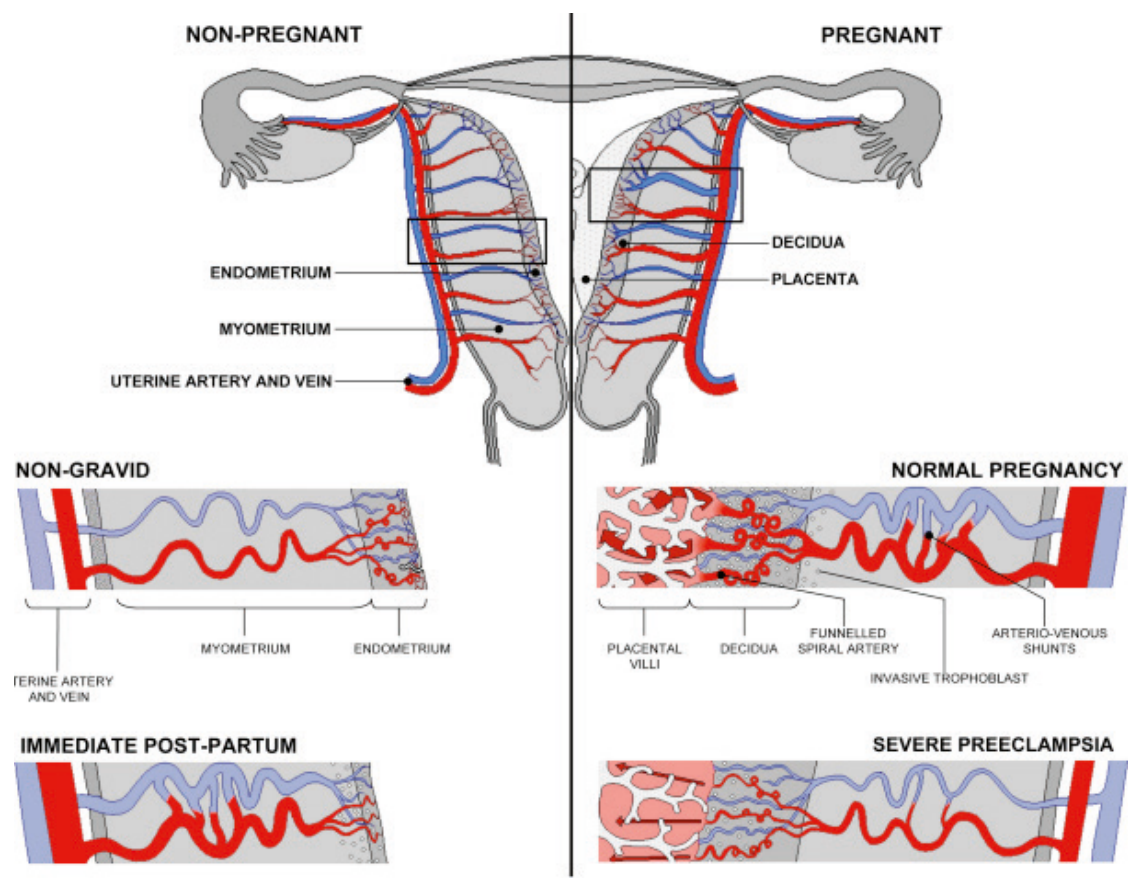

Figure 2. Uterine and placental vasculature (red shading = arterial; blue shading = venous) in the non-pregnant, pregnant and immediate post-partum state. Normal pregnancy is characterized by the formation of large arterio-venous shunts that persist in the immediate post-partum period. By contrast minimal arterio-venous shunts, and thus narrower uterine arteries characterize pregnancies complicated by severe preeclampsia. Extravillous cytotrophoblast invasion in normal pregnancy extends beyond the decidua into the inner myometrium resulting in the formation of funnels at the discharging tips of the spiral arteries. Contrast with severe preeclampsia. (Prepared by Ms. Leslie Proctor, MSc.) Figure reproduced with permission from Burton et al (22).

Another consequence of this changed blood flow due to incomplete remodelling of spiral arteries is an increase both in apoptosis of trophoblasts and in the number of micro- and nanovesicles released from placenta. Pro-inflammatory cytokines and chemokines and anti-angiogenic molecules are also enriched locally in the placenta $(23,24)$, leading to a shallow and defect placentation resulting in a high pressure pulsatile flow to the intervillous space with a risk of rapid changes in blood flow due to retained responsiveness to vasoconstrictors. These rapid changes can exacerbate oxidative stress further due to variations between a hypoxic state and reperfusion, with oxidation creating reactive oxygen species. The resulting oxidative stress, a feature of the preeclamptic placenta, is a potent pro-inflammatory state (25). 


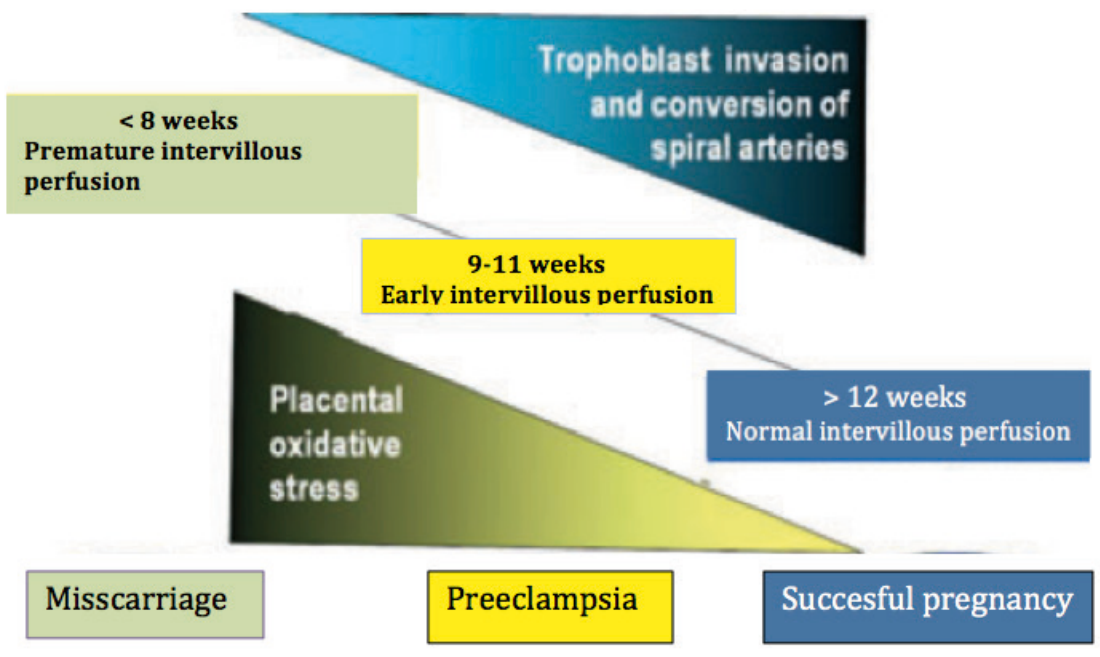

Figure 3. Establishing the intervillous circulation. Before 8 weeks, the spiral arteries are plugged by cytotrophoblast and there is no intervillous perfusion. During the next 4 weeks, the arteries progressively unplug. With inadequate trophoblast invasion of the placenta bed, unplugging happens prematurely. Then either miscarriage ensues or pregnancy continues with dysfunctional placental perfusion, which may lead to preeclampsia, depending of time of unplugging. Modified with permission from Burton and Jauniaux (20).

LOP and particularly term and post-term pregnancies are rarely complicated with IUGR and there is no obvious macroscopic placental insult. Despite this, LOP is associated with increasing plasma levels of the anti-angiogenic factor soluble Fmslike tyrosine kinase-1 (sFlt-1) and decreasing levels of the pro-angiogenic factor Placental Growth Factor (PlGF), indicating an increasing syncytiotrophoblast (STB) stress. Placental dysfunction in these cases has recently been suggested to be caused by villous overcrowding in the placenta, which is supported by the fact that preeclampsia becomes more frequent in post-term pregnancies. Uterine size might, in an intrinsic way, limit the placenta's growth capacity and cause stress to trophoblasts, manifested by decreasing levels of PlGF. This model with extrinsic (poor placentation) and intrinsic (villous overcrowding) placental dysfunction can explain important features of late preeclampsia, while at the same time it raises questions about how antecedent medical risk factors such as chronic hypertension and obesity affect early and late subtypes of the condition. An interesting and possible consequence of this hypothesis might be that all pregnant women are destined to get 
preeclampsia, but this outcome is averted by spontaneous or induced delivery for the majority of them (26).

Berthold Huppertz has recently challenged the hypothesis of a shallow placentation with poor infiltration of the spiral arteries as an obligate stage in the pathogenesis of preeclampsia, due to the fact that during the first trimester there is a limited flow of maternal blood cells into the intervillous space of the placenta (27). Still, there are predictive serum markers, e.g. PP13, for preeclampsia showing significant alterations in their concentrations as early as at seven gestational weeks. After implantation until about eight weeks of gestation, the spiral arteries are invaded and plugged by cytotrophoblasts. At around 11 to 12 gestational weeks the blocking plugs of extravillous trophoblasts are dislocated and the maternal blood flow towards the placenta opens up, which can be traced by the increase of oxygen from the first to the second trimester $(27,28)$. Thus, alterations in predictive serum markers can be demonstrated weeks before the onset of flow of maternal blood cells through the intervillous space. It seems thus, that early pathogenesis of preeclampsia seems to develop at the onset of placentation, somewhere around implantation. There may be different steps in the early stages of development of a placenta, where any insult could result in pregnancy complications such as preeclampsia and IUGR or miscarriage.

Huppertz' novel hypothesis is that early failure in placentation, involving villous trophoblasts, might end up in preeclampsia and IUGR. However, if there is only an insult of extravillous trophoblasts resulting in poorly invaded spiral arteries with decreased placental blood flow and less reperfusion and oxidative stress, IUGR without preeclampsia might result. In line with this, the pathophysiology of EOP, that almost always includes a certain degree of placental insufficiency, might include insults of both villous and extravillous trophoblasts due to a defect in immunological tolerance locally to the conceptus (28).

The clinical third phase of the pathogenesis of preeclampsia seems to be generated by a maternal systemic inflammatory reaction (SIR), which is unlikely to be alloantigen driven. Due to the hypoxia and the oxidative and endoplasmatic stress in the 
trophoblasts and in addition a rheological damage to villi, there is a release of different factors, e.g. anti-angiogenic factors, reactive oxygen species, micro- and nanovesicles, pro-inflammatory cytokines and chemokines and also free heme (29, 30). Heme is a degradation product of haemoglobin, which is pro-inflammatory and strongly pro-oxidant and shows increased expression in preeclamptic placenta (31). When these pro-inflammatory and pro-oxidant factors are released into the maternal circulation they cause a generalized systemic inflammatory response and a general activation in the endothelial lining of blood vessels which is probably resulting in the clinical features of preeclampsia; hypertension and glomerular endotheliosis with proteinuria $(9,30)$. Leakage of these factors to the maternal circulation increases with placental size. That is why clinical preeclampsia predominantly occurs in the third trimester and why the condition is more frequent in pregnancies with large placentas, for example multiple pregnancies (9). Activation of coagulation is an integral part of any inflammatory response and might contribute to pathogenesis not only by a direct thrombotic effect on the placenta, but also by stimulation of inflammation and production of anti-angiogenic molecules. Activated complement components also seem to be an integral factor of the increased inflammation seen in preeclampsia and IUGR (32). Thus, this third stage of the pathogenesis of preeclampsia gives us the potential to identify factors in peripheral circulation to be used as biomarkers of placental pathology associated with preeclampsia. 
Summary of the pathogenesis of preeclampsia

3 stages: 1 . Foetopaternal alloantigens seem to be immunologically recognized with a partial rejection reaction including a skewing of the immune system towards Th1/Th17 instead of Th2/Treg dependent immunity.

2. This immunological reaction seems to be involved in a defect trophoblast invasion of the spiral arteries creating a shallow placentation with both rheological damage and oxidative and ER stress in trophoblasts.

3. Systemic inflammatory response in the maternal endothelia (and sometimes in the central organs) is probably the result of release of pro-inflammatory and anti-angiogenic placental factors resulting in hypertension and renal endotheliosis with proteinuria.

In late-onset preeclampsia where there frequently is no obvious extrinsic placental insult, instead a villous overcrowding due to a limited uterine size might cause an intrinsic placental dysfunction with stressed trophoblasts mirrored by decreasing PIGF and increasing sFlt-1.

\section{Relevance for thesis}

The three-stage pathophysiology for preeclampsia seems to be relevant for earlyonset preeclampsia with associated placental insufficiency, whereas in late-onset preeclampsia, a placental insult is not always obvious. It is still not fully clear why the same placental insult results in IUGR, sometimes associated with and sometimes without preeclampsia. In what way the immunological mechanisms in the first stage end up in the defective invasion of EVT in the spiral arteries in the second stage is not well described and clarified. The third stage of pathogenesis depends on the release of placental pro-inflammatory and anti-angiogenic factors, but still it is unclear if there is one major responsible factor or if there are several placental factors with a combined effect on maternal endothelium, resulting in the clinical syndrome. In studies on the pathophysiology of preeclampsia there is always a problem distinguishing between the cause of the syndrome and the effects of it. 


\section{Immunological mechanisms in preeclampsia}

\section{Pre-conceptual mechanisms}

Preeclampsia, especially EOP, with placental insufficiency seems to be the result of an unsuccessful adaptation of the immune system to the foetoplacental unit. An observation that supports the importance of the immune system is that risk for preeclampsia is increased for primipara, and decreased for every consecutive pregnancy. However, a long inter-pregnancy interval increases the risk to the same level as for primipara. A short interval between first coitus and conception with the same partner also increases the risk of preeclampsia (33). These features suggest that exposure to paternal sperm or seminal fluid tolerizes the mother to foetopaternal alloantigens. Failure of this immunoregulation increases the risk of preeclampsia. Hence, a pre-conceptual phase involves maternal tolerization to paternal antigens by seminal fluid. Maternal contacts with factors in seminal fluid induce regulatory $\mathrm{T}$ cells (Treg cells) with the ability to induce tolerance to the foetoplacental antigens. In particular the seminal plasma, and not the sperm, is important since the seminal plasma is enriched with paternal antigens and high concentrations of transforming growth factor-beta (TGF- $\beta$ ) with the ability to induce Treg cells. However, in a more pro-inflammatory environment, Th17 cells are instead induced. Exposure to seminal fluid in mice induces tolerance to paternal alloantigens and an accumulation of Treg cells in the uterine draining lymph nodes, which may facilitate later implantation, at least in mice (34). The importance of pre-conceptual exposure to semen can explain why artificial insemination with donor sperm, intracytoplasmic sperm injection (ICSI), or barrier methods of contraception, are all associated with increased risks of preeclampsia (35). 
Summary of preconceptual mechanisms

Risk for preeclampsia is increased for primipara, and decreased for every consecutive pregnancy

A short interval between first coitus and conception with the same partner also increases the risk of preeclampsia

Maternal contacts with factors in seminal fluid induce Treg cells with the ability to create tolerance to the foetopaternal antigens (at least in mice).

\section{Failure of immunological mechanisms}

Even though foetal cells can escape to the maternal blood circulation, the main tolerance must take place at the foetal-maternal interface, involving maternal immune cells in the decidua. If this fails to happen, it may result in pregnancy failure (36). Hence, a healthy pregnancy is a model of successful tolerance. Complete failure of the above-described immunological mechanisms would cause a rejection of the foetoplacental unit, resulting in miscarriage, while partial failure would instead cause a poor and shallow placentation with an impaired uteroplacental perfusion. This model gives an explanation for the first pregnancy preponderance that characterizes preeclampsia and also why a degree of placental insufficiency is a common clinical feature in early-onset (placental) preeclampsia (9). The immunological mechanisms resulting in shallow placentation and defect trophoblast invasion of the spiral arteries are, however, still only partially mapped.

\section{Relevance for thesis}

Failure of immunological mechanisms may result in a complicated pregnancy with either miscarriage or preeclampsia with or without IUGR. However, in LOP without placental insufficiency the impact of immunological failure is not obvious, and in certain cases the cause of preeclampsia might be an increase in placental factors in maternal circulation due to a large placenta or a pre-existing affected maternal endothelium. Therefore, a stratified analysis of primipara and multipara might be of interest, in order to investigate whether mechanisms differ with increasing parity. The difference in mechanisms between IUGR with and without preeclampsia would 
also be interesting to analyse since they share the same placental insult but result in different clinical conditions.

\section{Natural killer cells (NK cells)}

NK cells are the most abundant of the leukocytes in the decidua and constitute 50 $90 \%$ of the leukocytes in first trimester (37). NK cells provide rapid responses to viral-infected cells and respond to tumour formation. Typically, they detect a downregulated expression of major histocompability complex (MHC) presented on infected cell surfaces, causing lysis or apoptosis of the target cell, and also triggering cytokine release. NK cells are unique as they have the ability to recognize stressed cells with lowered MHC class I expression and with a fast immune reaction. However, NK cells have both activating and inhibitory receptors that play important roles, including self-tolerance and sustaining NK cell activity (38). During pregnancy, uterine NK cells are found in intimate contact with the extravillous trophoblast at the implantation site. The trophoblastic invasion is highly regulated, and the increase in the uterine NK cells in early pregnancy as well as the strong proximity to the extravillous trophoblasts suggest that they play a role in trophoblast invasion and development of the placenta. NK cells can be divided into a major subset of $\mathrm{CD} 56{ }^{\mathrm{dim}} \mathrm{CD} 16^{\text {bright }}$ containing approximately $90 \%$ of circulating NK cells and a smaller $(\approx 10 \%)$ population of $\mathrm{CD} 56^{\text {bright }} \mathrm{CD} 16^{\text {dim }}$ cells $(39)$, which differ in several aspects, including cytotoxic potential, cytokine production, and expression of cell surface markers (40). The $\mathrm{CD} 56^{\text {bright }} \mathrm{CD} 16^{\mathrm{dim}}$ population could be referred to as regulatory because of its reduced cytotoxic capacity and increased potential to produce cytokines $(39,40)$. NK cells in the decidua seem to be a unique subset, different from both CD56 ${ }^{\mathrm{dim}}$ and CD56 $6^{\text {bright }}$ blood NK cells (37). Even though they express NK cell-activating receptors $(41,42)$ and cytolytic granules $(37,43)$, making them potentially cytotoxic, their cytotoxic ability is significantly reduced (37). The interaction of inhibitory receptors and MHC class I molecules (Human Leukocyte Antigen-C (HLA-C) and HLA-G) on trophoblasts seems to cause a lack of cytotoxic ability in these NK cells $(44,45)$. Foetopaternal HLA-C 
on extravillous trophoblasts can be recognized by decidual NK cells that express killer immunoglobulin-like receptors (KIR) for which HLA-C is the dominant ligand. Both HLA-C and KIR are oligomorphic gene systems, which is why local maternalfoetal immune recognition differs across individuals. The interaction between trophoblast HLA and maternal KIR can lead to stimulatory or inhibiting effects on NK cells' ability to secrete chemokines and angiogenic cytokines, and these effects guide trophoblast invasion. A dysregulated process might increase the risk for preeclampsia $(46,47)$.

A key characteristic of early placental development in human pregnancy is the remodelling of the spiral arteries. The NK cells are often clustered around the spiral arteries and arterioles during the early phase of pregnancy. This distribution may reflect the role NK cells play in mediating vascular changes during pregnancy. In vitro studies have demonstrated the interaction between the trophoblasts and the uterine NK cells, including the production of several cytokines and angiogenic factors $(41,48)$. The recruitment of EVT by NK cells occurs via secretion of C-X-C motif ligand 8 (CXCL8) (interleukin 8;IL-8) and CXCL10, for which EVTs express the receptors CXCR1 and CXCR3 (41). Decidual NK cells may contribute to spiral artery remodelling also through production of pro-angiogenic factors such as vascular endothelial growth factor (VEGF), PlGF, and angiopoietins (41, 49, 50). Collectively, proper decidual NK cell activation is a prerequisite for a normal placentation, including adequate trophoblast invasion and spiral artery remodelling (45). Failure of these mechanisms might be part of the pathophysiology in preeclampsia and IUGR $(45,51,52)$.

Summary: Natural killer cells

NK cells constitute 50 - 90 of the decidual leucocytes in first trimester. Interaction of inhibitory receptors on NK cells and HLA-C on trophoblasts may be involved in the inefficient cytotoxic ability of these NK cells

NK cells may contribute to spiral artery remodelling through recruitment of EVF via secretion of chemokines and production of pro-angiogenic factors.

Decidual NK cell killer immunoglobulin-like receptors (KIR) can be inhibitory or stimulatory on secreting chemokines, cytokines and angiogenic factors promoting trophoblast invasion. Ligation of HLA-C on foetal EVT with inhibitory KIR can increase the risk for preeclampsia. 


\section{Relevance for thesis}

In the pathogenesis of preeclampsia, an increasing amount of data indicates that immunological mechanisms are important for both increased inflammation and aberrant angiogenesis. Since both foetopaternal HLA-C on extravillous trophoblasts and KIR on NK cells are oligimorphic gene systems, both hereditary and acquired aberrations in these mechanisms could be involved in the pathophysiology of preeclampsia, ending up in defect angiogenesis and trophoblast invasion. It is however not clear if this is a common mechanism in preeclampsia and IUGR. Since decidual NK cells secrete cytokines and chemokines that promote trophoblast invasion (CXCL8 and CXCL10) and pro-angiogenetic factors (e.g. PlGF), studies on their role in preeclampsia (and IUGR) can contribute to illuminating the role of NK cells in preeclampsia.

\section{Macrophages}

Decidual macrophages are enriched at the foetal-maternal interface, making up approximately $20 \%$ of the decidual leukocytes in the first trimester (53). Macrophages in general are classified as M1 (classically activated) or M2 (alternatively activated) macrophages, where M1 macrophages are induced by interferon $\gamma$ (IFN $\gamma$ ), alone or together with lipopolysaccharides (LPS) and tumour necrosis factors (TNF), while alternatively activated macrophages initially were found to be induced by interleukin 4 (IL-4) and IL-13 $(54,55)$. However, M2 macrophages can also be induced by anti-inflammatory cytokines such as M-CSF and IL-10 (56). Recent studies have shown that decidual M2 macrophages are mainly induced by macrophage colony-stimulating factor (M-CSF) and IL-10 (57). Global gene expression analysis of decidual macrophages shows that they mainly adapt an M2 polarization status with functions predominantly associated with immune regulation and tissue remodelling (57). The phenotype, with expression of CD163, CD206 and CD209, is typical for M2 macrophages.

These macrophages produce predominantly immune-suppressive cytokines including IL-10 and IL-35 and less pro-inflammatory cytokines, like IL-12, IL-23 and TNF compared to M2 macrophages (57). Hence, they are involved in immune regulation 
and support tolerance and tissue homeostasis. They inhibit the cytolysis of trophoblasts by uterine NK cells and limit activation of T cells. As an important source of chemokines they are major regulators of cell trafficking at the foetomaternal interface and they induce the expansion of Treg cells but not of Th1, Th2 and Th17 cells by producing high levels of the monocyte- and Treg cellassociated chemokines C-C motif ligand 2 (CCL2) and CCL18, but low levels of Th1, Th2 and Th17-recruiting chemokines, thereby creating tolerance and adaptation. Besides these functions, decidual macrophages are also involved in the recognition and clearance of infections and support spiral artery remodelling, by producing angiogenic factors. By phagocytosing apoptotic cells and debris they also contribute to maintaining a homeostatic tissue environment (58-60).

\section{Relevance for thesis}

Decidual M2 polarized macrophages, induced by M-CSF and IL-10, producing immune suppressive cytokines (e.g. IL-10 and IL-35) and chemokines (e.g. CCL18 and CCL2) seem to be important for immune regulation and tissue remodelling at the foetomaternal interface. The impact of macrophages in preeclampsia has not been widely studied but a maladaptation of the immune system involving macrophages as an integrated part of the first stages of preeclampsia is possible and might be reflected by decreased expression of certain cytokines and chemokines, e.g. CCL18.

Summary: Macrophages

Decidual macrophages are enriched at the foetal-maternal interface.

They mainly adapt an M2 polarization status with functions predominantly associated with immune regulation and tissue remodelling.

They produce predominantly immune-suppressive cytokines including IL-10 and IL35 and they induce the expansion of Treg cells.

They are also involved in the recognition and clearance of apoptotic cells as well as of infections 


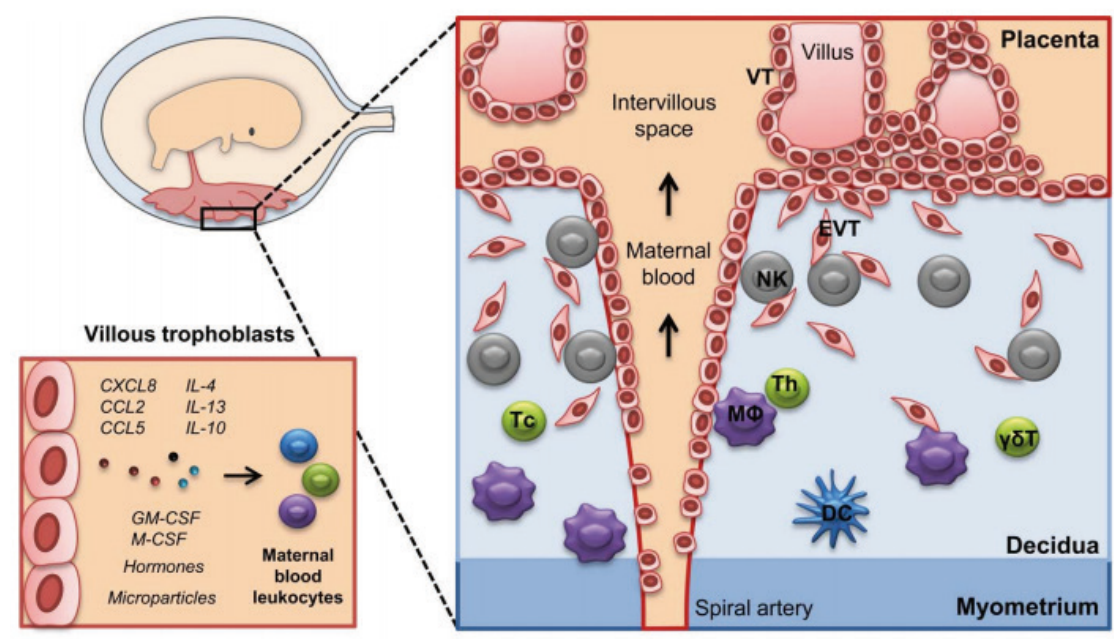

Figure 4. NK cells, Macrophages and Regulatory $\mathrm{T}$ cells at the foetomaternal interface. Figure reproduced with permission from SvenssonArvelund et al. (18)


\section{Regulatory T Cells}

The T helper cells (Th cells) play an important role in the immune system by helping, directing, the activity of other immune cells by releasing cytokines. Mature Th cells express the surface protein CD4 and are referred to as $\mathrm{CD} 4{ }^{+} \mathrm{T}$ cells. Regulatory $\mathrm{T}$ cells (Treg cells) consist of one $\mathrm{T}$ helper lineage derived from thymus (natural Treg cells) and another that is induced in the periphery (induced Treg cells). Treg cells maintain tolerance to selfantigens and prevent autoimmune diseases. Treg cells are immunosuppressive and generally suppress or downregulate the induction and proliferation of effector T cells (61). Treg cells express CD4, Forkhead box P3 (FOXP3), CD25 and lack the expression of CD127. Treg cells can be defined in different ways depending on the molecules expressed either on the cell surface (CD4, CD25) or intracellularily (FoxP3). Subpopulations of Treg cells, as active and resting 
Treg cells, can be defined depending on expression of CD45RA on the cell surface (62). After conception, Treg cells may interact with M2 macrophages, which induce an expansion of the Treg cells. Treg cells are induced by IL-10 and TGF- $\beta$ and the enzyme indoleamine 2,3-dioxygenase (IDO) and they secrete suppressive cytokines as IL-10, TGF- $\beta$ and IL-35 (63). IDO is involved in the catabolism of tryptophan, an important immune regulator. By catabolic depletion of tryptophan, IDO causes 'starvation' of T cells, which promotes their differentiation into Treg cells. Since IDO is particularly strongly expressed in invasive cytotrophoblasts (EVTs) it may be an important factor in creating tolerance in early pregnancy, and consequently, lack of IDO might be one of the pathogenetic factors of the early stages of preeclampsia. IDO is best studied in mice but Nishizawa et al. were able to show low IDO activity in placentas from preeclamptic compared to normal pregnant women and moreover that the enzyme activity inversely correlated with the blood pressure of the patients $(64,65)$.

Studies have demonstrated an enrichment of regulatory $\mathrm{T}$ cells in the decidua, probably contributing to local immunological tolerance and adaptation $(66,67)$. Treg cells are enriched in decidua, regardless of whether they are defined as $\mathrm{CD} 4{ }^{\text {dim }} \mathrm{CD} 25^{\text {high }}, \mathrm{CD} 4^{+} \mathrm{FOXP} 3^{+}, \mathrm{CD} 4^{+} \mathrm{FOXP} 3^{\text {high }}, \mathrm{CD} 25^{\text {high }} \mathrm{CD} 127^{\text {low }}$ or $\mathrm{CD} 4{ }^{+} \mathrm{CD} 25^{\text {high }} \mathrm{FOXP} 3^{\text {high }}(67)$. This adaptation seems to be absent or less pronounced in preeclamptic women. In murine pregnancy, Treg cells play a crucial role in implantation and maintenance, as shown in models of normal (68) and complicated pregnancy (36). Early human pregnancy decidua contains an abundance of Treg cells, which express cytotoxic T-lymphocyte-associated protein 4 (CTLA-4), a marker of suppressive function. CTLA-4 mediates potent inhibition of T-cell proliferation in a dose-dependent fashion. This suppressive function of Treg cells requires cell-to-cell contact. The proportion of decidual Treg cells has been shown to be lower in decidua from women with spontaneous abortion compared to decidua from women with induced abortions (69). In preeclampsia, decreased numbers of Treg cells have been reported at the foetomaternal interface $(66,67)$, contributing to a less tolerogenic environment and defective anti-inflammatory regulation. 
Schumacher et al. have demonstrated that Treg cells may be attracted by human choriogonadotropin (hCG)-producing trophoblasts in human placenta. Treg cells, attracted by hCG, may hence migrate to the foetomaternal site. There, contact occurs between paternal antigens and maternal immune cells, and immune tolerance towards the foetoplacental tissue can be ensured (70).

Some studies have demonstrated increased numbers of peripheral blood Treg cells during pregnancy However, other and more recent studies have shown that levels of peripheral blood Treg cells are not altered or even decreased during pregnancy (66, 67), indicating that their suppressive and tolerogenic function is more pronounced locally $(71,72)$. Some authors have shown that in preeclampsia the number of circulating Treg cells is decreased compared with healthy pregnant women $(12,73)$, while others could not confirm these results $(74,75)$. The inconsistencies regarding Treg cells may refer to how they were defined (67). Treg cells are not only enriched in the decidua, they also show a more pronounced suppressive and a much more homogenous phenotype than in blood with regard to expression of CTLA-4, FoxP3, CD25, and TGF- $3(71,72)$. In addition, the decidual enrichment of Treg cells may be a result of local proliferation since they have a higher expression of proliferation marker Ki-67 (72). Local maturation has also been suggested in normal pregnancy where they could demonstrate a local accumulation of decidual $\mathrm{CD} 4^{+} \mathrm{CD} 25^{-}$Foxp $^{+}$cells, suggesting an additional reservoir of Foxp $3^{+}$natural (resting) Treg cells that can be converted to 'classical' Treg cells in the uterus (71, 72). Hence, local expansion of Treg cells may occur in the decidua. This might also be accompanied by recruitment of Treg cells from the circulation, via pathways such as CCL2-CCR2, CCL22-CCR4, CCL17-CCR4 or CCL18-CCR8, which remains to be determined.

The amounts of Treg cells and Th17 cells in the decidua seem to be related, Treg cells being enriched and Th17 cells being barely detectable, however results are conflicting dependent on simulated or non-stimulated decidua $(72,76)$. Recent data show the reciprocal development of pathways between Th17/Treg subsets, and an imbalance of Th17/Treg development has been reported in preeclampsia (76). Th17 
cells activity might still be important for the first stages of implantation and placentation that are associated with inflammation, but it seems that this activity needs to be balanced by Treg cells. (77). Treg cells, which induce tolerance, and Th17 cells, which induce inflammation or rejection, appear to arise from common precursors, on exposure to either TGF- $\beta$ alone (induced Treg cells) or TGF- $\beta$ and the proinflammatory cytokines IL-1 $\beta$ or IL-6 (Th17) $(72,77,78)$. TGF- $\beta$ seems to promote Treg cell augmentation in the decidua, which fits well with the general view of this Treg cytokine as a pregnancy facilitator (79). This could explain why seminal fluid, with a high TGF- $\beta$ content has been found to promote expansion of the Treg cell compartment (34). Treg cells are also induced by IL-10 and TNF-related apoptosis-inducing ligand (TRAIL) in the decidua (58).

Protection from preeclampsia has relatively short-term partner specificity(33). This could imply that decidual Treg cells recognize paternal HLA-C, which can downregulate anti-paternal responses $(66,80)$. The stability of Treg cell memory is still to be determined. Natural (resting) Treg cells seem to be stable whereas induced (activated) Treg cells probably are less long-lived (81). Natural (resting) cells are differentiated into induced (activated) Treg cells at activation. It is therefore likely that decidual Treg cells might give, at least, short-term memory that could protect from preeclampsia in a second pregnancy with a short inter-pregnancy interval, but this needs further investigation (9). 


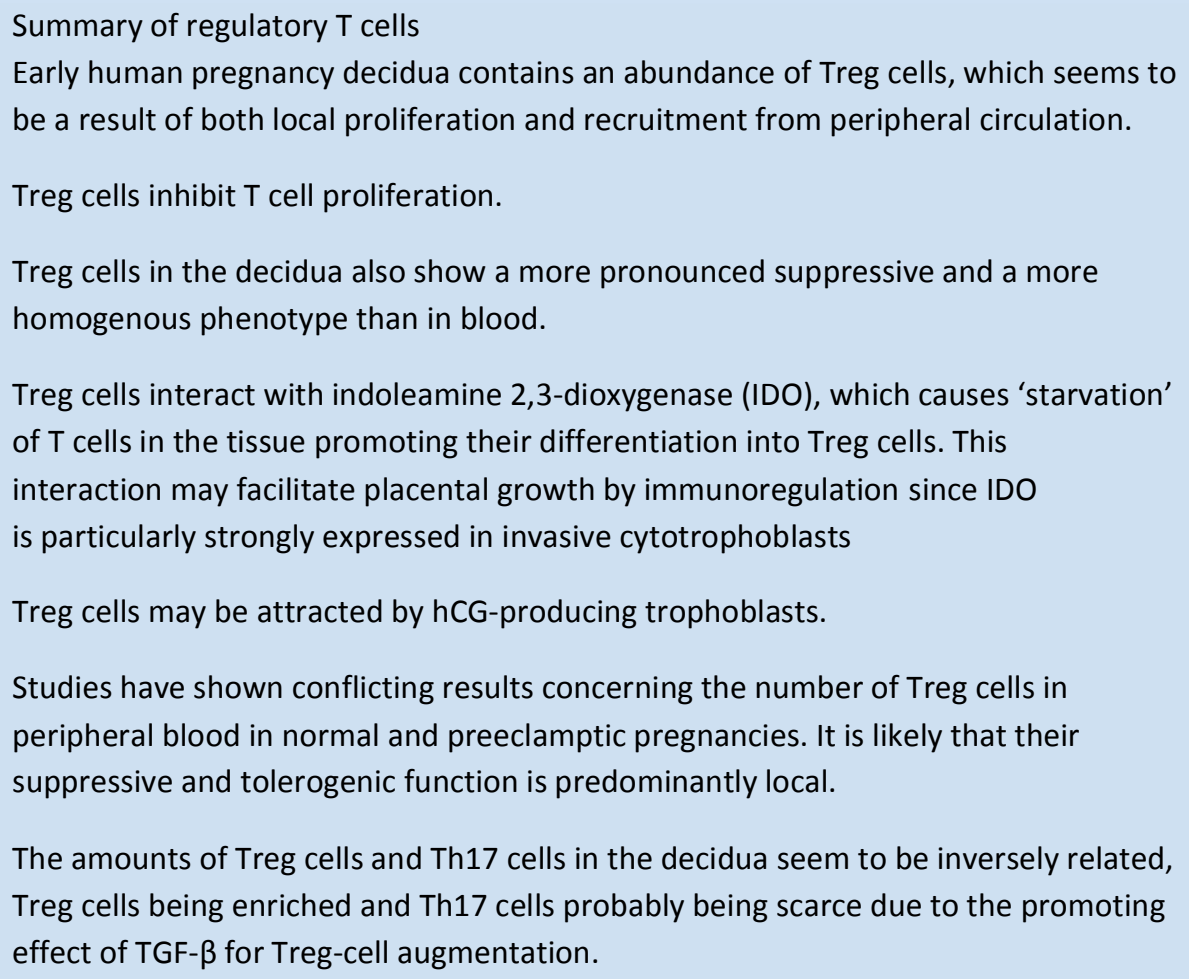

The amounts of Treg cells and Th17 cells in the decidua seem to be inversely related, Treg cells being enriched and Th17 cells probably being scarce due to the promoting effect of TGF- $\beta$ for Treg-cell augmentation.

\section{Relevance for thesis}

Treg cells seem to be of importance for a normal pregnancy but the role of Treg cells in normal pregnancy and preeclampsia is still controversial since studies have shown divergent results, which might depend on the chosen definition of Treg cells and whether Treg cells are studied in peripheral circulation or locally at the foetomaternal interface. It is not fully clear if EOP and LOP differ in this aspect, and the effect of corticosteroids, routinely used for foetal lung maturation in the case of $E O P$, have not been taken into account for in previous studies. Treg cells can be divided into subpopulations of resting and activated Treg cells. Resting Treg cells are recent thymic emigrants displaying a resting phenotype and residing in secondary lymphoid tissues, while activated Treg cells are stimulated by their T cell receptor (TCR) to be activated and reside in non-lymphoid tissues. Resting and activated Treg cells have not been studied in preeclampsia. 


\section{Cytokines and chemokines}

Cytokines are a category of small proteins that are important in cell signalling, for example regulating immune responses. Their release has an effect after binding to receptors on cells around them, although they can also have remote effects. A broad range of cells produces cytokines, including all immune cells as well as endothelial cells, epithelial cells, fat cells, fibroblasts and various stromal cells. A given cytokine may be produced by more than one type of cell (82). Virtually all known cytokines have been demonstrated to be expressed in the placenta during normal gestation (83). Besides modulating immunological function, cytokines, together with other growth factors produced in the placenta and in extra-placental membranes, seem to be involved in both implantation and placental development. Imbalances in the intrauterine cytokine milieu during pregnancy may cause both early pregnancy failure and abnormal trophoblast development seen in complicated pregnancies such as those involving EOP and IUGR. Cytokines thus appear to be a critical factor within the foetomaternal interface to establish a successful pregnancy. Moreover, cytokines are involved in regulation of placental growth during all stages of pregnancy as well as the protection from pathological organisms (83).

As mentioned, immunological mechanisms are involved in establishment of normal and pathological pregnancies. Several studies have indicated a shift of the immune system in normal pregnancies towards the Th2/Treg subset, categorized by typical secretion of the cytokines IL-4, IL-10, and TGF- $\beta$ possibly supported by progesterone. In preeclampsia, the immune system has been suggested to be more associated with a Th1/Th17 predominant profile with pro-inflammatory cytokines such as such as IL-6, tumour necrosis factor (TNF), IFN- $\gamma$ and IL-17 $(11,84,85)$. However, the pregnancy-associated Th1/Th2 paradigm is an over-simplification. The existing data are more suggestive of a system involving timing and tuning of different cytokines and chemokines in a complex way during pregnancy (85). Cytokines such as M-CSF and IL-10, are for example involved in the process of polarization of decidual macrophages to M2 macrophages in normal pregnancy (58). In contrast, decidual expression of granulocyte-macrophage colony-stimulating factor-(GM-CSF) 
has been reported to be increased in preeclamptic pregnancies $(31,34)$. A

foetomaternal relationship is not simply maternal tolerance of a foreign tissue, but a series of intricate cytokine interactions governing immune regulation and control of the adhesion and vascularisation processes (86).

Chemokines are a family of small cytokines (or signalling proteins) that in addition to recruitment of immune cells also have regulatory functions, such as maintaining suppression and homeostasis and induction of apoptosis (87). Since chemokines recruit immune subsets specifically, they contribute to forming the local immune environment, for example by recruitment of different subsets of $\mathrm{T}$ helper cells. Chemokines are part of the adaptation of the immune system during pregnancy. Examples of chemokines associated with different CD4 subsets (see table II) are 1) CXCL9-11, associated with Th1, 2) CCL17-18, associated with Th2 (+ Treg for CCL18), 3) CCL20, associated with Th17, and 4) CCL22, associated with Th2/Treg. There is still a paucity of studies of local and systemic chemokines in preeclampsia.

CXCL10 is a chemokine of the CXC family. It has pronounced anti-angiogenic activity, which includes regulation and control of the basal homeostasis and inflammatory leukocyte migration $(88,89)$. Moreover, despite its anti-angiogenic role it promotes adhesion, migration and invasion of trophoblast cells, possibly due to its pro-inflammatory properties (90). The biological functions of CXCL10 are mediated through the interaction with the receptor CXC chemokine receptor 3 (CXCR3) (91). Analysis of polarized T lymphocytes has demonstrated high CXCR3 expression on Th1 cells and low on Th2 cells, and therefore this receptor has been proposed as a useful marker of circulating Th1-type cells (92). CXCL10 expression is induced by extravillous trophoblasts (EVT) and IFN- $\gamma(93)$. CXCL10 has been found to be involved in conditions characterized by prominent $\mathrm{T}$ cell responses, particularly when a Th1/Th2 imbalance is involved (94). Increased levels of circulating CXCL10 have been shown in preeclamptic compared with normal pregnant women. Levels of CXCL10 were also increased in preeclamptic women when compared to women with IUGR delivering SGA (small for gestational age) babies. Moreover, pregnant women have a significantly higher serum concentration of CXCL10 than non-pregnant 
women (95).

Lee et al. showed that serum CXCL10 levels were higher in foetuses with placental lesions associated with maternal anti-foetal rejection than in those without such lesions (96). Preeclampsia is an anti-angiogenic condition. Since CXCL10 has antiangiogenic properties, a feature of preeclampsia, elevated CXCL10 in maternal serum concentrations, may contribute to generating an anti-angiogenic state along with sFlt-1 and endoglin (97).

CCL18 is a chemokine associated with Th2/Treg, induced by the Th2-associated cytokines IL-4 and IL-13 and also by IL-10. CCL18 is associated with Th2 immunity and its biological function is associated with suppression and homeostasis exerted mainly by binding to CCR8 (98). There are few studies of the role of CCL18 in normal and pathological pregnancy. We have previously shown that CCL18 is secreted by placental macrophages in normal human pregnancies $(58,99)$. Tranquilli et al. found that expression of CCL18 was significantly decreased in placentas from women experiencing HELLP compared with placentas from normal pregnancy (100).

CCL20 is a chemoattractant for Th17 cells. It is induced by the Th17-associated cytokine IL-17 and exerts its function by binding to CCR6 (101). There is a paucity of information about CCL20 in human pregnancy. One study with a small sample size suggests no change in maternal serum CCL20 concentrations in women with preterm labour and delivery compared with either preterm controls or women at term in labour (102). In another study, expression of CCL20 was increased in decidual biopsies in patients with preeclampsia compared to normal controls at the time of delivery (103). Hamill et al. were able to demonstrate increased levels of CCL20 in amniotic fluid (AF) during pregnancy with an increased bioavailability of AF CCL20 in spontaneous labour (term and preterm). 
Table I Chemokines associated to different CD4 subsets

\begin{tabular}{|c|c|c|c|c|c|c|}
\hline $\begin{array}{l}\text { Chemok } \\
\text { ine }\end{array}$ & $\begin{array}{l}\text { Other } \\
\text { name }\end{array}$ & $\begin{array}{l}\text { Induced } \\
\text { by }\end{array}$ & Secreted by & Effect & $\begin{array}{l}\text { CD4 } \\
\text { subset }\end{array}$ & $\begin{array}{l}\text { Recep } \\
\text { tor }\end{array}$ \\
\hline CXCL9 & MIG & IFN-y & $\begin{array}{l}\text { Monocytes } \\
\text { Endothelial cells } \\
\text { Fibroblasts }\end{array}$ & $\begin{array}{l}\text { T cell } \\
\text { chemoattractant }\end{array}$ & Th1 & $\begin{array}{l}\text { CXC } \\
\mathrm{R} 3\end{array}$ \\
\hline CXCL10 & IP-10 & IFN-y & $\begin{array}{l}\text { Monocytes } \\
\text { Endothelial cells } \\
\text { Fibroblasts }\end{array}$ & $\begin{array}{l}\text { Induction of } \\
\text { apoptosis and } \\
\text { chemotaxis. } \\
\text { Inhibition of bone } \\
\text { marrow and } \\
\text { angiogenesis } \\
\text { Promoting } \\
\text { antitumor activity } \\
\text { and adhesion, } \\
\text { migration and } \\
\text { invasion of } \\
\text { trophoblast cells }\end{array}$ & Th1 & $\begin{array}{l}\text { CXC } \\
\text { R3 }\end{array}$ \\
\hline CXCL11 & I-TAC & $\begin{array}{l}\text { IFN-y } \\
\text { IFN- } \beta\end{array}$ & $\begin{array}{l}\text { Leucocytes, } \\
\text { pancreas, RES } \\
\text { and lungs }\end{array}$ & $\begin{array}{l}\text { Chemoattractant } \\
\text { for activated } \mathrm{T} \\
\text { cells }\end{array}$ & Th1 & $\begin{array}{l}\text { CXC } \\
\text { R3 }\end{array}$ \\
\hline CCL17 & TARC & $\begin{array}{l}\text { IL-4, IL- } \\
13\end{array}$ & Thymus & $\begin{array}{l}\text { Chemoattractant } \\
\text { for T cells (and } \\
\text { fibroblasts) }\end{array}$ & Th2 & CCR4 \\
\hline CCL18 & $\begin{array}{l}\text { PARC } \\
\text { AMAC } \\
-1 \\
\text { DC- } \\
\text { CK1 } \\
\text { MIP-4 }\end{array}$ & $\begin{array}{l}\text { IL-4, IL- } \\
10, \text { IL-13 }\end{array}$ & $\begin{array}{l}\text { DC, monocytes, } \\
\text { macrophages }\end{array}$ & $\begin{array}{l}\text { Suppression, } \\
\text { Homeostasis, } \\
\text { Chemoattractant } \\
\text { for Th2 and Treg } \\
\text { cells }\end{array}$ & $\begin{array}{l}\mathrm{Th} 2 / \mathrm{Tr} \\
\mathrm{eg}\end{array}$ & CCR8 \\
\hline CCL20 & $\begin{array}{l}\text { LARC } \\
\text { MIP3A }\end{array}$ & IL-17 & $\begin{array}{l}\text { Lymphocytes, } \\
\text { lymph nodes, } \\
\text { liver, appendix }\end{array}$ & $\begin{array}{l}\text { Chemoattractant } \\
\text { for Th17 cells } \\
\text { Chemoattractant } \\
\text { for lymphocytes } \\
\text { (strongly) and } \\
\text { neutrophils } \\
\text { (weakly) }\end{array}$ & Th17 & CCR6 \\
\hline CCL22 & $\mathrm{MDC}$ & $\begin{array}{l}\text { IL-4 } \\
\text { IL-13 }\end{array}$ & $\begin{array}{l}\text { Macrophages, } \\
\text { monocyte- } \\
\text { derived } \\
\text { dendritic cells, } \\
\text { activated natural } \\
\text { killer (NK) cells } \\
\text { activated T } \\
\text { cells, epithelial } \\
\text { cells }\end{array}$ & $\begin{array}{l}\text { Chemoattractant } \\
\text { for Th2 and Treg } \\
\text { cells }\end{array}$ & $\begin{array}{l}\mathrm{Th} 2 / \mathrm{Tr} \\
\mathrm{eg}\end{array}$ & CCR4 \\
\hline
\end{tabular}


In the case of an intra-amniotic infection, a dramatic elevation in the CCL20 concentration was found, suggesting that this chemokine participates in the host response to infection (104).

CCL22, a Treg-associated chemokine that is an chemoattractant for Th2 and Treg cells, is induced by IL-4 and IL-13 and exerts its function by binding to CCR4 (56). CCL22 has recently been found in the human first trimester placenta by immunohistochemistry but decidual expression was only observed in miscarriage conditions and correlated with Treg infiltration. CCL22 seems to play a role in human pregnancy and may occur as a negative feedback response to proinflammatory events during miscarriage conditions (105). In another study, a decrease was found in serum levels of CCL22 as pregnancy progressed, in line with a maternal shift during pregnancy away from a Th2-biased immune reaction towards an inflammatory and counter-regulatory Th1-biased type (106).

\section{Summary: Cytokines and Chemokines}

Virtually all known cytokines have been shown to be expressed in the placenta.

Besides functioning as modulators of immunological function, cytokines and chemokines appear to be involved in various aspects of implantation and placental development.

Cytokine and chemokine patterns indicate a Th1-bias in preeclamptic pregnancies, but the Th1/Th2 paradigm is an oversimplification.

The timing and tuning of cytokine and chemokine interactions regulating immune homeostasis, trophoblast invasion and angiogenesis represent an intricate and complex activity.

M-CSF and IL-10 are important for polarisation of M2 macrophages.

Chemokines have not been widely studied in pregnancy.

High levels of the Th1-associated chemokine CXCL10 in preeclamptic women are an indication of a pro-inflammatory and anti-angiogenic state. 


\section{Relevance for thesis}

Cytokines and chemokines are important parts of the immune system, and are indicated to be involved in the pathogenesis of preeclampsia. Levels of circulating cytokines and chemokines show an immunological adaptation to normal pregnancy and maladaption in preeclampsia. However, it is not fully clear if they mirror the state in maternal endothelium or a placental insult. Hence, placental expression and plasma levels might not be correlated. Plasma levels and placental expression of cytokines and chemokines might increase or decrease during gestation depending on their function, indicating that the impact of the immune system is not constant, and the tuning of different cytokines and chemokines during different phases of gestation is a complex and vital function. This might explain why studies on plasma levels of cytokines in preeclampsia and normal pregnancy show divergent and partly conflicting results. Since in normal routines all EOP women are treated with corticosteroids for foetal lung maturation, there might be a bias in plasma levels of immune factors in connection to this treatment. The role of chemokines in preeclampsia has not been well studied.

\section{Increased inflammation in preeclampsia}

Preeclampsia has been described as a generalized maternal endothelial cell dysfunction as a part of a systemic inflammatory response (SIR) involving leukocytes as well as complement factors and the clotting system. Moreover, such an inflammatory response already exists in normal pregnancy, probably as a compensatory mechanism for the suppressed $\mathrm{T}$ cell function in pregnancy, which is due to immune modulation to avoid rejection of the foetoplacental unit (107). Normal pregnancy seems to be more like preeclampsia in this aspect than a nonpregnant state. In the case of an uncompensated maternal intravascular inflammatory response to placental factors, preeclampsia might be the consequence if the stimulus or the maternal response is too strong. This excludes a specific cause for preeclampsia that could explain all cases of the syndrome. Instead the syndrome can be considered as an extreme maternal adaptation to pregnancy $(30,108)$. The clinical 
syndrome of preeclampsia represents the third stage in pathogenesis of placental preeclampsia. It is believed to be generated, not by reactivity to foetal alloantigens, but as a non-specific vascular inflammatory reaction in the maternal endothelium secondary to placental factors (30). Due to the local hypoxia and the oxidative and endoplasmatic stress in placenta caused by an altered and impaired uteroplacental blood flow, there is a release of different factors into the maternal circulation. These factors are predominantly anti-angiogenic, such as soluble receptors of growth factors, and pro-inflammatory, such as reactive oxygen species, micro- and nanovesicles and pro-inflammatory cytokines and chemokines (108). The consequence of these placental factors in maternal circulation is a systemic inflammatory response and a general activation in the endothelial lining of blood vessels causing the clinical features of preeclampsia. These factors should be released during all pregnancies and should be particularly increased when there are stressed trophoblasts $(108,109)$.

The cellular, subcellular and molecular debris from the syncytial surface of the placenta is shed into the maternal circulation and is part of the systemic inflammatory stimulus during pregnancy. This debris is detected in the plasma of normal pregnant women and is significantly increased in preeclampsia. Microparticles (MPs) are cellular, membrane-bound vesicles that are shed into body fluids. MPs include a range of subcellular particles produced during apoptosis or cellular activation, usually $100-200 \mathrm{~nm}$ in diameter. In general, the largest are necrotic fragments, whereas smaller MPs are formed directly by blebbing of cell membranes after activation. One form of small MPs called exosomes has an immunosuppresive function via cell-cell contact $(110,111)$. MPs can be detected in the circulations of both normal pregnant and pregnant women. In the former, MPs are increased in conditions with systemic inflammation such as sepsis or metabolic syndrome. Even during normal pregnancy MPs are increased, but are further increased in preeclampsia. They include not only MPs derived from platelets, endothelium and various leukocytes but also syncytiotrophoblast-derived MPs (often called STBMs). STBMs interact with both endothelial and immune cells and may contribute to the systemic inflammation of 
both normal and preeclamptic pregnancies. STBMs resulting from turnover and renewal of the syncytial surface of the chorionic villi are included in this process. In vitro hypoxia induces apoptosis of cultured human cytotrophoblasts human cytotrophoblasts. Apoptosis of syncytial trophoblasts is significantly increased in preeclampsia, with syncytiotrophoblast microparticles as the sign of apoptosis. Also other markers of apoptotic debris, including cytokeratin and soluble foetal DNA, are increased in preeclampsia (112). Normal pregnancy is characterized by a mild systemic inflammatory response, observed not only during pregnancy but already during the luteal phase of the menstrual cycle before implantation. A local inflammatory response is an important feature of normal placentation and occurs early in pregnancy (113). However, inflammatory biomarkers indicate an increased inflammation throughout pregnancy. In preeclampsia, a similar response, but of greater intensity, occurs (30). Thus, preeclampsia is not an independent and separate condition but the extreme end of a continuum of maternal systemic inflammatory responses to pregnancy itself. Preeclampsia occurs when there is a decompensation of one or other maternal systems due to inflammation (114). The primary inflammatory cells are monocytes, neutrophil granulocytes, dendritic cells and NK cells. Endothelial cells can stimulate or be stimulated by inflammatory leukocytes and produce pro-inflammatory cytokines. A variety of components, including platelets and complement factors and the clotting cascade are part of an inflammatory response that includes tissue cells, which are not normally considered to be inflammatory, such as hepatocytes and adipocytes. Thus, the systemic inflammatory response is complex and synergistic, containing cross-regulating pathways. Oxidative stress and chronic inflammation seem to be related phenomena as inflammation always generates oxidative stress. Activated phagocytes undergo a respiratory burst, releasing reactive oxygen intermediates into the microenvironment. Moreover, oxidative stress products, such as lipid peroxides, are in fact proinflammatory. The oxidative stress of preeclampsia is an expected component of the systemic inflammatory response and is intensified in preeclampsia relative to normal pregnancy. When the clinical features of preeclampsia are established, the oxidative 
stress is not localized to the placenta but disseminated in the maternal peripheral circulation (114).

Women who are pregnant with unusually large placentas, e.g. twin pregnancies, have an excessively large inflammatory stimulus and they are also more susceptible to preeclampsia. Moreover, women with chronic inflammation due to obesity (115), hypertension or diabetes are particularly susceptible to preeclampsia. Many of the metabolic features of normal and preeclamptic pregnancies, including insulin resistance, hyperlipidemia, increased blood coagulability or hypoalbuminemia, previously seen as isolated phenomena being hormonally induced, could instead be different consequences of a systemic inflammatory response (9).






\section{Relevance for thesis}

Preeclampsia is obviously a condition of increased inflammation and so is normal pregnancy. In an individual case of preeclampsia it is still unclear to what degree inflammation is caused by placental or maternal factors. It is not clear if placental factors from stressed trophoblasts are different if placental dysfunction is extrinsic (poor placentation) or intrinsic (villous overcrowding). The difference between EOP and LOP in this respect, and between primi- and multipara needs further elucidation. The impact on inflammatory biomarkers of corticosteroid medication used by EOP women should be evaluated. Whether maternal endothelial inflammation is independent of the aberrant angiogenesis and activated coagulation in preeclampsia needs to be clarified.

\section{Role of complement component factors}

Complement factors are often a part of the inflammatory process. Studies in mouse models of pregnancy indicate that complement activation targeted to the placenta drives angiogenic imbalance, placental insufficiency, and endothelial injury. If regulators of complement components such as membrane cofactor protein (MCP), complement factor I (CFI; FI), also known as $\mathrm{C} 3 \mathrm{~b} / \mathrm{C} 4 \mathrm{~b}$ inactivator, or complement factor $\mathrm{H}(\mathrm{CFH} ; \mathrm{FH})$ are dysfunctional, excessive complement activation occurs. This may result in placental damage, thrombosis and release of anti-angiogenic factors, culminating in preeclampsia. One study has demonstrated that in a group of pregnant women with SLE or the antiphosfolipid syndrome, $18 \%$ of the women with preeclampsia had mutations for these regulatory proteins compared to none in the group without preeclampsia. When the authors examined preeclamptic women without autoimmunity, $10 \%$ of these women had the same mutations (116). Complement C5a-C5a receptor interactions trigger release of sFlt-1 in vitro, which is associated with a preeclampsialike condition in rodents and elevated in the circulation of pregnant women destined for preeclampsia. The alternative complement pathway amplifies foetoplacental 
injury in mice with abnormal pregnancies (116). Elevated levels of the alternative pathway complement activation fragment $\mathrm{Bb}$ in the first 20 weeks of pregnancy were recently found to be associated with preeclampsia (117). Hence, complement component factors, particularly the alternative pathway, might be of importance in this syndrome.

In another study, women with severe preeclampsia had increased levels of C5a and terminal complement complex, compared to a normal pregnant group at delivery. Derszy et al. found that the complement system is activated through the classical or alternative pathway with increased terminal complex formation in the third trimester of normal human pregnancy, and further increased in preeclampsia, as shown by the elevated amounts of activation markers in the systemic circulation. Excessive activation of the terminal pathway was associated with foetal growth restriction in preeclamptic women in the same study (32). The role of complement factors in the pathogenesis is however still controversial, since other studies have not found an association between elevated levels of complement factors and pregnancies complicated by preeclampsia.

Burwick and Feinberg presented a case of severe preeclampsia and HELLP in gestational week 26 where treatment with Eculizumab, an inhibitor of complement factor $\mathrm{C} 5$, resulted in a prolongation of pregnancy by 17 days, indicating an important role of complements at least in this specific case of EOP/HELLP (118).

Summary of role of complement component factors in preeclampsia

Complement activation targeted to the placenta drives angiogenic imbalance, placental insufficiency, and endothelial injury in mice.

Mutations of complement regulatory proteins seem not to be uncommon in preeclamptic women.

Complement activation triggers release of anti-angiogenic factors in vitro.

Elevated levels of the alternative pathway complement activation fragment $\mathrm{Bb}$ in the first 20 weeks of pregnancy have recently been found to be independently associated with preeclampsia. 


\section{Relevance for thesis}

Complement component factors seem to be involved in the inflammatory reaction in preeclampsia. It has not been clearly shown if complement components are primarily involved in the placental insult or if they are a part of the maternal systemic inflammatory response or both. If complement components participate in the placental insult they should be more increased in EOP compared to LOP and in IUGR compared to normal pregnancies, which needs to be clarified. The effect of corticosteroid medication for foetal lung maturation must be taken into account when evaluating levels of complement components in EOP. The high frequency of mutations for complement components indicates that increased levels can be a causative factor and not only an effect of preeclampsia

\section{Activated coagulation in preeclampsia}

In normal pregnancy there are changes in the coagulation and fibrinolytic systems. These changes include both increases in a number of pro-coagulant and clotting factors (I, II, VII, VIII, IX and XII and von Willebrand factor) which a maximum around term and a decrease in protein $\mathrm{S}$ levels and there is also an inhibition of fibrinolysis. As gestation progresses, there is also a fall in the activity of activated protein $\mathrm{C}$, an important anticoagulant. All these changes create a hypercoagulable state $(119,120)$ associated with an increase in prothrombin fragments and thrombinantithrombin complexes. In preeclampsia, at least in the severe and early-onset form, levels of anticoagulants such as protein $\mathrm{C}$ and antithrombin (AT) seem to be decreased, creating an even more hypercoagulable state. Abnormality in antithrombin activity is a marker of hypercoagulation and begins more than two weeks before the development of clinical signs of preeclampsia(121). The overall fibrinolytic activity is impaired during pregnancy, but returns rapidly to normal following delivery (122). While these physiological changes may be important for minimising intrapartum blood loss, they entail an increased risk of thromboembolism during pregnancy and the post-partum period. Local haemostasis at the placental trophoblast level is characterized by increased 
tissue factor (TF) expression and low expression of the inhibitor tissue factor pathway inhibitor (TFPI) (123). Invasion of the decidua by extravascular trophoblasts is accompanied by thrombin generation from TF from decidual cells. TF protects against haemorrhage as extravascular trophoblasts invade and remodel spiral arteries and arterioles by breaching capillaries. Via binding of plasma-derived factor VII TF forms a "haemostatic envelope" that gives protection against haemorrhage following vascular injury (124). Many cases of preeclampsia are associated with decidual haemorrhage and maternal thrombophilias, which form excess thrombin from decidual cells. Thrombin affects several cell functions by binding to proteaseactivated receptors. In first trimester decidual cells it enhances expression of soluble fms-like tyrosine kinase-1 (sFlt-1), a potent inhibitor of angiogenesis, which can block the angiogenic effects of VEGF and PlGF. Thrombin also increases monocyte-recruiting chemokine expression together with IL-1 $\beta$ and TNF leading to macrophage excess in the preeclamptic decidua (125). Immune cells and inflammatory mediators are capable of modifying haemostasis, while molecules in coagulation pathway have considerable immunomodulatory effects. T cells, NK cells and macrophages all seem to be involved in this process (126).

Activation of the coagulation cascade occurs early in the course of preeclampsia, often antedating clinically recognizable disease as a part of a systematic inflammatory response caused by the endothelium harming factors from the placenta. Since endothelial cell injury reduces the synthesis of vasorelaxing agents, increases the production of vasoconstrictors, impairs synthesis of endogenous anticoagulants and increases pro-coagulant production, endothelial cells are likely to be implicated in the pathophysiology of preeclampsia. Activated protein C (APC) resistance can explain coagulation activation in pregnancy, while activated coagulation in preeclampsia results, in part, from an increased thrombin generating capacity of plasma that is independent of APC resistance (127). Microparticles from placenta can injure the maternal endothelium although in one study there was no difference in thrombin generation from microparticles in preeclamptic compared to normal 
pregnant women, indicating that circulating microparticles are not directly involved in activation of coagulation in preeclampsia (127).

Thrombophilia is an inherited or acquired predisposition to thrombosis and embolism due to inherited or acquired changes in the coagulation system. Inherited thrombophilia is a congenital deficit of blood coagulation factors that inhibit or increased amount of factors that stimulate fibrogenesis and clot formation (128). During pregnancy, the thrombogenic influence of these conditions is amplified due to a pregnancy-related increase of the amount of most of the coagulation factors.

Activated protein $\mathrm{C}$ resistance is more pronounced during the second and third trimesters (129). Thrombin has an inflammatory effect that is balanced by APC and thrombomodulin (TM), which are both potent anti-inflammatory factors (130, 131). Thrombophilia has been considered a risk factor for pregnancy complications such as preeclampsia and placental insufficiency, but studies have shown conflicting results. Some studies have found that inherited thrombophilias, for example factor $\mathrm{V}$ Leiden mutation and prothrombin gene mutation, are significant risk factors for preeclampsia $(132,133)$ but results are divergent. In thrombophilia an increased tendency for microthrombosis in the placenta might be an additional mechanism in the pathogenesis of preeclampsia.

\section{Summary of Activated Coagulation}

In normal pregnancy there is increase in the number of pro-coagulants and a fall in anticoagulant factors.

In preeclampsia, at least in the severe and early-onset form, levels of anticoagulants such as protein $\mathrm{C}$ and antithrombin are decreased, creating an even more hypercoagulable state.

Local haemostasis at the placental trophoblast level is characterized by increased tissue factor (TF) expression and low expression of the inhibitor TFPI in normal pregnancies.

APC resistance can explain coagulation activation in pregnancy, while activated coagulation in preeclampsia results, in part, from an increased thrombin generating capacity of plasma that is independent of APC resistance. Thrombin enhances the expression of sFIt-1, which can block the angiogenic effects of VEGF and PIGF.

Immune cells and inflammatory mediators are capable of modifying haemostasis, while molecules in the coagulation pathway have considerable immunomodulatory effects.

Activation of the coagulation cascade occurs early in the course of preeclampsia, as part of a systematic inflammatory response. 


\section{Relevance for thesis}

In normal pregnancy, coagulation is activated as an integrated part of the increased inflammation occuring in pregnancy. It seems that coagulation is further activated in preeclampsia. It is not clear if this is a part of the systemic inflammatory response in pregnancy or an independent mechanism due to hormonal or other physiological changes during pregnancy, nor is it clear if activated coagulation is an effect of preeclampsia or if it could be an independent part of the pathophysiology. It is not fully clear if thrombophilia is an independent risk factor for preeclampsia. EOP and LOP might differ in this respect which needs to be examined.

\section{Aberrant angiogenesis in preeclampsia}

Developmental growth and the remodelling and regeneration of adult tissues can only occur accompanied by blood vessel formation. Endothelial cells can give rise to several types of functionally and morphologically distinct vessels.

Upon angiogenic stimuli, endothelial cells can migrate, forming capillary sprouts that project into the perivascular stroma, and subsequently differentiate to form new vessels that are functionally adapted to their tissue environment. Angiogenesis depends on the tightly controlled processes of endothelial cell proliferation, migration, differentiation, and survival. There are endothelial cell-specific growth factors and receptors that may be primarily responsible for the stimulation of endothelial cell growth, differentiation, and differentiated functions. The best studied of these is vascular endothelial growth factor (VEGF). Four VEGF variants (VEGF A-D) appear to be equally capable of stimulating mitogenesis of endothelial cells. Only endothelial cells have been reported to proliferate in response to VEGF and endothelial cells from different sources show different responses. Two receptors for VEGF have been characterized, VEGFR-1/FIt-1 (fms-like tyrosine kinase-1) and VEGFR-2/Kdr/Flk-1 (134). The first receptor also exists in a soluble form (sFlt-1), which can bind and neutralize the effect of VEGF, thereby acting in an anti- 
angiogenic manner. Another related angiogenic growth factor is placental growth factor (PIGF), which is important for placental development. Although PIGF is not a major mitogen for most endothelial cells, it potentiates the mitogenic activity of low concentrations of VEGF, whereas at higher VEGF concentrations PIGF has no additional effect (135). VEGF and its receptors act in a paracrine and cooperative manner to regulate the differentiation of endothelial cells and neovascularization of tissues. VEGF expression in cultured cells has been shown to be elevated by hypoxia. Thus, the hypoxic environment in early placentation can stimulate the expression of VEGF and thereby facilitate angiogenesis (136). Studies have shown that angiogenic factors such as VEGF and PlGF are dysregulated in preeclampsia due to high levels of sFlt-1 (sVEGFR-1), which leads to impaired placental angiogenesis. Analysis of supernatants taken from preeclamptic placental villous explants has shown a four-fold increase in sFlt-1 compared to normal pregnancies. In the same study the relative ratios of VEGF to sFlt-1 and PlGF to sFlt-1 released from explants decreased by $53 \%$ and $70 \%$, respectively, in preeclampsia compared with normal pregnancies. This was demonstrated by a procedure where normal villous explants were exposed to hypoxia compared with exposition to the tissue to normoxia. Conditioned medium (CM) from villous explants from normal placentas induced endothelial cell migration and in vitro tube formation. Both of these mechanisms were attenuated by pre-incubation with exogenous sFlt-1. Endothelial cells treated with preeclamptic CM showed significantly reduced angiogenesis compared with treatment with normal CM. Removal of sFlt-1 by immunoprecipitation from preeclamptic $\mathrm{CM}$ restored migration and tube formation to levels comparable to that induced by normal $\mathrm{CM}$, demonstrating that angiogenesis is inhibited in preeclampsia due to elevated levels of sFlt-1 (137).

In a study with morphometric measures of villous development and capillarization, foetoplacental angiogenesis and capillary lumen remodelling in normal pregnancies and pregnancies complicated with IUGR and/or preeclampsia, IUGR was associated with abnormal growth of villi and foetal capillaries. Reduced villous growth was not accompanied by changes in measures of villous capillarization or maturation or 
changes in lumen calibre or shape. In contrast, PE without IUGR (a high percentage of late-onset preeclampsia cases) was not associated with any effects on placental morphometry. The conclusion was that IUGR, but not PE without concomitant IUGR, is associated with impoverished villous development and foetoplacental angiogenesis (138). There is in fact an increasing amount of data that supports the hypothesis that placental insufficiency triggers an imbalance in the placental release of angiogenesis regulatory factors to the maternal circulation. This is characterized by elevated concentrations of anti-angiogenic factors such as sFlt-1 and decreased concentrations of pro-angiogenic factors such as PlGF (139).

Several studies have shown an imbalance of circulating angiogenic factors in preeclampsia with increased levels of sFlt-1 and decreased levels of PlGF, and this is demonstrated before the clinical onset of the syndrome. This imbalance has been shown both for EOP and LOP $(140,141)$. The sFlt-1/P1GF ratio has even been used clinically for prediction and diagnosis of preeclampsia but it cannot predict preeclampsia with acceptable specificity and sensibility before the second trimester (142).

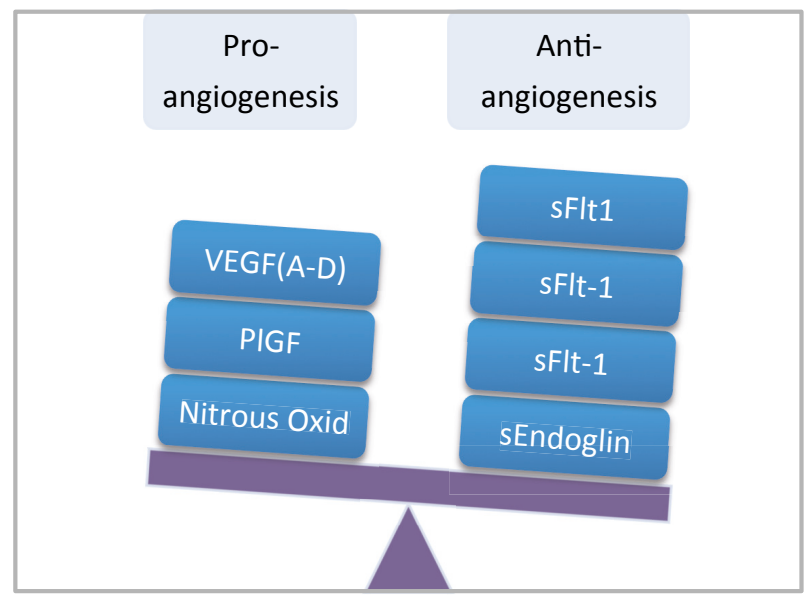

Figure 5. (Im) balance between proand anti-angiogenesis in preeclampsia. VEGF $=$ Vascular Endothelial Growth Factor. P1GF = Placental Growth Factor. sFlt-1 = soluble Fms-like tyrosine kinase-1. sEndoglin=soluble Endoglin 
Summary of aberrant angiogenesis

There are endothelial cell-specific growth factors and receptors primarily responsible for the stimulation of endothelial cell growth, differentiation, and differentiated functions. The best studied of these are VEGF A-D.

The hypoxic environment in early placentation can stimulate the expression of VEGF and thereby facilitate angiogenesis.

PIGF, an angiogenic growth factor, is important for placental development.

IUGR but not PE without concomitant IUGR is associated with impoverished villous development and foetoplacental angiogenesis. Endothelial cells treated with preeclamptic conditioned medium (CM) showed significantly reduced angiogenesis compared with treatment with normal CM.

Several studies have shown an imbalance of circulating angiogenic factors in preeclampsia with increased levels of sFlt-1 and decreased levels of PIGF, demonstrated before the clinical onset of the syndrome.

\section{Relevance for thesis}

There is an imbalance in angiogenesis in preeclampsia with increased antiangiogenic factors such as sFlt-1 and decreased levels of pro-angiogenic factors such as PlGF. Whether this imbalance is primarily at the placental level or an integrated part of the maternal reaction is not clear, nor is it clear if angiogenesis is an independent mechanism from increased inflammation and activated coagulation. If aberrant angiogenesis is primarily a placental phenomenon, we could expect antiangiogenic factors to be significantly more increased in EOP and probably also in IUGR compared to LOP without placental insufficiency, which has to be clarified. Moreover, it is not clear if this angiogenic imbalance in maternal serum of preeclamptic women is the major pathogenetic mechanism in the pathogenesis of the condition.

\section{Prediction, prevention and treatment}

The aim of much preeclampsia research is to find a way to predict and prevent and hopefully also treat the condition. Knowledge of the pathogenesis is therefore of outmost importance in order to find biomarkers and measures that can predict the 
condition with as high sensitivity and specificity as possible. The aim of predicting preeclampsia is primarily to be able to prevent the condition before the clinical onset, but it is also valuable to be aware of an increased risk for preeclampsia in planning for pregnancy monitoring. Since there actually is no effective treatment except delivery for preeclampsia, prophylaxis of the condition is of highest interest. Prophylaxis could theoretically be anything interfering with the described pathogenic conditions as inflammation, coagulation and angiogenesis or even with the immunological process that precedes the clinical condition. Prophylaxis must be safe for the pregnant woman without any major side effects, since many would have a normal pregnancy even without prophylactic treatment. If possible, also treatment of the established condition is highly interesting and even that purpose necessitates mapping of the pathogenetic mechanisms of the condition. Since inflammation, coagulation and angiogenesis seem to be involved in the pathogenesis of preeclampsia early in pregnancy, before there are any clinical signs of the condition, biomarkers of these conditions could be used for prediction of preeclampsia together with other measures as ultrasound, measurements of mean blood pressure and a carefully analyzed medical history including genetic predisposing factors (143). An effective prediction is a prerequisite if prophylaxis against the condition is to be used. Prophylactic treatments with Aspirin and/or low molecular weight heparin (LMWH) both interact with inflammation, coagulation and angiogenesis, and preliminary results from studies with prophylactic treatment to high risk groups are promising for both these alternatives(144-147). In the future, treatment of established preeclampsia will hopefully be an option. Already studies are ongoing on treatment with statins, which have an effect on inflammation, coagulation and angiogenesis, and at least in mice they seem to work $(148,149)$. Treatment of very early-onset preeclampsia with antithrombin has also been able to prolong gestation $(150,151)$. 


\section{Hypotheses and Aims}

The hypotheses of this thesis are:

1. Increased inflammation, abnormal coagulation and aberrant angiogenesis are independently involved mechanisms in the pathogenesis of preeclampsia.

2. Placental factors in maternal serum are responsible for maternal symptoms and could function as blueprints of the condition in preeclampsia.

3. A defect tolerance of the semiallogeneic foetus, manifested as an imbalance in regulating cells and molecules, is involved in the pathogenesis of preeclampsia.

The overall aim is to increase knowledge of the pathogenesis of and immunological background to preeclampsia including the role of inflammation, angiogenesis and coagulation, both locally at the foetomaternal interface and in the maternal circulation. A secondary aim is to identify candidate factors or a test that can effectively predict preeclampsia, for a future prevention of the condition.

\section{Specific aims}

1. The aim of Paper I was to determine if sera from preeclamptic women can function as blueprints of the condition and elicit symptoms of preeclampsia in mice and provide a basis for an in vitro predictive assay.

2. The aim of Paper II was to assess the involvement of and correlation between systemic inflammation, aberrant angiogenesis and activated coagulation in earlyand late-onset preeclampsia by using a broad panel of biomarkers in a large sample of pregnant women.

3. The aim of Paper III was to determine whether the frequency and phenotype of circulating Treg cells differ in women with preeclampsia compared with pregnant and non-pregnant controls when using a set of updated Treg phenotype markers.

4. The aim of Paper IV was to analyse and compare placental expression and plasma levels of chemokines associated with different $\mathrm{T}$ helper subsets in normal and preeclamptic pregnancies to determine if aberrant chemokine levels are associated with preeclampsia and if systemic chemokine levels reflect local expression. 


\section{Material and Methods}

\section{Subjects}

\section{Demographic background}

In the south-east region of Sweden approximately 10000 women gave birth annually during the period between 2003 and 2007. Of these women, almost $3 \%$ received the diagnosis of preeclampsia, of which cases $1 / 3$ were defined as severe and $2 / 3$ as moderate. $0.2-0.3 \%$ of these delivered at a gestational age of $<34$ gestational weeks (GW), an approximation for early-onset preeclampsia. The annual number of deliveries during the time of the study was approximately 1800 at the County Hospital Ryhov in Jönköping and 2500 at the University Hospital in Linköping. Most cases $(95 \%)$ of preeclampsia were recruited from these hospitals. During the study period, the total number of preeclampsia cases at these two hospitals was approximately 500 according to obstetrical databases, corresponding to $3.8 \%$ of deliveries. This prevalence is based on the referral status of these hospitals; most women with preeclampsia before 36 weeks of pregnancy are transferred to these hospitals

\section{Study group and control group (Paper I, II and IV)}

In a group of 114 women from the region with the diagnosis of preeclampsia (Table II), blood samples were drawn in connection to admission to the hospital and placental biopsies were collected post-partum.

The same measurements were taken in a control group of 100 women with normal pregnancies. As we planned to measure many different biomarkers it was difficult to calculate an exact power for the study, so we chose a large sample size. The preeclamptic women were recruited from the departments of obstetrics at the County Hospital Ryhov in Jönköping $(n=84)$, the University Hospital in Linköping $(n=24)$, and the County Hospital in Kalmar $(n=6)$. The control group was recruited from antenatal care centres and maternity wards in Jönköping $(n=63)$ and Linköping $(n=$ 
20) and from the maternity ward at the County Hospital Vrinnevi in Norrköping ( $\mathrm{n}=$ 17). All four major hospitals in the region were thus involved. Collection of blood samples was carried out during the years 2003-2007

Inclusion with written informed consent and blood sampling was performed during the daytime soon after admission to hospital for preeclamptic women, irrespective of gestational length. For the control group, the women were included similarly when they appeared for their regular visits at antenatal care centres or were admitted for elective caesarean section (CS) for other reasons than preeclampsia or IUGR. Blood sampling was carried out by midwives, and the samples were immediately sent to the laboratory for centrifugation, separation into plasma and serum samples, and storage in a $-80^{\circ}$ freezer.

Table II Clinical Spectrum of Preeclampsia Cases (Percentage within Brackets)

SGA, Small for gestational age; EOP, early onset preeclampsia; LOP, late onset preeclampsia;

\begin{tabular}{|l|l|l|l|l|l|}
\hline & $\begin{array}{l}\text { SGA } \\
\text { baby }\end{array}$ & $\begin{array}{l}\text { HELLP } \\
\text { syndrome }\end{array}$ & Eclampsia & Moderate PE & Severe PE \\
\hline EOP $(\mathrm{n}=31)$ & $14(45.2)$ & $7(22.6)$ & $1(3.2)$ & $6(19.4)$ & $25(80.6)$ \\
\hline LOP $(\mathrm{n}=83)$ & $6(7.2)$ & $3(3.6)$ & $1(1.2)$ & $63(75.9)$ & $20(24.1)$ \\
\hline PE $(\mathrm{n}=114)$ & $20(17.5)$ & $10(8.8)$ & $2(1.8)$ & $69(60.5)$ & $45(39.5)$ \\
\hline
\end{tabular}

Women with diabetes, kidney diseases, multiple pregnancies, and essential hypertension were excluded and so were women on anticoagulant or continuous steroid medication. Two cases were excluded from the control group because of foetal growth restriction and foetal death. In the preeclampsia group, four women were excluded because of diabetes, six because of twin pregnancy, one because of pregnancy-induced hypertension, one because of systemic lupus erythematosus (SLE) with steroid medication, and one because of prophylactic treatment with low molecular weight heparin (LMWH) during pregnancy. Preeclampsia was defined as new onset of proteinuric hypertension after 20 weeks of gestation. Moderate and severe preeclampsia diagnoses were made according to guidelines of American Congress of Obstetricians and Gynecologists (ACOG) (152). Preeclampsia was defined as EOP when onset was before 32 gestational weeks and LOP when onset was after. For the clinical spectrum of preeclampsia, see Table II. The control group was matched for maternal and gestational age with no significant difference between 
neither maternal nor gestational age.

In the immunohistochemistry study in paper IV we also included five placental biopsies from women after elective surgical abortion in first trimester. These pregnancies were all dated by ultrasonography. We examined placental but did not use fetal tissue.

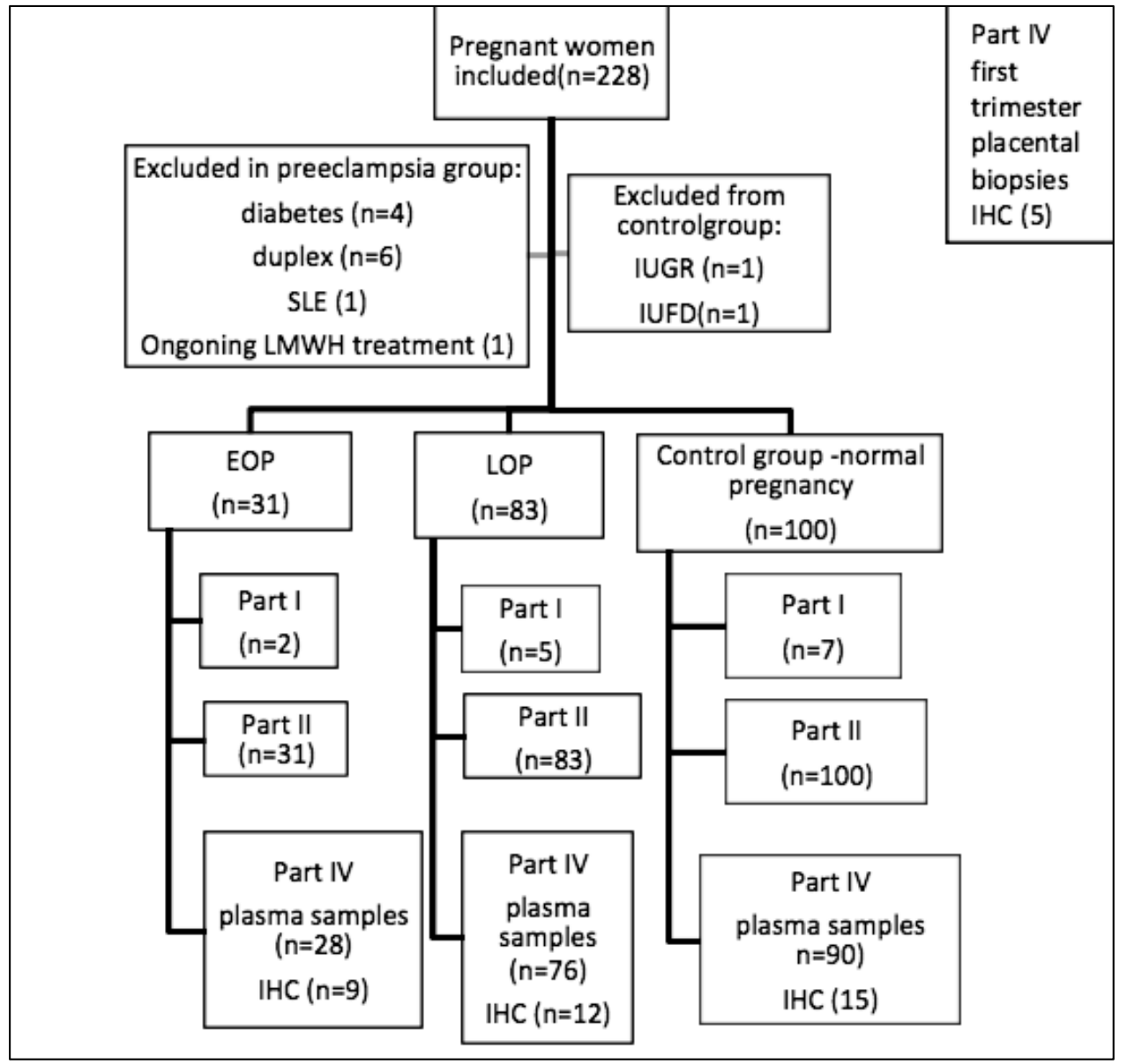

Figure 6. Flow chart showing participants in Part I, II and IV. IHC = Immunohistochemistry. SLE = Systemic Lupus Erythematosus. LMWH $=$ Low molecular Weight Heparin. IUFD = Intrauterine Fetal Death. IUGR = Intrauterine Growth Retardation. EOP $=$ Early-onset preeclampsia. $\mathrm{LOP}=$ Late-onset preeclampsia 


\section{Study group and control groups (Paper III)}

Eighteen women with de novo proteinuria and hypertension appearing after gestational week 20 were included (Table III). The inclusion criteria were either severe or early-onset preeclampsia. Severe preeclampsia was defined as highest measured blood pressure $\geq 160 / 110 \mathrm{~mm} \mathrm{Hg}$ and/or with signs of renal (oliguria or proteinuria $\geq 5 \mathrm{~g} / \mathrm{d}$ ), hepatic or neurological impairment or thrombocytopenia, while early-onset preeclampsia was defined by onset at gestational age of less than 34 weeks. Included patients had either severe $(n=1)$ or early-onset $(n=1)$ preeclampsia or both $(\mathrm{n}=16)$. Women with diabetes, BMI $>35$, chronic hypertension, thrombophilia and twin pregnancies were excluded. The majority (72.2\%) of preeclampsia patients delivered babies that were small for gestational age (SGA), which was a sign of placental involvement. SGA is in a Swedish context defined as a weight of 2 standard deviation scores below the mean foetal weight for gestational age or less, which means approximately $<-21 \%$.

Table III Clinical data on the preeclamptic women included in paper III.

* Highest value of measured BP. GW = gestational weeks; FW = fetal weight; HELLP = Hemolysis, Elevated Liver enzymes and Low Platelet count

\begin{tabular}{|c|c|c|c|c|c|c|c|}
\hline & Age & $\mathrm{BP} *$ & Proteinuria & Onset (GW) & FW deviation $\%$ & Corticosteroid & Complications \\
\hline 1 & 27 & $160 / 105$ & $1+$ & $29+0$ & -28.1 & Yes & \\
\hline 2 & 26 & $170 / 125$ & $3+$ & $28+0$ & -33.3 & Yes & \\
\hline 3 & 28 & $180 / 105$ & $2+$ & $30+6$ & -38.0 & Yes & Abrubtio placentae \\
\hline 4 & 36 & $170 / 120$ & $3+$ & $31+2$ & -19.4 & Yes & \\
\hline 5 & 34 & $200 / 120$ & $3+$ & $33+4$ & -26.4 & No & \\
\hline 6 & 31 & $185 / 115$ & $3+$ & $26+3$ & -28.3 & No & \\
\hline 7 & 17 & $190 / 120$ & $3+$ & $23+0$ & -13.8 & No & \\
\hline 8 & 21 & $180 / 110$ & $3+$ & $27+0$ & -27.4 & Yes & Eclampsia \\
\hline 9 & 46 & $195 / 115$ & $3+$ & $31+3$ & -31.7 & No & Oliguria \\
\hline 10 & 35 & $170 / 105$ & $3+$ & $30+0$ & -6.0 & Yes & HELLP \\
\hline 11 & 27 & $180 / 110$ & $3+$ & $27+0$ & -6.7 & Yes & \\
\hline 12 & 24 & $200 / 120$ & $3+$ & $30+0$ & -32.9 & Yes & \\
\hline 13 & 38 & $220 / 120$ & $3+$ & $29+4$ & -33.0 & Yes & \\
\hline 14 & 31 & $160 / 90$ & $3+$ & $30+0$ & -34.8 & No & \\
\hline 15 & 39 & $180 / 100$ & $3+$ & $35+0$ & -20.0 & No & \\
\hline 16 & 31 & $170 / 100$ & $3+$ & $30+1$ & -24.8 & No & \\
\hline 17 & 38 & $140 / 90$ & $3+$ & $34+0$ & -15.3 & No & \\
\hline 18 & 27 & $140 / 95$ & $1+$ & $29+4$ & -32.7 & Yes & Thrombocytopenia \\
\hline
\end{tabular}


Treatment with antenatal betamethasone for foetal lung maturity was started prior to blood sampling in 10 out of 18 preeclamptic women in close proximity to blood sampling. The patients were recruited from the obstetrical departments of Linköping University Hospital and County Hospital Ryhov in Jönköping. As controls, 20 women with normal pregnancy and 20 healthy non-pregnant women were included (Table IV). The normal pregnant women were included (gestational week 24-27) at their regular second trimester control at the antenatal clinic. Ten of the normal pregnant and ten of the non-pregnant women were also included in research reported in a previous paper (67). There was no significant difference across the three groups with regard to age, parity and body mass index, whereas the gestational age was significantly lower $(\mathrm{p}<0.001)$ in the normal pregnant compared with the preeclamptic women. Inclusion in the study with blood sampling was carried out during the period 2007-2011.

Table IV Demographic and clinical data for women included in paper III, as median (range within brackets) or as categorical data.

\begin{tabular}{|llll|}
\hline Subject characteristics & $\begin{array}{l}\text { Preeclamptic } \\
\text { women } \\
(\mathrm{n}=18)\end{array}$ & $\begin{array}{l}\text { Healthy pregnant } \\
\text { women } \\
(\mathrm{n}=20)\end{array}$ & $\begin{array}{l}\text { Non-pregnant } \\
\text { women } \\
(\mathrm{n}=20)\end{array}$ \\
\hline Age at inclusion & $31(17-46)$ & $28(19-38)$ & $26.5(20-36)$ \\
\hline Blood pressure & $\begin{array}{l}177 / 108 \\
(140 / 95-\end{array}$ & $\begin{array}{l}115 / 70 \\
(110 / 60-130 / 80)\end{array}$ & no information \\
\hline $\begin{array}{l}220 / 120) \\
\text { Proteinuria (dipstick) }\end{array}$ & $\begin{array}{l}3+ \\
(1+-3+)\end{array}$ & no proteinuria & no information \\
\hline $\begin{array}{l}\text { Grading) } \\
\text { inclusion (weeks) }\end{array}$ & $29(23-33)$ & $25(24-27)$ & NA \\
\hline Partus (weeks) & $30(26-37)$ & $41(35-42)$ & NA \\
\hline $\begin{array}{l}\text { Previous pregnancies } \\
\text { (n) }\end{array}$ & $2(1-5)$ & $0(0-2)$ & $0(0-2)$ \\
\hline Previous births $(n)$ & $0(0-2)$ & $0(0-1)$ & $0(0-2)$ \\
\hline
\end{tabular}




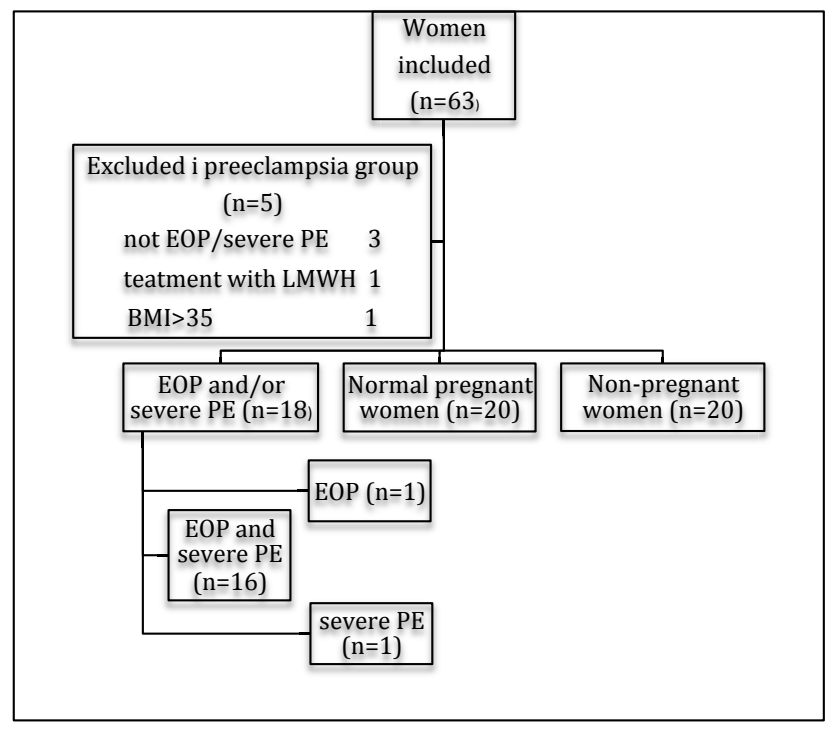

Figure 7. Flow chart showing subjects in paper III. EOP= Early-onset preeclampsia. LMWH $=$ Low Molecular Weight Heparin. BMI = Body Mass Index

\section{Ethical consideration}

The studies in my thesis have all been ethically approved by the regional ethical review board in Linköping and the study in paper I has also been approved by a local ethical review board in Providence. In line with the Swedish ethical standards informed consent was obtained from the pregnant women who participated, concerning blood sampling and placental biopsies. The studies were well designed for its purpose even if exact power was difficult to calculate. Ethical concerns in paper II-IV is mostly about blood sampling and placental biopsies. Blood sampling is not associated with any significant risks for the participating women's health but it could be inconvenient and for some women all forms of use of needles are associated with discomfort and sometimes even anxiety. Participation was, however, voluntary, and care of the woman was not affected if they denied to participate. After the delivering women has been shown the placenta directly post partum they normally never see it again. Thus, taking a biopsy from placenta is not associated with any discomfort or risk. However, the use of animal studies in paper I and samples from 
first trimester women undergoing elective abortions in paper IV raises some special ethical concerns.

\section{Animal experiments}

Animal research has made a pivotal contribution to a large number of scientific advances of the past century and continues to aid our understanding of various diseases (153). However, since animal experiments can cause harm and suffering for the involved animals, this type of research has been questioned for ethical reasons. Therefore, different ethical concepts have been developed in this field of research. Russel and Burch defined the "3Rs" concept in 1959, i.e., that all efforts to replace, reduce, and refine experiments must be undertaken $(154,155)$. The licensing of animal experiments normally requires an ethical evaluation process, often undertaken by ethics committees (156) and in this case our study was approved by the Lifespan Institutional Animal Care and Use Committee in United States. Important ethical aspects concern whether there are reasonable expectations that the research will result in increased scientific knowledge and also will increase understanding of the species under study or provide results that could improve the quality of health or welfare of humans or other animals. Since preeclampsia is a condition that globally is a major cause of maternal morbidity and mortality we consider that animal research that can contribute to find ways to predict and prevent this condition is justified. Another important aspect is that species chosen for study should be the best suited to answer the questions posed, and there is no species that is more suitable to study in reproductive research than the mouse, due to its similarities to human placentation and its short gestational age. Moreover, a good experimental design helps in reducing the number of animals used in research since it allows collection of data using the minimum number of animals. However, a sufficient number must be used to enable precise statistical analysis and results (153). All individuals who used animals at the lab had received instruction in experimental methods and in the care, maintenance, and handling of mice. It is also important to carefully assess the method of administration and the effects of the substance on the animal, and the amount of 
handling and restraint required. For this reason and to avoid a negative impact of stress on the results, we chose to inject serum into mice intraperitoneally, since it is less traumatic than intravenous injection. Moreover, surgical procedures require close supervision and attention to humane considerations by the scientist and use of sufficient anaesthesia, which means that all surgical procedures and anesthetization should be conducted under the direct supervision of a person who is competent in the use of the procedures, which was the case in this study. Aseptic techniques must be used on laboratory animals whenever possible and in this lab the mice were kept under strict aseptic conditions.

Legislation on animal experimentation in modern societies is based on the supposition that this is ethically acceptable when certain more-or-less defined formal demands and ethical principles are met (157).

\section{First trimester samples}

We used placental samples from five first trimester women undergoing elective surgical abortions. In our study we only used trophoblasts from placenta but no foetal tissue. That means that the aborted foetus was treated according to ordinary clinical guidelines and with respect. Whether it is ethically correct to ask vulnerable women considering an abortion to participate in a study is another important ethical consideration. To deal with this, the medical staff was informed not to include women if they found it inappropriate. Moreover, the women were all given oral and written information about the study, and this information was given after a final decision to undertake the abortion procedure. Participation was always voluntary and it was made clear that present and future treatment would not be affected by their decision, which could at any moment be withdrawn. Normally the women had several weeks to consider their decision during the time between when the information was given until the procedure was performed. Most women agreed to participate as they felt they were contributing to something good.

There are some other concerns about using samples from first trimester human placentas. Since the outcome of pregnancy is unknown it is possible that some of 
these pregnancies would have ended up with pregnancy complications such as preeclampsia, IUGR, IUFD or premature delivery. Since some pregnancy complications with onset late in pregnancy are caused by placental insult, we do not know if our first trimester samples represented normal placentas. Nevertheless, the vast majority ( $>90 \%$ ) of the first trimester pregnant women will end up in a normal pregnancy without the mentioned complications, so the impact from samples that would have ended up in a complication should be limited.

There are not many alternatives if one wishes to study human first trimester placenta. However, new approaches might add some options. First trimester decidual tissue can be obtained during chorionic villous sampling, which is done for diagnosis of chromosomal abnormalities. Since in most cases it is associated with an ongoing pregnancy, the outcome of pregnancy can be correlated with the result of examination of the sample. One limitation is the small amount of tissue obtained and another is the limited number of patients undergoing this procedure. Another option could be to use artery Doppler ultrasound to define first trimester pregnancies with a high pulsatile index, which is associated with defect spiral artery remodelling that is common in early-onset preeclampsia and IUGR. This will, however, only approximate the risk of a certain complication, and moreover it will necessitate an extra examination of the woman considering an abortion.

\section{Material}

\section{Blood sampling}

The blood samples for Parts I, II and IV were drawn into EDTA and Na-citrate tubes. For isolation of plasma, blood samples were centrifuged within $1 \mathrm{~h}$ after sampling, and serum and plasma samples were immediately frozen and stored at $-70^{\circ} \mathrm{C}$ until analysed at the laboratory at the University Hospital in Linköping, except for complement measurements, which were carried out at a laboratory at the Linneaus University in Kalmar, and cortisone measurements, which were carried out at the Doping Control Laboratory, Karolinska University Hospital, Huddinge, Stockholm. 


\section{Placental biopsies}

Placental tissues were collected from the majority of the preeclamptic and healthy pregnant women included in Parts I, II and IV. They were collected at birth by cutting a cube, approximately $1 \times 1 \times 1 \mathrm{~cm}$ in size on the maternal side of the placenta, using a scalpel and fixated in formalin for further transport to the Department of Clinical Pathology at the University Hospital in Linköping to be embedded in paraffin. For the immunohistochemistry (IHC) study (Paper IV) we chose to study placental samples from three groups, early- and late-onset preeclamptic women and normal pregnant women (Figure 9). Professor Heriberto Rodriguez-Martinez, who has great experience in immunohistochemistry helped us to find placental slides of acceptable quality. We preferred placental samples from women delivered by elective caesarean section to avoid the impact of labour, which was possible for early-onset preeclampsia and normal pregnant women, but for late-onset preeclampsia a large majority were delivered vaginally so we had to accept that some were delivered by acute CS and some were spontaneously vaginally delivered. We chose also to avoid biopsies from preeclamptic women pre-treated with corticosteroids antenatally before blood sampling. Probably, the vast majority of the early-onset women were at some point treated with corticosteroids in line with medical routines at the involved hospitals. We were able to identify nine samples in the early-onset PE group, 12 in the late-onset PE group and 15 in the normal pregnancy control group fulfilling the above-mentioned criteria. The tissue samples were sectioned $(4 \mu \mathrm{m})$ and deparaffinised. The immunohistochemistry study was performed as described in Paper IV.

The samples for the IHC study were obtained from the department of obstetrics at the University Hospital in Linköping (two early-onset) and the County Hospital Ryhov in Jönköping (seven early-onset; 12, late-onset; two normal pregnancy). The rest of the control group samples were collected from the maternity ward at the County Hospital Vrinnevi in Norrköping (13 normal pregnancy). 


\section{Methods}

The methods used in Paper I-IV are described in detail in the Material and Methods section in each paper. In this part of the thesis I will describe the methods that has been used with emphasis on strengths and weaknesses.

\section{Animal experiments}

The reproductive immunology research team at Linköping University has for many years been involved in cooperation with a research laboratory at the Women and Infants Hospital of Rhode Island under the direction of Professor Surendra Sharma. As a part of our preeclampsia project we sent some of the collected serum samples to Providence (Figure 6) to be used in research involving mice studies and a tube formation test, which is described in Paper I of this thesis. The laboratory has much experience in mice experiments and all animal protocols were approved by the Lifespan Institutional Animal Care and Use Committee, which means that all the requirements for conducting animal studies were met. Both C57BL/6 wild type and IL-10 knockout mice were housed and mated in a specific pathogen-free facility under the care of the Central Research Department of Rhode Island Hospital. All mating experiments were repeated at least three times, with at least four to six mice per treatment.

The mice were treated with intraperitoneal injections (to minimise stress from injections) of serum from women with moderate or severe preeclampsia or normal pregnancy. Blood pressure was measured during pregnancy, which lasted for approximately 20 days, and urine was assessed for proteinuria. Kidney tissue and uteroplacental units were harvested for histopathological examination and evaluated for tissue hypoxia. Finally, blood samples were drawn via cardiac puncture. All this is described in more detail in Paper I. 


\section{Animal studies - Strengths and weaknesses}

Animal studies have many advantages. Most important is that it is possible to test a hypothesis directly in vivo as in our study, which for ethical reasons is impossible on humans. The gestational length in a murine pregnancy is only 20 days, which facilitates studying what happens during pregnancy. Moreover, animals can be genetically manipulated by knocking out certain genes, which gives the opportunity to test what happens when certain proteins are not produced, for example IL-10 in some mice in the actual study. Weaknesses in animal studies are that there are differences in anatomy and physiology between animals and humans, and pregnancy differs in many ways. The placenta is one of the organs with the highest evolutionary diversity among animal species. In consequence, an animal model that exactly reflects human placentation does not exist. However, the mouse is the most frequently used animal model for placenta and pregnancy research. Like humans, mice possess a discoid haemochorial placenta, but there are also differences between the human and murine placenta. In the mouse placenta, the trophospongium is located at the bottom of the placental disc that is built up by wandering giant cells that infiltrate the maternal tissue and eventually come into contact with maternal blood vessels, which they open up, thereby creating the haemochorial state. The major portion of the placental disc is the placental labyrinth composed of syncytiotrophoblasts and cytotrophoblasts where very thin foetal capillaries are surrounded by trophoblasts bathed in the maternal sinusoidal blood as in a haemochorial placenta (158) (Figure 8). In the mouse the placenta is much thinner than the human placenta and it is not uncommon to have $>10$ foetuses. Hence, results from murine studies must be interpreted with caution. Another problem with animal studies is the ethical dilemma that the studies induce disease and suffering and eventually death for the mice, which must be balanced against the benefits of the study. Ethical considerations regarding animal experiments have already been highlighted (see "Ethical considerations"). 



Nature Reviews | Genetics

Figure 8. The murine compared to the human placenta (159). Figure reproduced with permission from Janet Rossant and James Cross.

\section{Tube formation test}

In the laboratory in Providence, a serum-based three-dimensional dual cell culture model to study endovascular activity involving trophoblasts and endothelial cells has been established called the Tube formation test (160), which I have had the opportunity to work with. This model was used to evaluate the differential effects of pregnancy serum. Briefly, trophoblasts or endothelial cells $\left(2.5 \times 10^{4}\right)$, labelled with cell tracker green CMFDA or cell tracker red CMTMR (Molecular Probes, Eugene, OR), respectively, were co-cultured on matrigel coated plates in the presence of serum from normal pregnancy or preeclampsia. Serum-initiated endothelial celldirected tube formation by trophoblasts was monitored and recorded as described in a previous study (160). Based on the initial dose-related findings, we routinely used 10 $\%$ of normal pregnancy serum or preeclampsia serum for majority of studies unless specified. To evaluate the system to predict the onset of preeclampsia, serum samples from 12 to $14(\mathrm{n}=18), 24$ to $27(\mathrm{n}=5)$, and 32 to $36(\mathrm{n}=22)$ weeks of gestation were tested and compared with gestational age-matched normal pregnancy serum. The average number of tubes/vacuoles formed was quantified in a fluorescence microscope as described earlier $(50,160,161)$. 


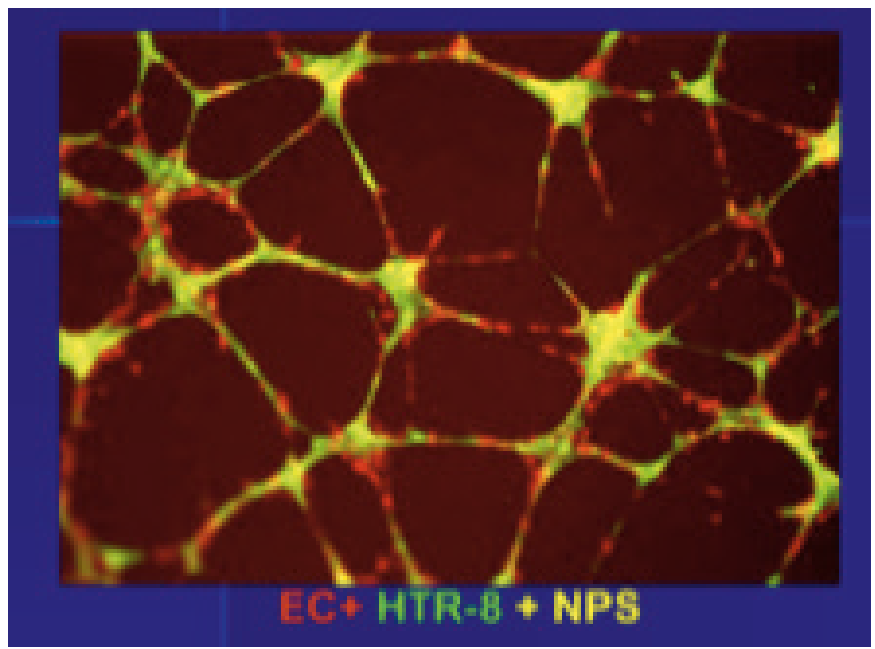

Figure 9 Fluorescence microscopy demonstrating tube formations in a co-culture of endothelial cells (EC; green colour) and trophoblast cells (HTR-8; red colour) in normal pregnancy serum (NPS) on matrigel.

\section{Tube formation test - strengths and weaknesses}

The tube formation test has the advantage of being a test in a laboratory, which might be valuable for prediction of preeclampsia. Another advantage is the possibility to test the effect on tube formations of different molecules, e.g. pro- and antiinflammatory cytokines, complement components, anti-angiogenic factors, heparin and $\mathrm{LMWH}, \mathrm{hCG}$, heme and other molecules with a potential effect on placental angiogenesis. Thus, the test can be utilized to better explore the mechanisms in the pathogenesis in preeclampsia and moreover, the effects of potential drugs can be tested. An obvious weakness is that it is an in vitro test and its results might not be valid in vivo. Therefore, the results from the tests so far are mainly hypothesiscreating. There is still no data concerning specificity and sensibility as predictive tests for preeclampsia. Another disadvantage is that a fluorescence microscope is expensive and the method requires experience of working with immortal cell lines.

\section{Coagulation tests}

All coagulation analyses were performed on citrated plasma $(1 / 10$ volume $0.13 \mathrm{~mol} / \mathrm{L}$ citrate) on an automated coagulation instrument, ACL Top. For a more detailed description see the section on coagulation tests in Paper II. Coagulation tests are done 
in a highly standardized way with a continuous evaluation of the methods in laboratories that serve both clinical health care and research. The strengths and weaknesses of this test depend mainly on the cost-effectiveness of the equipment. The problem with analysis of coagulation tests during pregnancy is that there are no generally accepted reference values correlated to gestational age, which means that for an individual woman it could be difficult to find out if a coagulation test is pathologic or just dependent on pregnancy. Inherited thrombophilia, e.g. factor $\mathrm{V}$ Leiden mutation is, however, a condition that exists before pregnancy and does not depend on pregnancy.

\section{ELISA (for complement, angiogenetic factors and PTX3)}

An ELISA is typically performed in a polystyrene plate with wells, which will passively bind antibodies and proteins. This binding and immobilization of reagents makes the ELISA easy to design and perform. When the reactants of the ELISA are immobilized to the microplate surface it is easy to separate bound from non-bound material during the assay. This ability to wash away non-specifically bound materials makes the ELISA a powerful tool for measuring specific analytes within a crude preparation.

A detection enzyme or other tag can be linked directly to the primary antibody, to a secondary antibody that recognizes the primary antibody, or to a protein such as streptavidin if the primary antibody is biotin labelled. The most commonly used enzyme labels are horseradish peroxidase (HRP) and alkaline phosphatase (AP). A large selection of substrates are available for performing the ELISA with an HRP or AP conjugate. The choice of substrate depends upon the instrumentation available for signal detection and the required assay sensitivity. An ELISA can be performed with modifications to the basic procedure. Immobilization of the antigen can be achieved by direct adsorption to the plate or indirectly via a capture antibody attached to the plate. The antigen is then detected either directly (labelled a primary antibody) or indirectly (labelled a secondary antibody). Direct detection is not widely used but is quite common for immunohistochemical staining of tissues and cells. A sandwich 
ELISA, which we have used, is a powerful ELISA format. It is called a "sandwich" assay because the analyte to be measured is bound between two primary antibodies the capture antibody and the detection antibody. The sandwich format is used because it is sensitive and robust, since it is the detection step that largely determines the sensitivity of an ELISA. The antigen to be measured must contain at least two antigenic epitopes capable of binding to antibodies, since at least two antibodies act in the sandwich (162), see Figure 10.

\section{Sandwich ELISA}

1

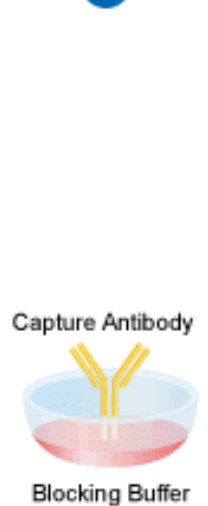

2

3

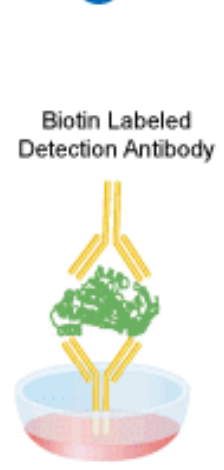

4

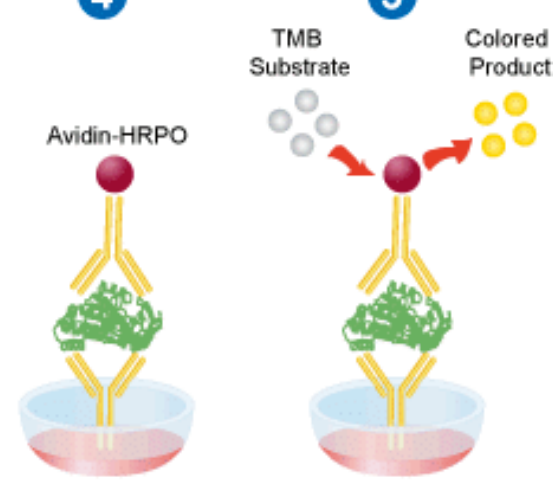

1 a.) Plate is coated with a suitable capture antibody. b.) Blocking buffer is added to block remaining protein-binding sites on plate.

2 Sample is added to plate and any antigen present is bound by the capture antibody.

(3) A suitable biotin labeled detection antibody is added to the plate and also binds to any antigen present in well.

4 UltraAvidin ${ }^{\mathrm{TM}}$-HRPO (Leinco Prod. No. A106) is added and binds the biotin labeled detection antibody.

5 TMB substrate (Leinco Prod. No. T118) is added and converted by HRPO to a detectable form.

Figure 10 Illustration of Sandwich ELISA method. 


\section{ELISA - strengths and weaknesses}

The main advantages of the ELISA is that it is a quick and convenient method and that antigens of very low or unknown concentration can be detected since a capture antibody only grabs a specific antigen. It is generally safe, and does not require radioactive substances, contains diluted sulfuric acid, and is used in wide variety of tests.

disadvantage of the ELISA might be if a monoclonal antibody, that recognize one specific binding site also called epitope, has to be used for matched pairs, since monoclonal antibodies are more expensive and more difficult to find than polyclonal antibodies. Polyclonal antibodies are a mix of antibodies that recognize several epitopes, while monoclonal antibodies are specific to a single epitope. However, it is quite common to use a polyclonal antibody for detection. Another problem is if a negative control by binding to open sites in a well indicates a positive result due to an ineffective blocking solution. Moreover, enzyme/substrate reaction is short-term, while microwells must be read as soon as possible. There are several advantages to the sandwich ELISA and one is the high specificity, since two antibodies are used, the antigen/analyte is specifically captured and detected. The method is suitable for complex samples, since the antigen does not require purification prior to measurement.

\section{Multiplex bead array (MBIA) (for cytokines and chemokines)}

Multiplex arrays have been developed from traditional ELISA assays with the purpose of measuring multiple cytokines in the same sample at the same time. They are available in several different formats based on the utilization of flow cytometry, chemiluminescence, or electrochemiluminescence technology. Flow cytometric multiplex arrays, also known as bead-based multiplex assays, represent probably the most commonly used format at the present time. The Luminex multi-analyte profiling (xMAP) technology from Luminex (www.luminexcorp.com) employs a proprietary bead set, which is distinguishable under flow cytometry by a red laser that excites the 
red dyes of the bead and classifies the bead by a special type of light emission, which can be recorded. Each bead set is coated with a specific capture antibody, and fluorescence or streptavidin-labelled detection antibodies bind to the specific cytokine-capture antibody complex on the bead set. Green laser excites the reporter fluorochrome and quantifies the analyte. Multiple cytokines and chemokines in a biological liquid sample can thus be recognized and measured by the differences in the bead set, with chromogenic or fluorogenic emissions detected using flow cytometric analysis. Commercially available bead-conjugated antibodies permit the measurement of up to 25 different cytokines and chemokines in the same sample. However, this number can be greatly expanded if the investigator is willing to custom-conjugate antibodies of interest to one of nearly 100 different available beads $(163,164)$.

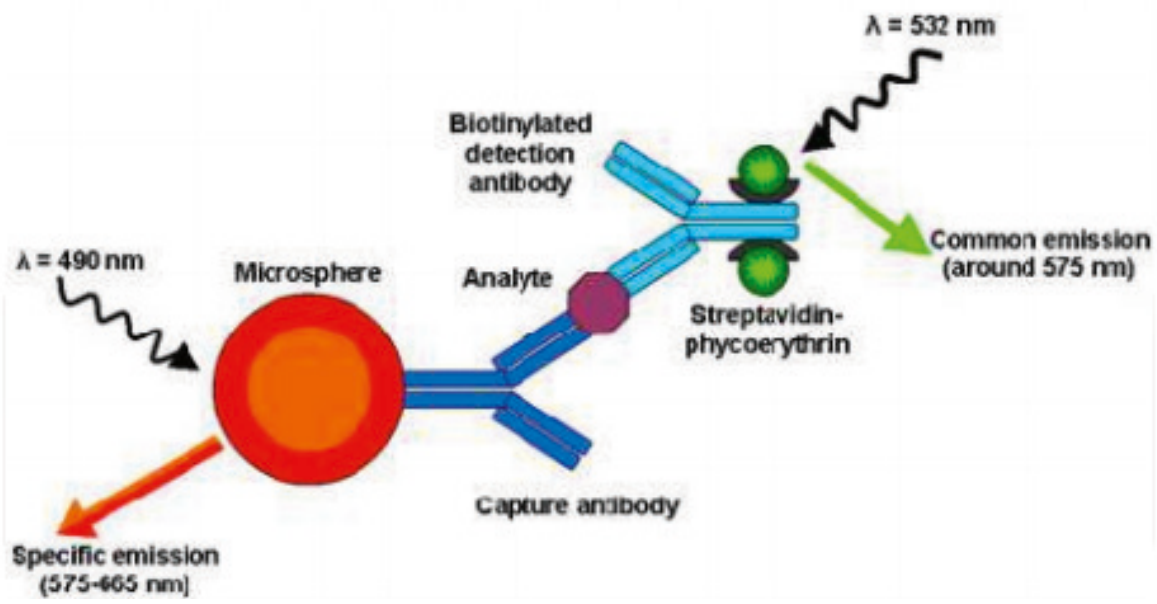

Figure 11 The capture monoclonal antibody is coupled to the bead (microsphere). After binding of the analyte a second biotinylated antibody is added. After addition of a streptavidin-phycoerythrin conjugate, dyes embedded in the beads and phycoerythrin are excited (wavy lines) and both compounds give two types of light emission. Modified with permission from Barrios et al. (163) 
The development of new multiplexed panels fills a great demand for this instrument, which can analyse many different cytokines and chemokines simultaneously, but special attention must be paid when this method reports absolute values. The acceptance of this technique depends on comparable results to those achieved by using classical techniques, accepted as the "gold standard" in the laboratory (165, 166). A limitation in some MBIAs is the interpretation and reporting of analyte values at extremely low concentrations. One of the possible advantages of this assay is that the dynamic range is much broader than classical ELISAs. However, many sensitivity issues in the very low range of concentrations remain unresolved (165, 167), especially for several cytokines. Therefore, the improvement in the detection of determined parameters that are present at low levels in serum is a challenge for the investigators and the MBIA manufacturers. These methods have an excellent accuracy and reliability, together with an excellent sensitivity for most analytes. Another important aspect is the improvement of specificity for some parameters, which is essentially limited by the quality of antibodies employed in the MBIA (164).

\section{Flow cytometry}

Flow cytometry is a technology that is used to analyse the physical and chemical characteristics of particles in a fluid as it passes through at least one laser. Cell components are fluorescently labelled and then excited by the laser to emit light at varying wavelengths. The fluorescence can be measured to determine various properties of the studied particles, which are usually cells. Thousands of particles per second can be measured as they pass through the liquid stream to determine their relative granularity, size and fluorescence intensity as well as their internal complexity. An optical-to-electronic coupling system is used to record the fluorescence emitted by a particle and how it scatters incident light from the laser. Three main systems make up the flow cytometer instrument:

1. The fluidics

2. The optics 


\section{The electronics}

The purpose of the fluidics system is to transport the particles in a stream of fluid to the laser beam where they are interrogated. Any cell or particle that is 0.2 to $150 \mu \mathrm{m}$ in size can be analysed. Cells from solid tissue require disaggregation before analysis. The section of the fluid stream that contains the particles is referred to as the sample core. The optics system is made up of lasers, which illuminate the particles in the stream as they pass through and scatter light from the laser. Any fluorescent molecules that are on the particle emit fluorescence, which is detected by carefully positioned lenses. Generally, the light scattered from up to six or more sources of fluorescences is determined for two different angles. Optical filters and beam splitters then direct the light signals to the detectors, which emit electronic signals proportional to the signals that hit them. Data can be collected on each particle or event and the characteristics of those events or particles are determined based on their fluorescent and light scattering properties. The analysis of the measurements is performed using software in an attached computer. The data generated by flow cytometers can be plotted in a single dimension, to produce a histogram, or in twodimensional dot plots or even in three dimensions. The plots can be divided into regions depending on the intensity of the fluorescence, to create a series of subset extractions called gates. The plots are often made on logarithmic scales. Because different fluorescent dyes' emission spectra overlap, signals received by the detectors have to be compensated electronically as well as computationally. Data accumulated using the flow cytometer can be analysed using software, Once the data is collected, there is no need to stay connected to the flow cytometer and analysis is usually performed on a separate computer (168).

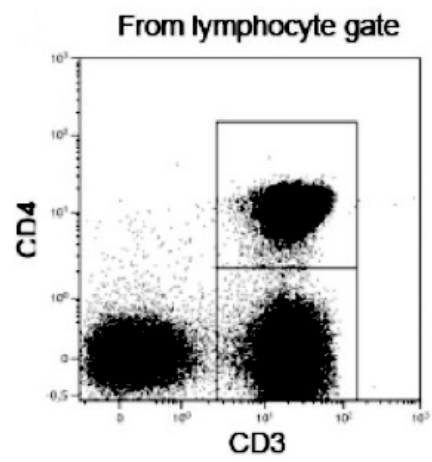

Figure 13. A two dimensional "dot plot" with data from flow cytometry analysed on a computer and presented as frequencies of CD3 and CD4 


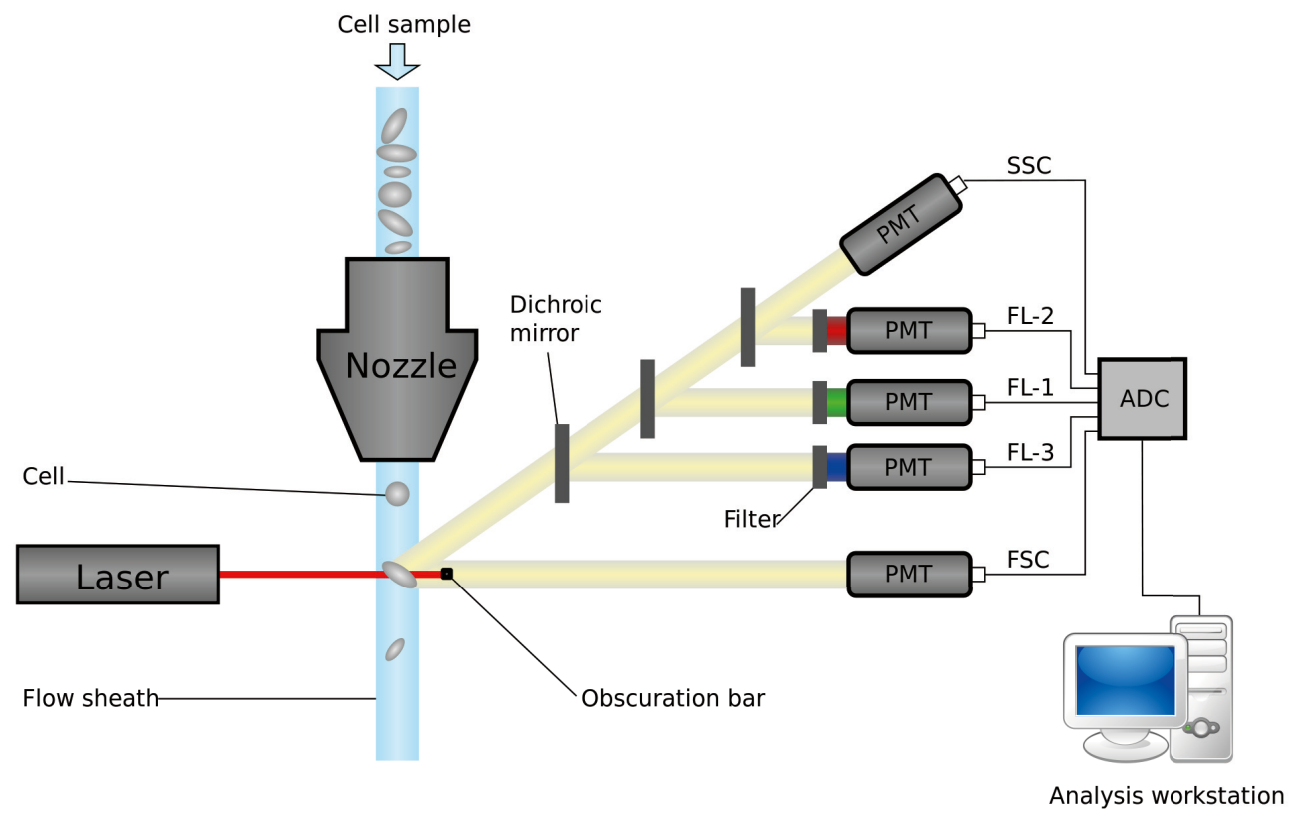

Figure 12 Principles of flow cytometry, published with permission from O'Neill et al. (169)

\section{Flow Cytometry- Strengths and weaknesses}

Flow cytometry is a sensitive and powerful method for simultaneously obtaining information on cellular processes, including expression of surface markers, signaling proteins and intracellular cytokines. These characteristics are measured on each cell individually in a high-throughput fashion and the method is excellent in characterizing heterogeneous cell populations.

There are however some severe limitations and weaknesses in using this scientific technique. Data resulting from flow cytometric analysis is at an aggregate level, and therefore it is not easy to observe and measure individual cell behaviour. Flow cytometry is restricted to cell suspension solutions since it requires the passing of the cells through a fluid stream making information on tissue architecture and cell-cell interactions unavailable.

Cell subpopulations with similar marker expression are difficult to differentiate and analyses that employ more fluorophores are subject to signal spillover. Another 
disadvantage is the low cell throughput rate. A flow cytometer has very sophisticated instrumentation, which is why only skilled and highly trained operators can run it and get any acceptable levels of performance from such apparatus, which is also a disadvantage. Experience is also necessary to be able to define the different described gates even if that can be computerized. Finally flow cytometers are expensive (170).

\section{Immunohistochemistry}

\section{Background}

Immunohistochemistry (IHC) refers to the process of detecting antigens (e.g. proteins) in a tissue section by using the principle of antibodies binding specifically to antigens in biological tissues. It is a method that has been used for more than 70 years, particularly in examination of malignant tumours. Immunohistochemistry is widely used in basic research to understand the distribution and localization of biomarkers in different parts of a biological tissue. Visualising an antibody-antigen interaction can be accomplished in a number of ways (171).

\section{Sample preparation}

Sample preparation is critical to maintain cell morphology, tissue architecture and the antigenicity of target epitopes. Therefore proper tissue sampling, fixation and sectioning is very important. If not examined directly, the sample needs to be embedded in medium, e.g. paraffin. The tissue is then normally sliced by a microtome to a width in the range of $4-40 \mu \mathrm{m}$. The next step is to mount the slices on slides and dehydrate using alcohol washes of increasing concentrations $(50 \%, 75 \%$, $90 \%, 95 \%, 100 \%$ ). Before incubating the samples with antibodies they need to be deparaffinised with Histoclear or another medium containing Xylene, and rehydrated using alcohol in the reverse order. Thereafter, retrieval of antigen with heat is necessary. These steps may make the difference between the target antigens staining or not staining. Dependent on the tissue type and the method of antigen detection, endogenous biotin or enzymes need to be blocked or suppressed, prior to antibody staining. Antibodies might show preferential avidity for non-specific proteins that are 
similar to the binding sites on the target antigen. A great amount of non-specific binding causes high background staining which will mask the detection of the target antigen. To reduce background staining in IHC, samples are incubated with a buffer, e.g. normal goat serum, which blocks the reactive sites to which the primary or secondary antibodies may otherwise bind. Methods to eliminate background staining include dilution of the primary or secondary antibodies, modifying the time or temperature of incubation or using a different primary antibody. Quality control should include a tissue known to express the antigen as a positive control, and negative controls of tissue with the test tissue treated in the same way, with omission of the primary antibody $(171,172)$.

\section{Antibody types}

The antibodies used for specific detection can be polyclonal or monoclonal.

Polyclonal antibodies are made by injecting animals with the actual protein, or a part of it and, after a secondary immune response they are stimulated, isolating antibodies from serum. Polyclonal antibodies are therefore a mix of antibodies that recognize several epitopes while monoclonal antibodies are specific to a single epitope. For detection strategies, antibodies are classified as primary or secondary. Primary antibodies are raised against an antigen of interest and are typically unlabelled, while secondary antibodies are raised against immunoglobulins of the primary antibody species. The secondary antibody is thus usually conjugated to a linker molecule, which either recruits reporter molecules, or is directly bound to the reporter molecule $(171,172)$.

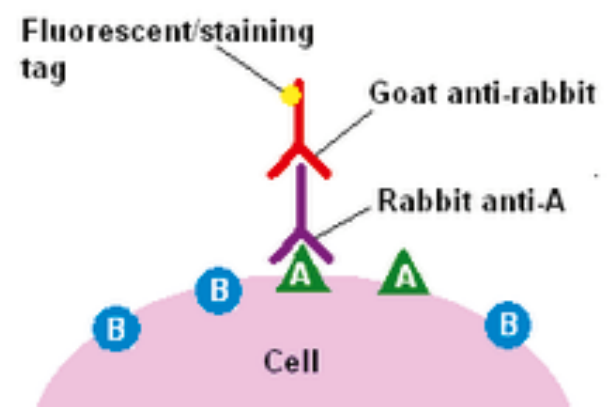

Figure 14 The indirect method of immunohistochemical staining. One primary antibody against the antigen being probed for, and a second labelled, antibody against the primary. 


\section{Reporter molecules}

Reporter molecules vary based on whether the detection method is chromogenic or fluorescence detection, mediated either by an enzyme or a fluorophore. With chromogenic reporters, an enzyme label reacts with a substrate to yield a coloured product that can be analysed with an ordinary light microscope. Different substrates are available for use, e.g. DAB, which produces a brown staining, wherever the enzymes are bound. Reaction with DAB can be enhanced with nickel that gives a deep purple/black staining. For chromogenic and fluorescent detection methods, analysis of the signal, either manually or with the assistance of digitalised analysis, can provide semi- and acceptable quantitative data, to correlate the level of reporter signal to the level of protein expression $(171,172)$.

\section{Antigen detection methods}

The direct method is a one-step staining method and involves a labelled antibody reacting directly with the antigen in tissue samples. This technique, utilizing only one antibody, is simple and rapid. However, the sensitivity is lower, due to little signal amplification, in contrast to the indirect method, which therefore is used more frequently. The indirect method utilizes an unlabelled primary antibody that binds to the target tissue antigen and a labelled secondary that reacts with the primary antibody. The secondary antibody must be raised against the IgG of the animal species in which the primary antibody has been raised. This method is more sensitive due to the binding of several secondary antibodies to each primary antibody, which will amplify the signal. If the secondary antibody is conjugated to biotin molecules, e.g. avidin, it can recruit complexes of avidin-bound enzyme with further amplification as a result. Another advantage of the indirect method besides its greater sensitivity is that only a limited number of standard labelled secondary antibodies need to be produced. For example, a secondary antibody raised against rabbit IgG is useful with any primary antibody raised in rabbit, while with the direct method, it would be necessary to label each primary antibody for every antigen of interest. 


\section{Counterstain}

After staining of the target antigen, a second stain is often of value to provide contrast that helps the primary stain stand out. For example, the hematoxylin stain is used for this purpose since it has specificity for the cell nucleus $(171,172)$.
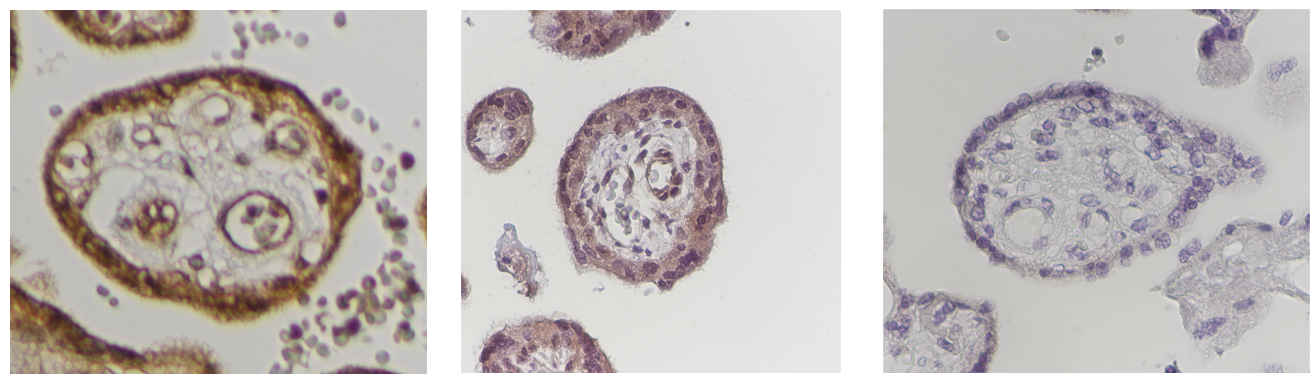

Figure 15. Placental samples showing terminal villi with syncytiotrophoblasts. Brown DAB staining differ due to different expression of the biomarker. First sample shows expression of CCL18 in trophoblasts from a normal pregnancy, while the other two samples show expression of CCL22 I n first and third trimester trophoblasts in normal pregnancy. Cell nucleuses are blue due to staining with hematoxylin

\section{Immunohistochemistry - strengths and weaknesses}

The most important strength of the method is that it can detect the analysed protein directly in the tissue, which can provide much information on both the expression of the measured protein and the functions since expression can vary greatly between different parts of the examined tissue sample, e.g. between the decidua and trophoblasts. The major problems include strong background staining, weak target antigen staining and autofluorescence. Endogenous biotin or reporter enzymes or primary/secondary antibody crossreactivity are examples of strong background staining, while weak staining may be due to poor enzyme activity or insufficient primary antibody potency. Moreover, autofluorescence may be due to the nature of the tissue or the method of fixation. These aspects of the immunohistochemistry method need to be systematically addressed to identify and overcome staining issues. Another weakness is the semi-quantitative nature of the method, even if digitalised analysis is used $(171,172)$. 


\section{Statistical methods}

Details regarding the statistical methods used are provided in each paper.

In paper I we used both a parametric test for normally distributed data and a nonparametric test for non-normally distributed data after performing normality diagnostics. Statistical analyses were performed using Microsoft Excel software version 11.1.1 and Jump version 8.0.2. P values $<0.05$ were considered significant. In paper II we performed our statistical analyses by using SPSS and GraphPad Prism 5.0 Statistical. A Mann-Whitney non-parametric test was used to compare preeclamptic women with healthy controls except for coagulation factors, where we used Student's unpaired t-test, because these factors were normally distributed. Subgroup analyses were performed for EOP and LOP using the same statistical method. A university statistician supported us by performing a multivariate logistic regression test for the impact of gestational and maternal age, cortisone treatment, blood sampling during active labour or the peripartal period for all biomarkers, because all these factors, including timing of blood sampling, could potentially affect the result. A Chi-square test was used to compare occurrence of lupus anticoagulant or mutation for factor V Leiden between the PE group and the control group. Stratified analysis for parity was performed for the women from Jönköping, who represented approximately $2 / 3$ of the included women. We considered adjustment of the significance level based on the numerous comparisons but because we only report differences after multivariate logistic regression test, we perceive that to be statistically sufficient. Using the most significant marker within each group we employed a Spearman's rank correlation test to analyse the correlations between coagulation, inflammation, and angiogenesis. In paper III we also used SPSS and GraphPad Prism 5.0 Statistical for the analyses. As the majority of the data sets followed a Gaussian distribution, data were analysed using an ANOVA followed by a Student's unpaired t-test if the ANOVA indicated $\mathrm{p} \leq 0.05$. For correlation analyses, Pearson's correlation test was used. In paper IV all statistical tests were performed on GraphPad Prism 5.0 Statistical Analysis. Since the data set comprised small groups in IHC and some of the data on plasma did not follow Gaussian distribution, non- 
parametrical tests were consistently used (Kruskal-Wallis and if $\mathrm{p}<0.05$ followed by Mann-Whitney $U$ test). Statistical significance was defined as $p<0.05$. A Chi-Square test was used for comparison of the detection rate in plasma, and Spearman's Correlation test was used for bivariate correlations. 


\section{Results and discussion}

\section{Paper I}

In this study we tested the hypothesis that serum could blueprint the symptoms of preeclampsia. We did this by injecting serum from preeclamptic and normal pregnant women into pregnant wild type and IL- $10^{-/-}$mice, and, as controls, non-pregnant mice. In vivo effects of human preeclampsia serum on foetal weight, blood pressure, proteinuria, renal pathology and production of sFlt-1 and sEng were studied by injecting the mice with serum from women with moderate and severe preeclampsia intraperitoneally on gestational day 10 , while a control group received normal pregnancy serum. The mice were sacrificed after seven days. Similarly non-pregnant female mice were injected for comparative analysis after seven days. The mode of administration intraperitoneally was chosen to minimise stress, since that might otherwise negatively interfere with pregnancy. The time for injection was chosen after an optimising test in the laboratory. Injection earlier resulted in increased pregnancy loss and injection later had less impact on pregnancy.

Serum from women with preeclampsia showed higher average values of sFlt-1 and sEng compared to normal pregnancy serum samples. However, we did not observe a cross-sectional relationship with the incidence of preeclampsia, as several serum samples from this group had comparable values to normal pregnancy samples, suggesting that other factors contribute to induction of this disorder in humans. Injection of severe preeclampsia serum resulted in elevated blood pressure and proteinuria in both IL-10 $0^{-/-}$mice and their wild type counterparts. However, elevated blood pressure and proteinuria were observed only in IL- $10^{-/}$mice in response to mild preeclampsia serum samples, suggesting that IL-10-deficient mice are more susceptible to developing preeclampsia when challenged with serum from preeclamptic patients. Treatment of pregnant IL-10 $10^{-/}$mice with serum from severely preeclamptic women invariably resulted in IUGR, a phenomenon not observed with samples from mild preeclampsia. Foetal weights were not significantly affected in wild type mice by even severe preeclampsia samples. The effects of preeclampsia 
serum cannot be directly attributed to human sFlt-1 and sEng because their absolute values in the $100 \mu \mathrm{l}$ samples were relatively low. Similarly, our observations could not confirm previous studies that found preeclampsia was associated with the presence of angiotensin II type 1 receptor autoantibody (AT1-AA) in serum because co-treatment with AT-receptor antagonist losartan or neutralizing AT1 receptor epitope in IL-10 $0^{-/}$mice did not reverse the abnormalities in foetal weight, blood pressure and proteinuria. Mild preeclampsia resembles late-onset preeclampsia without obvious early pregnancy placental insult, and there might be some serum factors in severe preeclampsia from an insulted placenta that affect even wild type mice, and together with a deficiency of the anti-inflammatory cytokine IL-10 causes IUGR. Alternatively, it may be an effect dependent on serum level. It is also possible that IL- $10^{-/-}$mice already had a minor placental insult that was worsened by the impact of anti-angiogenic factors in preeclamptic serum.

Interestingly, there were no effects of normal pregnancy serum, confirming the hypothesis of preeclampsia serum as a blueprint of the condition. The non-pregnant mice were not affected by either the normal pregnancy or preeclampsia serum injection, suggesting that there must be a placental factor involved in the condition. Our data for the first time provide evidence for the induction of pregnancy-specific preeclampsia-like systemic symptoms, as serum from patients with preeclampsia did not cause any effects in non-pregnant mice irrespective if they were wild type or IL$10^{-/}$. This implies the crucial role of the placenta in regulating the onset of preeclampsia in response to the administration of preeclampsia serum. This further implies that onset of placental pathology is essential for release of soluble antiangiogenic factors or other inflammatory regulators that are likely to cause maternal symptoms of hypertension and proteinuria. Previous studies have shown that the administration of AT1-AAs from human preeclampsia serum samples could promote excess production of sFlt-1 leading to preeclampsia-like symptoms in mice (173, 174). We could not confirm this mechanism in this study since the AT1 receptor antagonist losartan potassium or neutralizing seven-amino acid epitope binding peptide did not relieve serum-induced IUGR, hypertension, and proteinuria in IL-10 
pregnant mice.

Glomerular endotheliosis and impaired renal function are cardinal features of preeclampsia. To assess whether preeclampsia serum samples cause renal pathology, kidney tissue was harvested from the different treatment groups, stained and examined for the presence of endotheliosis, which was observed in both IL- $10^{-/ 2}$ mice and wild type animals in response to preeclampsia serum. Similar changes were observed in the pregnant mice treated with high doses of sFlt-1and/or sEng (data not shown) suggesting that glomerular endotheliosis is a result of anti-angiogenic activity. The assessment of the kidneys was blinded for the examiner. The fact that only serum from the severe patients, but not mild preeclampsia or normal pregnancy, caused renal pathology in both wild type and IL- $10^{-/-}$mice suggests that intrinsic interactions are able to impart graded pathology in response to causative factors. The differential activity of serum samples from mild or severe preeclampsia could, however, not be attributed to the varying concentrations of sFlt-1 and sEng because several preeclampsia serum samples showed values of these factors at same levels as the samples from normal pregnancy. This indicates that more than one serum factor is causative for the manifestations of preeclampsia. Pregnant mice treated with normal pregnancy serum did not show any signs of kidney pathology. Treatment with mild preeclampsia serum did not result in severe kidney pathology (data not shown); a possible explanation for the only moderate proteinuria readings observed. The glomerular endotheliosis noted after administration of severe preeclampsia serum was consistent in all experiments and parallels the observations seen in renal biopsies in human preeclampsia (175).

The excess presence of sFlt-1 in circulation, possibly released by the placenta, has been detected in a significant proportion of patients with preeclampsia. It has been thought to be associated with endothelial dysfunction, hypertension, and proteinuria (176). Moreover, sEng has been shown to act synergistically with sFlt-1 in causing preeclampsia-like features in an experimental model (177). It is possible that injection of preeclampsia serum in wild type or IL-10 $10^{-/}$mice triggers excess production of these anti-angiogenic factors. Thus, we assessed the effect of 
preeclampsia serum on the circulating levels of mouse sFlt-1 and sEng by using a mouse-specific ELISA. Injection of severe preeclampsia serum significantly elevated the levels of mouse sFlt-1 in IL- $10^{-/-}$mice without affecting its production in the wild type counterparts. However, the serum levels of mouse sEng were significantly elevated both in wild type and IL-10 $10^{-/}$mice in response to a single injection of severe preeclampsia serum. In IL- $10^{-/-}$mice, mild preeclampsia serum treatment led to a relatively significant increase in sEng but not sFlt-1. In addition, this treatment did not cause sFlt-1 or sEng production in wild type animals. In this context, sEng has been shown to induce hypertension and proteinuria. However, foetal growth restriction in pregnant rats was observed only when sFlt-1 was co-administered with sEng, suggesting an association between sFlt-1 and placental insult while sEng is more associated with the manifestation of maternal inflammation. Moreover, these observations suggest that combined elevation of both sFlt-1 and sEng in IL-10 deficient mice contributes to severe pathology affecting all maternal symptoms. Preeclampsia is considered to be characterized by placental hypoperfusion due to defective spiral artery remodelling, causing hypoxic/ischemic injury to the placenta and resulting in excess production of soluble factors that contribute to the maternal syndrome (178). We hypothesized that treatment with severe preeclampsia serum could cause hypoxic injury in IL-10 $0^{-/-}$mice and employed a widely used method of hypoxia detection by EF5 (179). Preeclampsia serum was associated with significant hypoxic injury in uteroplacental tissue when compared with normal pregnancy serum treatment, as suggested by intense immuno-fluorescent staining for EF5. Since the response to hypoxia is regulated by hypoxia-inducible factors, we evaluated HIF $1 \alpha$ protein levels by Western blotting in IL-10 ${ }^{-/-}$uteroplacental tissue collected on gd 12 . Treatment with preeclampsia serum significantly induced the protein levels of HIF $1 \alpha$. These results suggest that preeclampsia serum induces significant hypoxia at the maternal-foetal interface in IL- $10^{-/-}$mice, which means that preeclampsia serum not only affects the maternal endothelium but also seems to cause a placental insult. Several studies have shown that hypoxia could be an upstream factor that promotes placental pathology, including apoptosis, increase in oxidative stress, shedding of 
villous microparticles, and elevated production of anti-angiogenic factors such as sFlt-1 and sEng $(180,181)$. Hypoxia-induced HIF $1 \alpha$ accumulation in the placenta is associated with defective trophoblast invasion into spiral arteries, possibly resulting in remodelling defects and further ischemia (182). Moreover, HIF $1 \alpha$ has been shown to be expressed in the placenta from preeclamptic subjects (183). Hypoxia has also been shown to affect cytokine balance by reducing IL-10 production and promoting IL-6 and CXCL8 (however, mice lack CXCL8(184)) in placental explants and trophoblasts $(185,186)$. As evident from our studies, preeclampsia serum was indeed associated with placental hypoxia, as indicated by EF5 incorporation in the decidua basalis and the junctional zone with significant induction of HIF $1 \alpha$ in IL-10 $0^{-/-}$mice. We did not, however, observe a similar effect in the wild type counterparts. Hypoxia has been shown to trigger HIF $1 \alpha$ expression with excess production of sFlt-1 and sEng in trophoblasts from preeclamptic placenta (187). Thus, placental hypoxic injury with preeclampsia serum could be a possible cause for production of sFlt-1 and sEng in IL- $10^{-/-}$mice.

Spiral artery transformation is an essential feature of normal pregnancy that ensures the enhanced flow of nutrients and blood to the foetus. Poor remodelling of spiral arteries is a common histopathological feature of placentation in preeclampsia, IUGR, and preterm birth associated with preeclampsia. We assessed the morphological changes in the uteroplacental sections after staining with H\&E. The histological sections, marked mesometrium, decidua basalis, placenta, and spiral arteries, are shown in Figure 16A (upper panel, $\times 4$ magnification). The average area of spiral arteries in wild type and IL- $10^{-/-}$mice was quantified and is shown in Figure 16B. Treatment with severe preeclampsia serum but not normal pregnancy serum significantly reduced the circumference of the modified spiral arteries and the total number of transformed spiral arteries in the mesometrial region in IL- $10^{-/-}$mice. There was a statistically insignificant effect of different treatments in the wild type animals, as shown in Figure 16B. Morphometric analysis of the spiral arteries at higher magnification $(\times 40)$ using One Spot software (Figure 16A, lower panel) 
clearly showed that treatment of IL- $10^{-/-}$mice with severe preeclampsia serum significantly blocked the transformation of the spiral arteries.
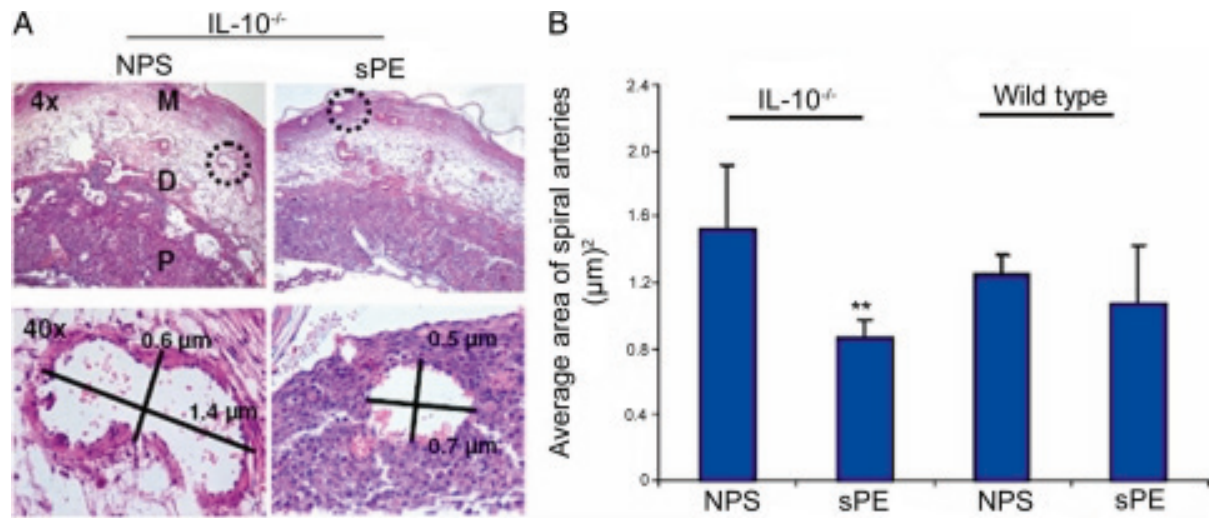

Figure 16. A: H\&E staining of a uteroplacental section from one representative NPS- or sPEtreated pregnant IL-10 $0^{-/-}$mouse is shown (upper panel; original magnification, $\times 4$ ), and the representative morphometry of a spiral artery indicated by a dotted circle is shown at higher magnification $(\times 40$, lower panel). The lengths and widths of spiral arteries expressed in micrometres $(\mu \mathrm{m})$ were measured and stamped by using SPOT Advanced software. Treatment with SPE resulted in poor remodelling of spiral arteries as indicated by their reduced size compared with NPS-treated control animals. B represents the average area of the spiral arteries of at least six spiral arteries per placental unit from three independent animals per treatment group. ${ }^{* *} \mathrm{P}<0.05$ compared with the NPS-treated group. M, mesometrium; D, decidua basalis; P, placenta.

It is possible that in preeclampsia serum-treated mice, dysregulated cross talk between uterine natural killer cells and endothelial cells as a result of hypoxic injury or altered angiogenesis-cytokine machinery, not trophoblast invasion, may be a major regulator of spiral artery remodelling.

Since preeclampsia serum impaired spiral artery remodelling and induced production of anti-angiogenic factors, we hypothesized that these serum samples would disrupt the endovascular interaction between endothelial cells and trophoblasts. We used an in vitro model that we have established (160) to assess serum samples from women with preeclampsia. These samples were collected at 32 to 36 weeks and we then compared them with gestational age-matched serum from normal pregnancies for their effect on endovascular interaction between endothelial cells and trophoblasts on matrigel. Normal pregnancy serum supported the endothelial cell-guided tube formation by first trimester trophoblast HTR8 cells (Figure 17A). In contrast, serum 
from severe or mild preeclampsia disrupted the endovascular cross talk between endothelial cells and trophoblasts (Figure 17B). Interestingly, the endovascular disrupting activity was independent of the serum levels of human sFlt-1 and sEng.

Normal pregnancy serum spiked with amounts of recombinant sFlt-1 or sEng equal to that found in preeclampsia serum samples did not perturb tube formation. However, it should be pointed out that endogenous sFlt-1 or sEng could differ from their recombinant counterparts in functional potency. We also ruled out the disruption of endovascular interaction by apoptotic cell death induced by serum. We analysed the cytotoxic potential of the serum samples on endothelial cells and first trimester HTR8 trophoblast cells by FACS analysis. As shown in (Figure 17C), the preeclampsia serum did not induce significant cell death as compared with normal pregnancy serum in either of the cell types.

Table IV. Results of injecting mice intraperitoneally with serum from pregnant women. $\mathrm{PE}=$ preeclampsia. $\mathrm{NP}=$ normal pregnancy. $\mathrm{BP}=\mathrm{Blood}$ Pressure. $\mathrm{IUGR}=$ IntraUterine Growth retardation. sFlt-1= soluble Fms-like tyrosine kinase-1. sEng=soluble Endoglin. EF-5= a hypoxiaassociated derivative of etanidazole. HIF $1-\alpha=$ Hypoxia Induced Factor alfa. $\theta=$ diameter

\begin{tabular}{|c|c|c|c|c|c|c|c|c|c|c|}
\hline $\begin{array}{l}\text { Serum } \\
\text { from } \\
\text { women } \\
\text { with } \\
\end{array}$ & $\begin{array}{l}\text { Mouse } \\
\text { type }\end{array}$ & BP & $\begin{array}{l}\text { Protein } \\
\text {-uria }\end{array}$ & \begin{tabular}{|l|} 
IUG \\
R
\end{tabular} & \begin{tabular}{|l|}
$\begin{array}{l}\text { Endo- } \\
\text { theliosis }\end{array}$ \\
\end{tabular} & sFIt-1 & sEng & EF-5 & HIF1- $\alpha$ & $\begin{array}{l}\text { Spiral } \\
\text { artery } \\
\varnothing\end{array}$ \\
\hline Severe PE & IL10 $0^{-/-}$ & + & Yes & Yes & Yes & + & + & + & + & - \\
\hline Severe PE & wild type & + & Yes & No & Yes & $\mathrm{n}$ & + & $\mathrm{n}$ & $\mathrm{n}$ & $\mathrm{n}$ \\
\hline Severe PE & non-pregn. & $\mathrm{n}$ & No & No & No & $\mathrm{n}$ & $\mathrm{n}$ & $\mathrm{n}$ & $\mathrm{n}$ & $\mathrm{n}$ \\
\hline Mild PE & IL10 $0^{-/-}$ & + & Yes & No & No & $\mathrm{n}$ & + & $\mathrm{n}$ & $\mathrm{n}$ & $\mathrm{n}$ \\
\hline Mild PE & wild type & $\mathrm{n}$ & No & No & No & $\mathrm{n}$ & $\mathrm{n}$ & $\mathrm{n}$ & $\mathrm{n}$ & $\mathrm{n}$ \\
\hline Mild PE & non-pregn. & $\mathrm{n}$ & No & No & No & $\mathrm{n}$ & $\mathrm{n}$ & $\mathrm{n}$ & $\mathrm{n}$ & $\mathrm{n}$ \\
\hline NP & IL10 $0^{-/-}$ & $\mathrm{n}$ & No & No & No & $\mathrm{n}$ & $\mathrm{n}$ & $\mathrm{n}$ & $\mathrm{n}$ & $\mathrm{n}$ \\
\hline $\mathrm{NP}$ & wild type & $\mathrm{n}$ & No & No & No & $\mathrm{n}$ & $\mathrm{n}$ & $\mathrm{n}$ & $\mathrm{n}$ & $\mathrm{n}$ \\
\hline $\mathrm{NP}$ & non-pregn. & $\mathrm{n}$ & No & No & No & $\mathrm{n}$ & $\mathrm{n}$ & $\mathrm{n}$ & $\mathrm{n}$ & $\mathrm{n}$ \\
\hline
\end{tabular}

Thus, in the context of human pregnancy, we have been able to demonstrate an in vitro model of impaired cross talk between trophoblasts and endothelial cells caused by preeclampsia serum. In this model, extravillous trophoblasts from the first trimester uniquely fingerprint the endothelial cell-guided tube formation in the pregnancy milieu provided by normal pregnancy serum. Under identical conditions, preeclampsia serum from both mild and severe conditions consistently disrupted this endovascular cross talk. The disruption of tube formation by preeclampsia serum was 
graded according to the severity of the disease and was, at least partly, independent of the serum levels of sFlt-1, sEng, vascular endothelial growth factor, or PlGF (data not shown). Importantly, using this bioassay with samples from a longitudinal study, we demonstrated the disruption of endovascular trophoblast interaction by serum samples from patients with preeclampsia collected as early as 12 to 14 weeks of pregnancy. This observation is significant in view of the fact that the disease clinically manifests as symptoms that typically occur only in the third trimester of pregnancy. Moreover, the heterogeneous nature of the disease has hampered the search for discovery of "biomarkers" applicable to the majority of the patient population. In this regard, our in vitro predictive assay using serum from pregnant women is likely to provide a robust approach to study disease-related changes and to blueprint placental pathology. Longitudinal studies and a larger collection of patient serum samples that validate the bioassay may have the potential to identify a functional biomarker.

Collectively, our data support the "blueprint" concept of preeclampsia serum as demonstrated here in a novel semi-humanized mouse model of preeclampsia and in an in vitro bioassay for predicting the onset of preeclampsia. Since a multifactorial aetiology has been widely discussed for preeclampsia, we propose that the pregnancy-specific IL- $10^{-/-}$mouse model that closely mirrors the human condition is now suitable for studying the myriad of molecular events, and for testing novel therapeutic interventions. This model could be further improved by using the telemetry approach in place of the tail cuff blood pressure measuring device and by better characterizing the renal histology using electron microscopy. Our results also suggest that a possible role of IL-10 should be investigated in preeclampsia in humans 

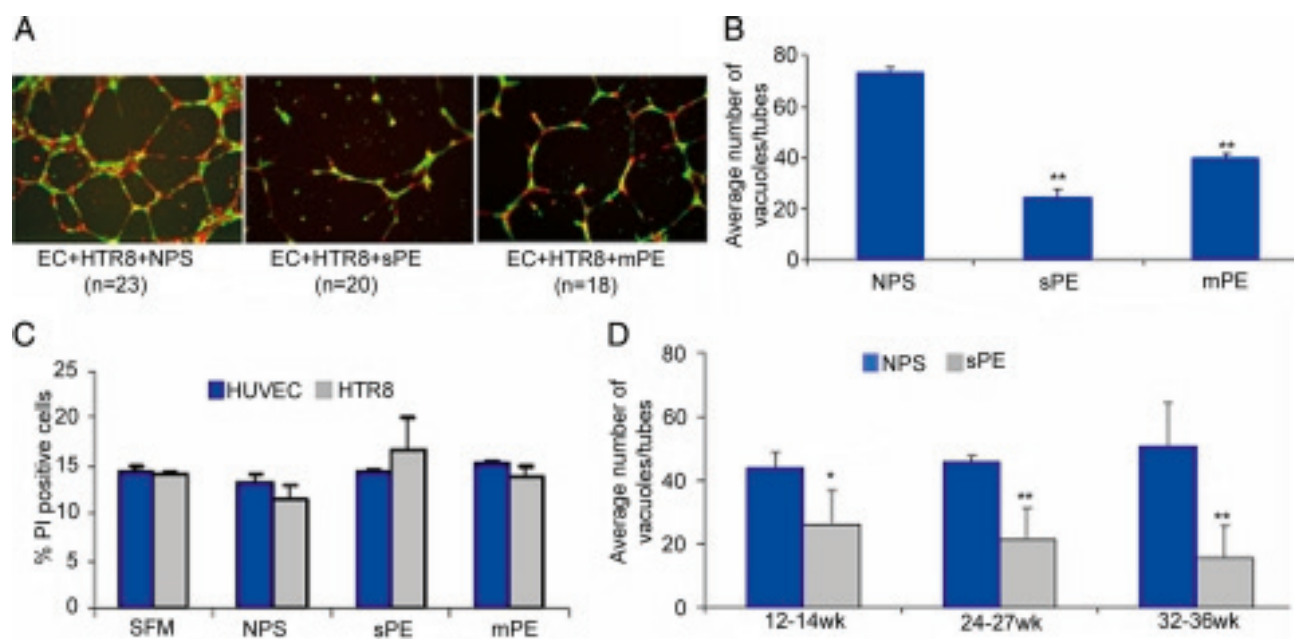

Figure 17A: Representative figures of EC-directed (EC; labeled red) tube formation by HTR8 cells (HTR8; labeled green) are shown. NPS significantly supported tube formation, whereas sPE and $\mathrm{mPE}$ serum disrupted this interaction, albeit in a mild or severe pathology-dependent manner. B shows the quantification of dual cell endovascular tube formation in response to different serum samples. C: Cytotoxic potential of NPS and SPE on EC and HTR8 by propidium iodide (PI) staining analyzed by FACS as \% PI positive cells. Treatment with sPE or NPS did not induce cytotoxicity in either EC or HTR8. D: Longitudinal studies involving pregnancy serum samples from women who were later diagnosed with preeclampsia from weeks 12 to $14(\mathrm{n}=18), 24$ to 27 $(n=5)$, or 32 to $36(n=22)$ weeks of gestation were tested for supporting tube formation. Data represented as a comparative analysis between these samples and those from gestational agematched normal pregnancies. The average number of tubes/vacuoles formed was quantified and plotted. As seen in D, unlike NPS, the tube disrupting activity in preeclampsia serum could be traced back to 12 to 14 weeks of pregnancy. All values expressed as the mean $\pm \mathrm{SD}$. ${ }^{*} \mathrm{P}<0.01$ or $* * \mathrm{P}<0.05$ compared with the respective control NPS-treated group.

\section{Paper II}

Although preeclampsia pathology has been associated with inflammation and coagulation as well as angiogenesis, their relative contributions are unknown. It is also not clear if these mechanisms are all parts of a systemic inflammatory response or if they represent independent pathogenic mechanisms. We therefore measured 32 biomarkers involved in these systems in a large sample of women with preeclampsia and normal pregnancy. We were able to demonstrate that markers for increased inflammation, activated coagulation, and aberrant angiogenesis were all associated with preeclampsia. Notably, these factors were not intercorrelated in preeclampsia, suggesting that they reflect different parts or phases of the pathogenesis. By 
simultaneously comparing several systems, we were able to show that preeclampsia was particularly associated with pro- and anti-angiogenic factors and a Th1associated chemokine and complement activation profile, whereas cytokines showed weaker associations.

\section{Coagulation parameters}

Coagulation is activated in preeclampsia but it has not been clarified if that is only a result of a systemic inflammatory response in preeclampsia or if activated coagulation can contribute to the pathogenesis of the syndrome. We were able to show that the antithrombin (AT) levels $(\mathrm{p}=0.002)$ were lower in the preeclampsia group than in healthy controls (Table V), confirmed by multivariate logistic regression. We also performed a stratified analysis for parity, showing reduced levels of the coagulation factor AT for preeclamptic compared to normal pregnant women in both nulliparous and multiparous women ( $p<0.001$ for both groups). The difference in AT levels was also more pronounced in the EOP than in the LOP group $(\mathrm{p}=0.006)$. Our expected high correlation between AT as a marker for activated coagulation and inflammation markers such as pentraxin-3 and Th1-related CXCL10 was not corroborated. Therefore, the activated coagulation found in preeclampsia may be at least in part an independent pathogenic mechanism and not only a mirror of the systemic inflammation, at least at the time point investigated in this study.

Table V. Coagulation factors in preeclampsia and normal pregnancy

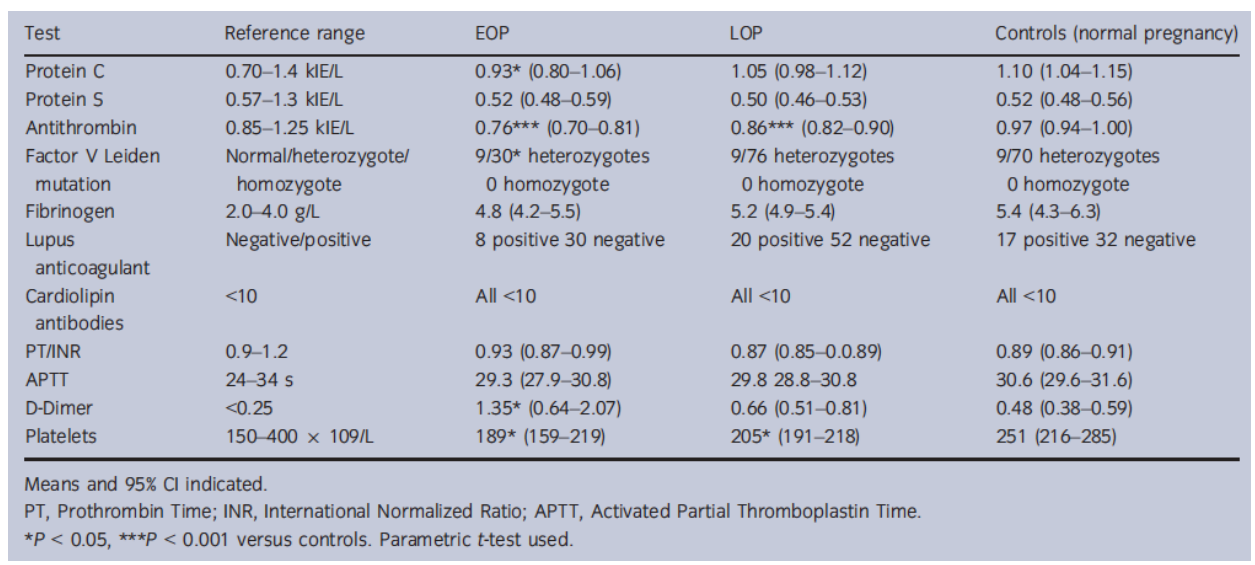


Interestingly, mutation for factor $\mathrm{V}$ Leiden was more frequent in EOP compared to the controls (chi2-test, $\mathrm{p}=0.045$ ) but no difference was found between the entire preeclampsia group and the controls. This is in line with previous studies that have not found an increased risk for preeclampsia for women with factor V Leiden, where there was no subgroup analysis of EOP and LOP. Since the mutation exists before the pregnancy starts it cannot be an effect of preeclampsia. Hence, it seems that activated coagulation is a part of the pathophysiology involved in the development of clinically manifest preeclampsia, at least for EOP, and that inherited thrombophilia might be a risk factor for pathological placentation and thus for early-onset preeclampsia. We did not find any differences in levels of either cardiolipin antibodies (no cardiolipin antibodies found in any of the groups) or lupus anticoagulant between the groups. The concentrations of protein S and fibrinogen as well as INR values were similar in the preeclampsia and control group. Significantly increased D-Dimer levels $(p=0.001)$ and decreased numbers of platelets $(p=0.026)$ and reduced concentration of

protein $\mathrm{C}(\mathrm{p}=0.045)$ in women with preeclampsia compared to healthy controls could not be confirmed with a multivariate logistic regression test.

For the complete results of measurement of coagulation factors see table V.

\section{Complement components and activation products}

The C3a levels $(\mathrm{p}<0.001)$ were elevated in the preeclampsia group as compared with the control group, confirmed with a multivariate logistic regression test $(p=0.020)$, which also showed a more pronounced elevation in EOP $(p=0.003)$ than in LOP (Figure 18), which is in line with complement component involvement in placental insufficiency typical for EOP. Preeclampsia was also associated with increased sC5b-9 levels ( $p=0.026)$, which were more pronounced for EOP $(p=0.036)$, although these differences did not remain after multivariate logistic regression. No differences were found for $\mathrm{C} 3$ and factor $\mathrm{H}$. Data on measurements of complement components and activation products are found in Figure 18 and Table VI. 


\section{C3a}

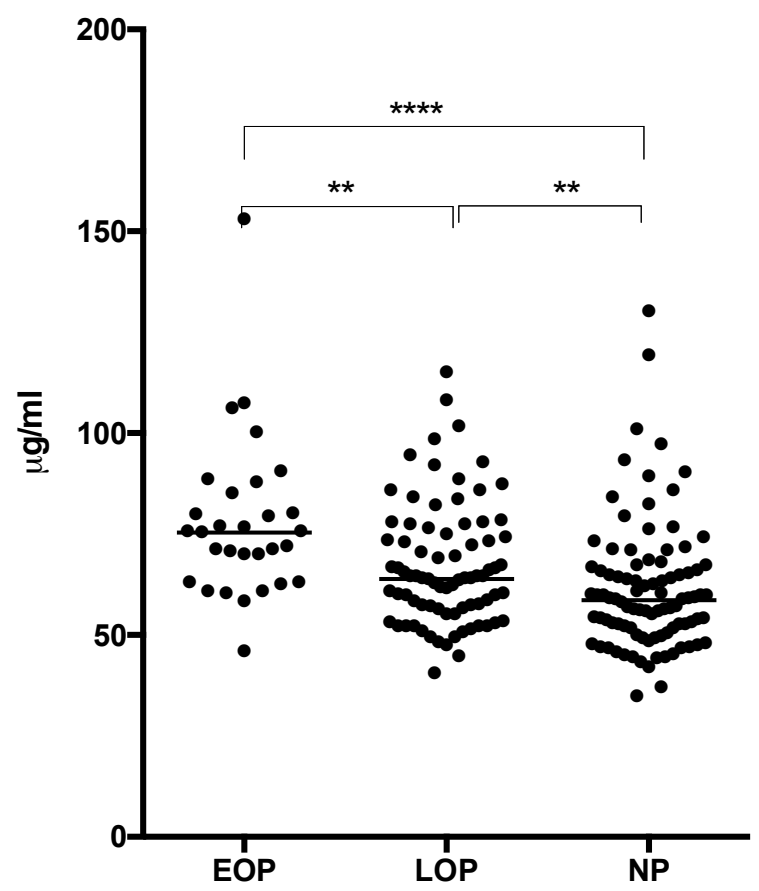

Figure 18 Plasma levels of C3a in women with early onset (EOP) and late onset preeclampsia (LOP) as well as in normal pregnancies (NP). Medians and interquartile ranges are indicated. ${ }^{*} \mathrm{p}<$ $0.05, * * \mathrm{p}<0.01, * * * \mathrm{p}<0.001$.

The increased concentration of $\mathrm{C} 3 \mathrm{a}$ and $\mathrm{sC} 5 \mathrm{~b}-9$ in preeclamptic compared to healthy women demonstrates that also the complement system is involved in the inflammatory reaction in preeclampsia. Because the first step in the generation of sC5b-9 is the cleavage of $\mathrm{C} 5$ to $\mathrm{C} 5 \mathrm{a}$ and $\mathrm{C} 5 \mathrm{~b}$, this observation is in agreement with others who have suggested that C5a-dependent mechanisms might be of interest in placental pathology in preeclampsia $(188,189)$. In the stratified analysis for parity, the activation of the complement system could not be demonstrated for multiparous women. For nulliparous women, however, the levels of C3a $(p=0.001)$ and TCC (p $=0.034)$ were elevated as well as the $\mathrm{C} 3 \mathrm{a} / \mathrm{C} 3$ ratio $(\mathrm{p}=0.02)$ in the preeclampsia group with a tendency for elevated levels of factor $\mathrm{H}(\mathrm{p}=0.059)$.

In agreement with the cytokine, chemokine, and pentraxin-3 data, this might indicate a less intense inflammatory response in multiparous compared to nulliparous women, possibly related to the immune regulatory effects of previous pregnancies. $\mathrm{C} 3 \mathrm{a}(\mathrm{p}=$ 
$0.001)$ and TCC $(p=0.034)$ were elevated as well as the $\mathrm{C} 3 \mathrm{a} / \mathrm{C} 3$ ratio $(\mathrm{p}=0.020)$ in the preeclampsia group with a tendency to elevated levels of factor $\mathrm{H}(\mathrm{p}=0.059)$. In agreement with the cytokine, chemokine, and pentraxin-3 data, this might indicate a less intense inflammatory response in multiparous compared to nulliparous women, possibly related to immune regulatory effects of previous pregnancies.

Table VI Complement components and activation products, inflammation marker and anti- and pro-angiogenic factors in early- and late-onset preeclampsia and normal pregnancy.

\begin{tabular}{|c|c|c|c|}
\hline & $\mathrm{EOP}(n=30)$ & $\operatorname{LOP}(n=78-80)$ & Controls $(n=94-97)$ \\
\hline C3 mg/L & $1326(1118-1691)$ & $1245(1110-1480)$ & $1265(1058-1460)$ \\
\hline $\mathrm{C} 3 \mathrm{a} \mu \mathrm{g} / \mathrm{L}$ & $75^{\star \star \star}(63-86)$ & $64^{\star \star}(56-76)$ & $59(51-67)$ \\
\hline Factor $\mathrm{H} \mathrm{mg/L}$ & $606(528-703)$ & $597(526-683)$ & $593(554-659)$ \\
\hline C5b-9 AU/ML & $36^{\star}(26-54)$ & $28(22-38)$ & $2519-43$ \\
\hline Pentraxin-3 pg/mL & $9122^{\star \star \star}(4221-13519)$ & $5938^{\star \star \star}(3222-9557)$ & $3249(2208-6120)$ \\
\hline sFlt-1 pg/mL & $10470^{\star \star \star}(5682-18789)$ & $5760 * \star *(2851-9936)$ & 839 (368-1543) \\
\hline Placental Growth Factor pg/mL & $3.9^{\star \star \star}(3.9-14)$ & $13^{\star \star \star}(3.9-31)$ & $59(26-149)$ \\
\hline \multicolumn{4}{|c|}{ 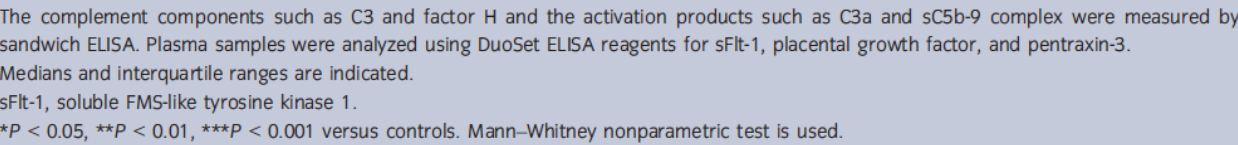 } \\
\hline
\end{tabular}

\section{Inflammation markers}

\section{Cytokines and chemokines}

The IL-4 levels were lower in preeclamptic than in healthy women $(p=0.020)$, with a significant difference for the EOP $(p=0.003)$ but not the LOP group as compared to the control group. Levels of GM-CSF were also lower in the EOP group while all other cytokine levels showed no difference when comparing preeclampsia and control women (Table VII). A multivariate logistic regression test confirmed a tendency for lower levels of IL-4 in the preeclampsia group $(p=0.058)$, but this was not the case for GM-CSF.

The levels of the Th1-associated chemokine CXCL10 $(\mathrm{p}<0.001)$ were increased in the preeclampsia group compared to the controls, and EOP was associated with elevated levels of the Th1-associated chemokine CXCL11, both confirmed with multivariate logistic regression tests (for CXCL10 $p=0.001$ and for CXCL11 $p=$ 0.038, Figure 19). Although the levels of the Th2-associated chemokine CCL17 were increased in the EOP group, this was not confirmed with the multivariate logistic regression test. CCL22 (also Th2-associated) levels were similar in women with and 
without preeclampsia (see Table VII). Several studies have demonstrated a shift from Th2 to Th1 in preeclampsia with an increase in pro-inflammatory and a decrease in anti-inflammatory cytokines $(84,190-192)$. We failed to demonstrate this suggested shift by mere cytokine analysis, although levels of the Th2 cytokine IL-4 were decreased in preeclamptic women. However, in chemokine analysis a shift was obvious towards a predominant inflammatory activity, with elevated levels of two Th1-associated chemokines and no clear increase in two Th2-associated chemokines in the preeclampsia group. Circulating Th1- and Th2-associated chemokine levels can be used as markers for the Th1/Th2 balance $(193,194)$. Thus, Th1 responses increase the levels of the CXCR3 ligands CXCL10 and CXCL11, while Th2 responses enhance the levels of the CCR4 ligands CCL17 and CCL22 (56). CXCR3 is preferentially expressed on Th1 cells and CCR4 on Th2 cells, thus further amplifying Th1 and Th2 immunity, respectively (195). Several previous studies have shown a Th1-like pattern of cytokines in preeclampsia. However, some of them have been rather small and in general they were not controlled for gestational age and cortisone treatment, commonly used in $\operatorname{EOP}(84,192,196)$. As other studies have failed to show differences in levels of cytokines between normotensive and preeclamptic pregnancies $(197,198)$, the previous results are inconsistent. There might also be a publishing bias for studies showing this Th1/Th2-cytokine shift.

Cytokines could also be difficult to measure in the circulation because their function is mainly in paracrine interactions between cells in different tissues, whereas chemokines also mediate effects over longer distances. Thus, chemokines might be more suitable markers for immunological changes during pregnancy and for preeclampsia because of their stability and presence in higher levels in the circulation, whereas circulating levels of cytokines seem less useful for monitoring preeclampsia. 


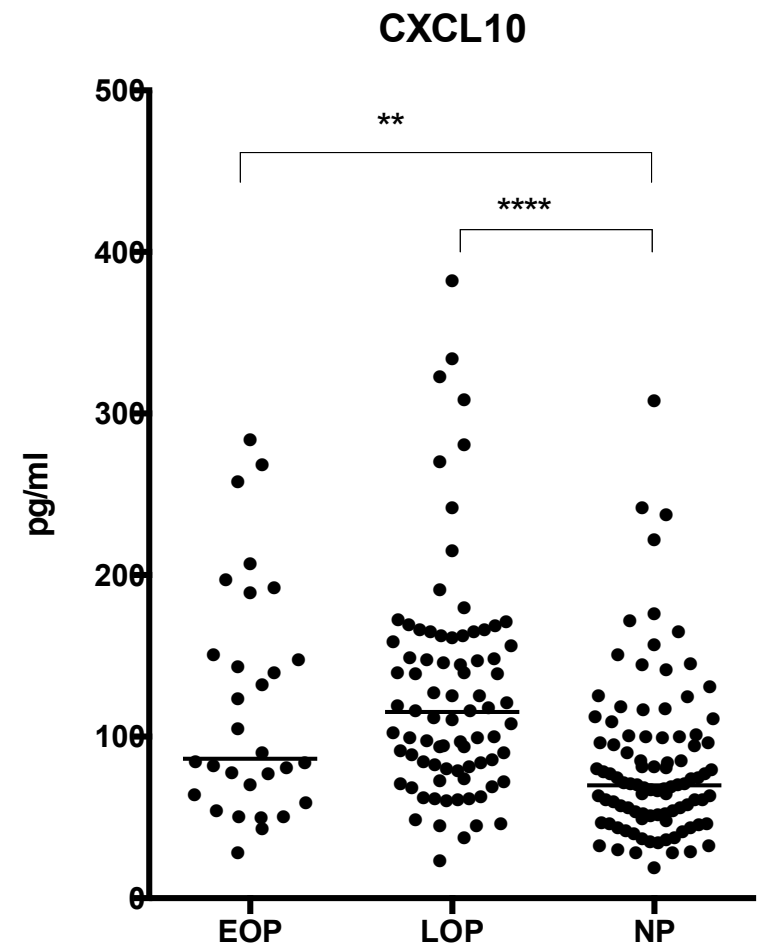

Figure 19. The plasma levels of CXCL10 in women with early onset (EOP) and late onset preeclampsia (LOP) as well as normal pregnancies (NP). Medians are indicated. $* \mathrm{P}<0.05, * * \mathrm{P}<$ $0.01, * * * \mathrm{P}<0.001$. Mann-Whitney nonparametric test is used.

However, this has to be proved by multiple evaluations throughout pregnancy. Furthermore, local cytokine levels at the maternal-foetal interface are probably strongly associated with preeclampsia, although not reflected in the circulation, while circulating levels of third trimester chemokines might mirror systemic inflammatory response in maternal endothelium. Stratifying for parity showed, for chemokines, that the CCXL10 levels were more dramatically elevated in nulliparous $(p<0.001)$ than in multiparous women $(\mathrm{p}=0.048)$ for preeclampsia compared with the controls.

However, the levels of cytokines showed no differences between the preeclampsia and control group for multiparous women, while for nulliparous women, IL-4 levels $(p=0.005)$ were lower in the preeclampsia group. Again, this difference between nulli- and multiparous women indicated protection against intense inflammatory response by previous pregnancies. 
Table VII Cytokines and chemokines in preeclamptic and normal pregnant women

\begin{tabular}{|c|c|c|c|}
\hline & $\operatorname{EOP}(\mathrm{pg} / \mathrm{mL})(n=29-30)$ & $\operatorname{LOP}(\mathrm{pg} / \mathrm{mL})(n=80-81)$ & Controls (pg/mL) $(n=96-97)$ \\
\hline M-CSF $n=80-81)$ & $49(49-49)$ & $49(49-49)$ & $49(49-49)$ \\
\hline GM-CSF & $20 *(13.2-35.1)$ & $34(15-61)$ & $32(20-49)$ \\
\hline IFN- $\gamma$ & $39(22-57)$ & $42(27-68)$ & $44(30-76)$ \\
\hline IL-1 $\beta$ & $0.9(0.4-1.7)$ & $1.0(0.5-1.6)$ & $1.0(0.5-1.5)$ \\
\hline IL-2 & $60(44-99)$ & $74(45-122)$ & $69.5(44-113)$ \\
\hline IL-4 & $29 \star \star(18-57)$ & $47(24-75)$ & $46(31-83)$ \\
\hline IL-5 & $6.1(4.0-10.4)$ & $8.0(5.0-13)$ & $7.8(5.5-13)$ \\
\hline IL-6 & $9.7(5.3-17)$ & $11(6.3-20)$ & $11(7.2-20)$ \\
\hline IL-8 & $2213-31$ & $24(17-35)$ & $26(18-36)$ \\
\hline IL-10 & $9.2(5.1-13)$ & $13(5.9-18)$ & $11(7.0-17)$ \\
\hline TNF & $26(14-36)$ & $29(20-48)$ & $31(20-52)$ \\
\hline CXCL11 & $120 *(81-182)$ & $93(62-125)$ & $89(65-125)$ \\
\hline CXCL10 & $86^{\star \star \star}(62-160)$ & $115^{\star \star \star}(80-161)$ & $70(51-99)$ \\
\hline CCL17 & $12.0 * \star(8.7-22)$ & $8.7(6.3-13)$ & $8.3(5.4-13)$ \\
\hline CCL22 & $106.6(72-142)$ & $97.5(67-130)$ & $93.4(68-117)$ \\
\hline \multicolumn{4}{|c|}{  } \\
\hline
\end{tabular}

\section{Pentraxin-3}

The pentraxin-3 levels were increased in the PE group compared to the controls $(\mathrm{p}<$ $0.001)$, and the levels tended to be higher in the EOP than the LOP group $(\mathrm{p}=0.061)$, see Figure 16 and Table VI. A multivariate logistic regression test confirmed these associations by analysis of quartiles $(p=0.001)$. Stratifying for parity showed, surprisingly, that pentraxin-3 levels were higher in the preeclampsia group compared to the controls among multiparous $(p=0.004)$ but not nulliparous women $(p=$ 0.096), which might indicate that levels of pentraxin-3 are not only indicators of the intensity of the inflammatory response but might also reflect the status of the maternal endothelium that might be more affected after repeated pregnancies. The increased levels of Pentraxin-3 underscore clearly the inflammatory status that is typical for preeclampsia, and which is more pronounced in early-onset preeclampsia, suggesting that placental inflammatory factors are released into circulation much earlier in early-onset due to a placental insult. 




Figure 20 The plasma levels of Pentraxin-3 (b), in women with early onset (EOP) and late onset preeclampsia (LOP) as well as normal pregnancy (NP). Medians and interquartile ranges are indicated.

$* \mathrm{P}<0.05,{ }^{* *} \mathrm{P}<0.01,{ }^{* * *} \mathrm{P}<0.001$. Mann-Whitney nonparametric test is used.

\section{Angiogenesis factors}

In accordance with several previous studies, we found a highly significant increase in the anti-angiogenic factor sFlt-1 $(\mathrm{p}<0.001)$ and a decrease in the pro-angiogenic factor PlGF $(\mathrm{p}<0.001)$ in women with preeclampsia compared to normal pregnant women, both for nulliparous and for multiparous women (199-201). The differences were more pronounced in the EOP compared with the LOP group, both for sFlt-1 ( $p$ $=0.003)$ and for PlGF $(p=0.012)$, see Fig. 16 and Table VI. This was confirmed with a multivariate logistic regression test $(\mathrm{p}<0.001$ for sFlt- 1 and $\mathrm{p}<0.001$ for PlGF) and stratified analysis did not show any difference between nulli- and multipara.

Even if there is a highly significant difference between preeclamptic and normal pregnancies for both pro- and anti-angiogenic factors, it is not clear if this mirrors stressed trophoblasts or a systemic inflammatory response in the maternal 
endothelium or both. The decreased level of PlGF also occurs in women with IntraUterin Growth Restriction (IUGR) without preeclampsia, indicating that low levels of PlGF mirror placental insult and stressed trophoblasts.

However, no obvious correlation was found between these factors and markers for coagulation and inflammation, suggesting that these pathogenic mechanisms are in part independent or separated in time. Correlation tests were performed to compare selected markers for coagulation, inflammation, and angiogenesis. AT, C3a, IL-4, CXCL10, pentraxin-3, sFlt-1, and PlGF were used. We chose the marker in each group (coagulation factors, complement, cytokines, chemokines, inflammation, and angiogenesis markers), which both showed the most significant association and also remained after multiple logistic regression. The correlation coefficients (rho) between these markers ranged from -0.18 to 0.27 in the preeclampsia group. The strengths of the correlations were even smaller when subgroup analysis for EOP and LOP was performed.

\section{PIGF}

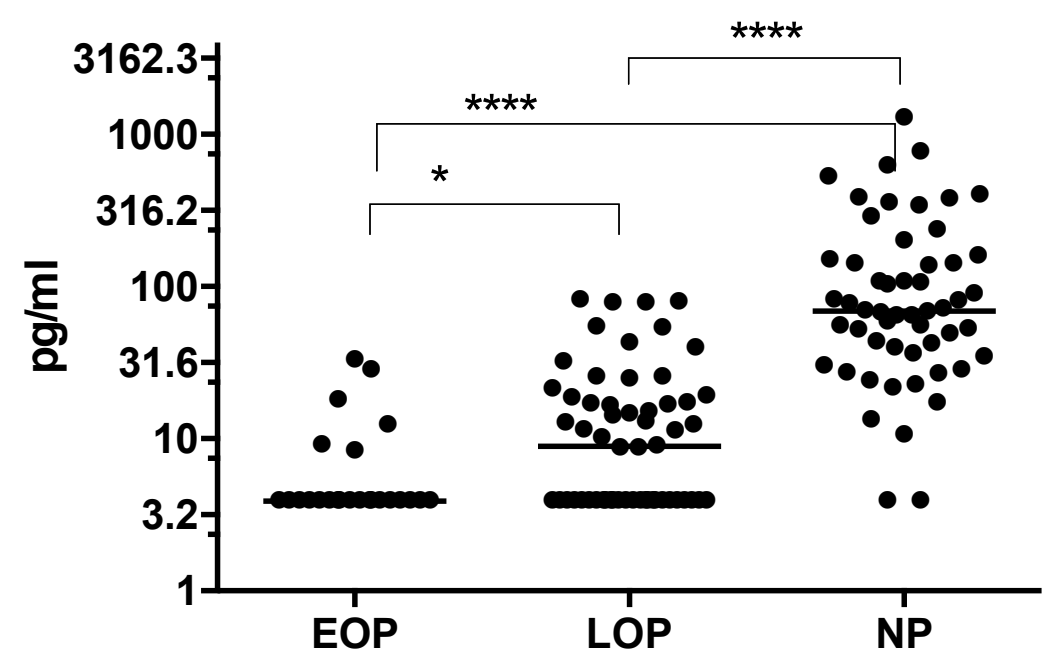

Figure 21 The plasma PIGF levels in early onset (EOP) and late onset preeclampsia (LOP) as well as in normal pregnancies (NP). Medians are indicated. $0.05, * * \mathrm{P}<0.01, * * * \mathrm{P}<0.001$. Mann-Whitney nonparametric test is used PlGF, placental growth factor. 


\section{Concommitant placental insufficiency}

A subgroup analysis was also performed to separately analyse women who gave birth to Small for Gestational Age (SGA) and Appropriate for Gestational Age (AGA) babies. Levels of s-Flt were increased $(p=0.006)$ and for PlGF decreased $(p=0.013)$ in the case of SGA, but for cytokines, chemokines, pentraxin-3, complement components and activation products, there were no differences between the two groups. Thus, pro- and anti-angiogenic factors seem to be good indicators of placental pathology, while other biomarkers might also indicate maternal endothelial pathology. Both women giving birth to AGA and SGA babies were included in the preeclampsia group.

\section{Conclusions}

EOP was associated with more pronounced differences in the levels of almost all of these markers of increased inflammation, activated coagulation and aberrant angiogenesis as compared with LOP. Thus, EOP might be a more homogenous condition based on placental pathology.

The strengths of the study are the large sample and the fact that a substantial proportion of the preeclamptic women in a specific region were involved in the study. The described mechanisms have each been studied separately by others, but never simultaneously in the same sample, thus giving us the possibility to analyse the relative contributions and correlations between these mechanisms. In contrast to previous studies, the results of the analyses were controlled by multivariate logistic regression for maternal and gestational age, peripartal blood sampling, and steroid treatment, which all might influence the result. As the pathogenesis for EOP and LOP might differ, subgroup analyses of these conditions are valuable.

The limitations of this study include the fact that samples were drawn from a quite homogenous population with an internationally low prevalence of preeclampsia. The prevalence of both preeclampsia and congenital thrombophilia differ between different regions for hereditary or other reasons. Also, the correlations between the described mechanisms may be temporally displaced. Thus, correlations might not be 
apparent from measurement of these biomarkers at a particular moment. Also, the cross-sectional design does not allow conclusions regarding causal relationships. In conclusion, markers for hypercoagulation, increased inflammation, and aberrant angiogenesis were independently associated with preeclampsia. Cytokines, chemokines, and complement factors seem to be part of a Th1-associated inflammatory reaction in preeclampsia. Most of the differences were more pronounced for EOP than for LOP, suggesting a more homogeneous pathogenesis in EOP. Chemokines, in contrast to cytokines, may prove to be useful markers in preeclampsia, in addition to established markers.

\section{Paper III}

In this study, we used different up-to-date phenotyping strategies to assess Treg frequencies in early-onset and severe preeclampsia. Most previous studies on Treg cells in preeclampsia have reported decreased frequencies compared with normal pregnancy (202). Factors that may affect results and explain divergent findings include flow cytometry strategy and markers of Treg phenotyping, patient selection, and influence of corticosteroid treatment.

The total numbers of lymphocytes, CD3+ cells, and CD4+ cells (expressed as cells/lL of whole blood) were similar in non-pregnant, normal pregnant, and preeclamptic women ( $\mathrm{p}=0.59-0.70$, data not shown). Thus, Treg populations could safely be reported as the proportion of CD4+ cells (expressed as percentage of CD3+CD4+ cells). Corticosteroid treatment neither affected the total number of lymphocytes nor the number of $\mathrm{CD} 3+$ or $\mathrm{CD} 4+$ cells $(\mathrm{p}=0.67-0.84)$ when comparing corticosteroidtreated $(n=10)$ and untreated $(n=8)$ women.

Although there is still no perfect marker of Treg cells, there has been a gradual improvement in phenotyping strategies and markers to both define Treg cell subpopulations and exclude non-suppressive CD4+ cells that express FOXP3 and CD25 after activation. A major breakthrough was the report by Miyara et al., demonstrating that by combining FOXP3 with CD45RA, Treg cells could be classified as either resting $\left(\mathrm{FOXP} 3^{\mathrm{dim}} \mathrm{CD} 4 \mathrm{RA} \mathrm{A}^{+}\right.$) or 
activated (FOXP $3^{\text {high }} \mathrm{CD} 4 \mathrm{RA} \mathrm{A}^{-}$), while at the same time, FOXP ${ }^{\text {dim }} \mathrm{CD}^{\mathrm{N}} 4 \mathrm{RA}{ }^{+}$cells could be classified as activated non-suppressive Th cells ('false positive' FOXP3 expression) and therefore correctly excluded from the Treg cell enumeration $(62,202$, 203),

When using this strategy, we found no major alterations in circulating Treg frequencies in preeclamptic compared with healthy pregnant and non-pregnant women (Figure 22). Also, when adding the resting and activated Treg populations, as well as when defining Treg cells by CD127 $7^{\text {low }}$ combined with CD25 or FOXP3, there were no differences between groups. When Treg cells were defined as $\mathrm{CD} 4{ }^{\mathrm{dim}} \mathrm{CD} 25^{\text {bright }}(67)$ pregnant women, both with preeclampsia and healthy pregnancy, showed lower Treg frequencies as compared with non-pregnant women (Figure $22 \mathrm{~d}$ ).

Due to the early onset of the disease and the high risk of premature birth, ten of the preeclamptic women in our study received the potent glucocorticoid betamethasone, which was given in almost all cases in close proximity to blood sampling. This treatment is normally started directly on the admission of a patient with early-onset preeclampsia. The women in the preeclampsia group were recruited at the County Hospital Ryhov in Jönköping and the University Hospital in Linköping, but several women were transferred from smaller hospitals and corticosteroid treatment had already been started on admission. Importantly, we found that the corticosteroidtreated group showed significantly decreased frequencies of resting Treg cells, and corticosteroid treatment also affected the composition of Treg subpopulations (Figure 23 and 24). 

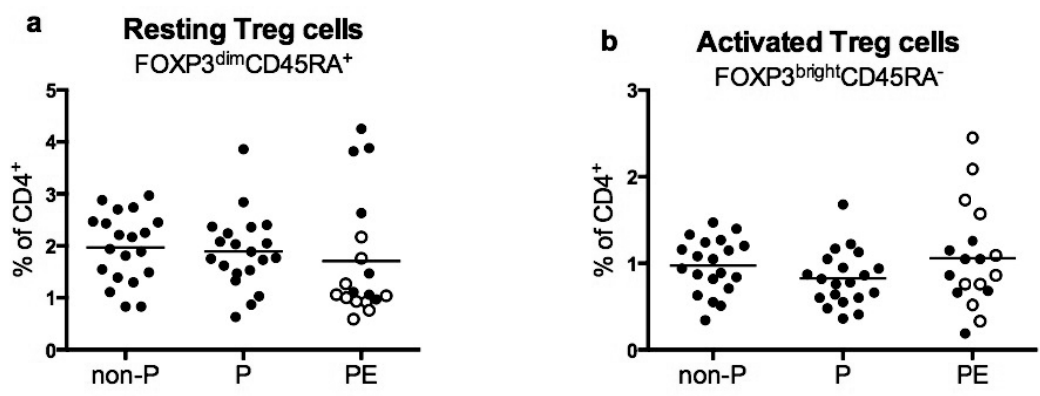

C Non-suppressive FoxP3+Th cells d $\quad$ CD4 ${ }^{\text {dim }}$ CD25 $5^{\text {bright }}$ Treg cells


Figure 22. Proportions (\%) of Treg subpopulations in non-pregnant (non-P; $n=20)$, normal pregnant $(\mathrm{P} ; \mathrm{n}=20)$ and preeclamptic (PE; $\mathrm{n}=18)$ women: (a) resting Treg cells $\left(\mathrm{FOXP} 3{ }^{\mathrm{dim}} \mathrm{CD}^{4} \mathrm{RA}^{+}\right)$; (b) activated Treg cells (FOXP $\left.3{ }^{\text {high }} \mathrm{CD}^{2} 5 \mathrm{RA}^{-}\right)$; (c) non-suppressive FOXP3 ${ }^{+}$Th cells (FOXP $3{ }^{\text {dim }}$ CD45RA $)\left(\right.$ d) Treg cells defined as CD $4{ }^{\text {dim }}$ CD $25^{\text {bright }}$ cells. Lines indicate mean values. Empty circles indicate corticosteroid treated preeclamptic women.

$* \mathrm{p}<0.05 ; * \mathrm{p}<0.01$ by Student's unpaired t-test if the ANOVA indicated $\mathrm{p} \leq 0.05$ 

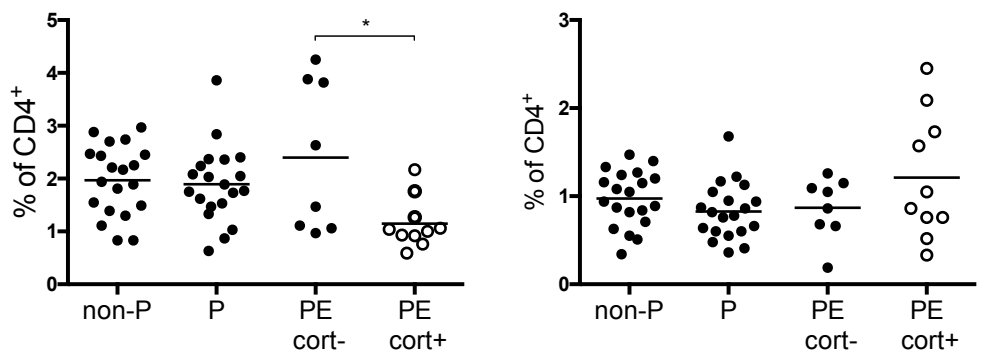

c Non supressive FOXP3 ${ }^{+}$Th cells

\section{Resting+Activated Treg/}

d Non-suppressive FOXP3 ${ }^{+} \mathrm{T}$ cells
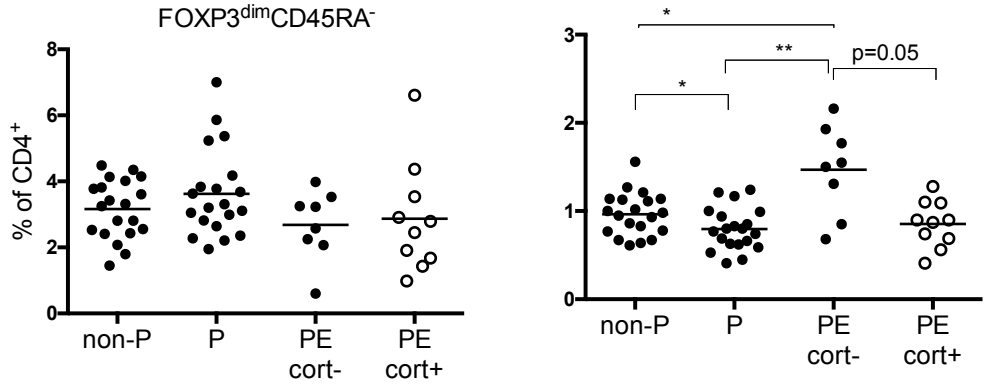

e CD4 ${ }^{\text {dim }}$ CD25 $5^{\text {bright }}$ Treg cells



Figure 23. Proportions (\%) of Treg subpopulations in non-pregnant (non-P; $n=20)$, normal pregnant $(\mathrm{P} ; \mathrm{n}=20)$, non-corticosteroid treated preeclamptic (PEcort-; $\mathrm{n}=8)$ and corticosteroid treated (PEcort+; $n=10$ ) women: (a) resting Treg cells (FOXP $3{ }^{\text {dim }}$ CD45RA); (b) activated Treg cells (FOXP $3{ }^{\text {high }} \mathrm{CD}^{4} 5 \mathrm{RA}^{-}$); (c) non-suppressive FOXP3 ${ }^{+}$T cells $\left(\mathrm{FOXP3}{ }^{\mathrm{dim}} \mathrm{CD} 45 \mathrm{RA}^{-}\right.$); (d) ratio between the sum of resting and activated Treg defined as in $a-b$, divided by the proportion of nonsuppressive FOXP3 ${ }^{+} \mathrm{T}$ cells (e) Treg cells defined as $\mathrm{CD} 4{ }^{\mathrm{dim}} \mathrm{CD} 25^{\text {bright }}$ cells. Lines indicate mean values. 
As can be seen in Figure 22 (unfilled versus filled circles in the preeclampsia group), the Treg populations seemed to be differently distributed in corticosteroid-treated versus non-treated women. We therefore stratified the preeclampsia group according to the status of corticosteroid treatment given prior to blood sampling (Figure 22). Thereby, among preeclamptic women, corticosteroid treatment was associated with a reduced proportion of resting Treg cells (Fig. 22 a), whereas there were no significant differences with regard to activated Treg cells (Figure $22 \mathrm{~b}$ ) or the activated nonsuppressive FOXP $3{ }^{\mathrm{dim}} \mathrm{CD} 45 \mathrm{RA}^{-}$population (Figure $22 \mathrm{c}$ ). In humans, dexamethasone has been shown to promote Treg cells (204-206), while BALB/c mice treated with dexamethasone showed enhanced $\mathrm{CD} 4{ }^{+} \mathrm{CD} 25^{+}$but suppressed $\mathrm{CD} 4{ }^{+} \mathrm{FOXP} 3^{+}$Treg cell numbers (207). Further, Treg cell numbers were unaffected by hydrocortisone in a murine model of autoimmune disease (208). Obviously, the glucocorticoid effects on Treg cells are complex and related to the dose and duration of the treatment. Hence, using samples from non-glucocorticoid-treated women is desirable. In previous studies, the use of corticosteroid treatment was in general not reported, and its effects on Treg cells have not been previously evaluated in preeclamptic women. However, in an attempt to relate the Treg cells to the effector CD4 cells, we found that the ratio (Figure $23 \mathrm{~d}$ ) between the sum of resting and activated Treg (FOXP $3{ }^{\text {dim }} \mathrm{CD}^{2} 4 \mathrm{RA}^{+}$and FOXP $3{ }^{\text {high }} \mathrm{CD} 45 \mathrm{RA}^{-}$) and the activated non-suppressive FOXP3 ${ }^{\text {dim }}$ CD45RA- population was significantly higher in non-corticosteroid-treated preeclamptic women compared with normal pregnant women. This difference was also found in the entire group of preeclamptic women $(\mathrm{P}=0.01)$, while there was no significant increase in the corticosteroid-treated preeclamptic women compared with normal pregnant women. Non-pregnant women had a higher ratio than normal pregnant women (Figure $23 \mathrm{~d}$ ). Finally, the $\mathrm{CD} 4{ }^{\mathrm{dim}} \mathrm{CD} 25^{\text {bright }}$ Treg population was lower in the corticosteroid-treated group, but not in the untreated group, as compared with non-pregnant women (Figure $23 \mathrm{e}$ ).

Our findings do not support the majority of previous studies that in general showed lower frequencies of Treg cells in the blood of preeclamptic as opposed to healthy 
pregnant women $(12,73,209-214)$, although some previous studies did not show a difference between these group $(74,75,215)$. In a more recent study using an updated phenotyping strategy, Steinborn et al. (211) did not find any differences with regard to the whole Treg cell population, while alterations in the preeclampsia group were found in Treg subpopulations, in line with our findings. Taken together, the phenotyping strategy has a major impact on Treg cell frequencies and must be taken into account when evaluating previous studies that may have included activated nonsuppressive $\mathrm{FOXP}^{+}$or $\mathrm{CD} 25^{+}$cells. In addition to the phenotyping strategy, the selection of material can affect findings. Although previous studies have enrolled patients with mainly moderate to severe preeclampsia, none has focused on earlyonset disease, and in several studies, the findings were not related to gestational age. Hence, some of the Treg disturbances reported previously may have been confined to the group of women presenting with late-onset preeclampsia, possibly having had a subclinical disease for a long time, and the findings could therefore reflect the effect of, rather than the cause of the disease. We focused our attention on women with severe or early-onset preeclampsia, hypothesizing that this would provide us with a homogenous group of diseased women presenting with a more distinct placental disease $(7,215)$. This is also the patient group suffering the most severe consequences of their disease, but our findings do not support a numerical defect in Treg cells in early-onset preeclampsia.

However, by analysing the expression of functional and migratory markers (CTLA-4 and CCR4) within subpopulations, we found that the proportions of CTLA $-4^{+}$and $\mathrm{CCR} 4^{+}$were higher both in resting and in activated Treg populations (Figure $24 \mathrm{a}-\mathrm{d}$ ) in untreated preeclamptic compared with normal pregnant women. In contrast, normal pregnancy was associated with lower proportions of CTLA- $4^{+}$(Figure $24 \mathrm{~b}$ ) and $\mathrm{CCR} 4^{+}$cells (Figure $24 \mathrm{~d}$ ) within the activated Treg population as compared with non-pregnant women. Thus, differences in CTLA-4 and CCR4 expression within Treg populations were found in preeclamptic women. However, these differences were confined to the non-corticosteroid-treated group, again indicating an influence of corticosteroid treatment on the Treg phenotype 


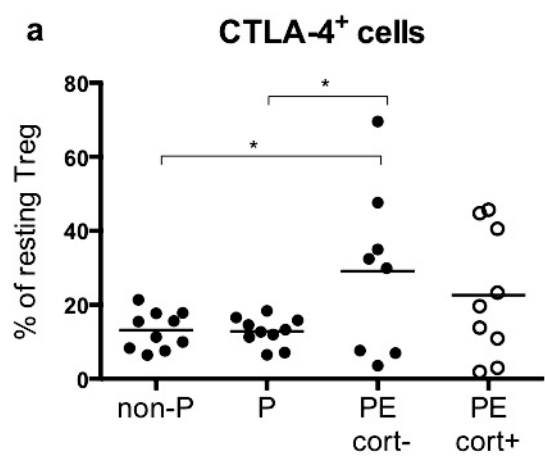

b $\quad$ CTLA $-4^{+}$cells


Figure 24. Proportions $(\%)$ of CTLA $-4^{+}$and $\mathrm{CCR} 4^{+}$cells within $(\mathrm{a}, \mathrm{c})$ resting $\left(\mathrm{FOXP} 3{ }^{\mathrm{dim}} \mathrm{CD}^{\mathrm{C}} \mathrm{RO} \mathrm{R}^{-}\right)$ and $(\mathrm{b}, \mathrm{d})$ activated $\left(\mathrm{FOXP} 3{ }^{\text {bright }} \mathrm{CD} 45 \mathrm{RO}^{+}\right.$) Treg subpopulations in non-pregnant (non-P; $\mathrm{n}=20$ ), normal pregnant $(\mathrm{P} ; \mathrm{n}=20)$, non-corticosteroid treated preeclamptic (PEcort-; $\mathrm{n}=8)$ and corticosteroid treated (PEcort $+; \mathrm{n}=10$ ) women. Lines indicate mean values. ${ }^{*} \mathrm{p}<0.05 ;{ }^{*} \mathrm{p}<0.01$ by Student's unpaired t-test if the ANOVA indicated $\mathrm{p} \leq 0.05$

In normal pregnancy compared with the non-pregnant state, we found a reduced frequency in the blood of both CTLA $-4^{+}$and CCR $4^{+}$cells within the activated Treg population $\left(\mathrm{FOXP} 3{ }^{\text {high }} \mathrm{CD} 45 \mathrm{RO}^{+}\right)$. This reduction in blood is in line with an accumulation of suppressive Treg cells in the decidua, as reported previously (66). Consequently, the presently noted increase in preeclampsia of the $\mathrm{CTLA}^{+}$and CCR4 $4^{+}$ proportions of Treg cells could reflect a failure to accumulate Treg cells in the decidua, hence leading to a lack of anti-inflammatory regulation at the foetalmaternal interface. Indeed, a reduced frequency of Treg cells in the decidua has been found in preeclampsia $(210,216)$. In an attempt to relate the Treg cell frequency to effector CD4 cells, we used the resting plus the activated Treg cells as reliable 
measures of true Treg cells, and the activated non-suppressive CD4 population as an established activated population (62). When making a ratio between resting and activated Treg cells divided by the effector $\mathrm{T}$ cells, we found a higher ratio in noncorticosteroid-treated women compared with both normal pregnant and corticosteroid-treated women. This finding is in line with a possible migratory defect of Treg cells in preeclampsia, by which Treg cells do not properly reach their destination in the uterus, while the effector cells are recruited to the uterus, hence occurring at a lower level in the circulation relative to the Treg cells. It should be noted that the differences in the ratio must be interpreted with great caution, as there were no significant differences when evaluating the proportions one by one. A limitation of our study is that we have only studied Treg cell frequency in peripheral blood and not locally in the decidua. A strength of the study is that only women with early-onset or severe preeclampsia with clear signs of placental pathology were included and another strength is our stratifying for corticosteroid treatment as well as the use of an updated phenotyping panel assessing Treg subpopulations and excluding non-suppressive activated FOXP3-expressing cells. The sample size is quite modest but is similar to most previous studies that have noted differences in Treg cell frequencies. When stratifying for corticosteroid treatment, the subgroups are rather small and our findings need to be confirmed. However, significant differences were still noted and they are sufficient to draw attention to the issue of corticosteroid treatment in future studies. There was also a difference of approximately four weeks in mean gestational age between the group of preeclamptic women and the normal pregnant women. Steinborn et al. (211) found that the suppressive action of Treg cells was quite stable after 20 weeks of pregnancy until close to labour. None of the women in the study were close to spontaneous labour in the study, and we therefore believe that this difference has not affected the results in any significant way.

In conclusion, although we found no major alterations in circulating Treg numbers, the increased proportions of CTLA- 4 and $\mathrm{CCR} 4^{+}$cells within Treg subpopulations are in line with a migratory defect of Treg cells in preeclampsia, potentially 
associated with a reduced number of suppressive Treg cells at the foetal-maternal interface. As corticosteroid treatment seems to affect the distribution of Treg subpopulations, this variable should be accounted for in studies of Treg cells in preeclampsia

\section{Paper IV}

An increasing amount of data indicates an involvement of the immune system in the pathogenesis of preeclampsia and chemokines are an important part of the immune system. We aimed to elucidate a possible role of chemokines in the pathogenesis of preeclampsia by investigating if expression of chemokines in trophoblasts differed between placentas from preeclamptic and normal pregnancies. We therefore used immunohistochemistry to quantify the expression of a set of chemokines representing different immune profiles; CXCL10 (Th1), CCL22 (Th2), CCL20 (Th17) and CCL18 (Th2 and Treg). We also studied first trimester placentas from women with terminated pregnancies to find out if there was a change in expression during pregnancy. In addition, we measured the plasma levels of these chemokines to see whether they correlated with the expression in trophoblasts and whether they differed in preeclampsia versus normal pregnancy. The blood samples from these subjects have previously been used in paper II (217), which included CXCL10 (Th1) and CCL22 (Th2), but now we also included CCL18 and CCL20 to study a broader spectrum of immune profiles.

\section{Immunohistochemistry part}

We examined chemokine expression in trophoblasts in terminal villi. A main finding was the decreased expression of CCL18, a chemokine associated with Th2/Treg, in trophoblasts from preeclamptic women compared to normal pregnancies, indicating a local regulatory defect in preeclampsia. When analysed separately, both placentas from women with EOP and LOP expressed significantly less CCL18 than those from women with normal pregnancies (Figure 25a). The finding is in line with the reported decreased presence of Tregs at the foetomaternal interface in preeclampsia $(66,67)$, which is also in accordance with our previous finding of a possible migratory defect 
of circulating Treg cells based on the phenotype in paper III (218). Furthermore, the lack of CCL18 might also skew local immunity from Th2/Treg towards Th1/Th17 in preeclampsia $(14,219,220)$. There are few studies of the role of CCL18 in normal and pathological pregnancy. We have previously shown that CCL18 is secreted by placental macrophages in human normal pregnancies, thereby contributing to a tolerogenic immune environment $(58,99)$. In line with our present finding, Tranquilli et al. using microarray analysis, confirmed by PCR, found that placental expression of CCL18 was significantly decreased in women with HELLP syndrome compared with normal pregnant women (100). We did not find any differences in placental CCL18 expression between first and third trimester placentas, indicating that CCL18 plays an important role throughout pregnancy, and the finding also indicates that the low CCL18 expression in EOP was not due to the lower gestational length in EOP compared with the controls.

We found no differences in trophoblast expression of the Th17-associated chemokine CCL20 in normal compared with preeclamptic women (Figure $25 \mathrm{~b}$ ), which is in contrast to one previous study showing increased CCL20 expression in the decidua basalis of placental bed biopsies from preeclamptic women compared with normal pregnant controls (103). The main reason for the discrepancy between studies could be the location studied; trophoblasts versus decidua. At present it is not known which compartment is quantitatively most important for CCL20 production. Also, the normal function of CCL20 and Th17 immunity in pregnancy is not known. Our finding of an increased CCL20 expression in first trimester placenta compared with placentas from third trimester pregnancies supports the theory that there is a physiological role for Th17 immunity in early pregnancy. Although earlier studies showed inconsistent data on Th17 presence in the decidua, probably due to whether or not there was stimulation of the decidual cells $(72,76)$, it was recently shown that decidual stromal cells through CCL20 production can recruit IL-17 secreting Th17 cells to the foetomaternal interface to promote proliferation and invasion of human trophoblast cells (221).

Despite a prominent role for CXCL10 in trophoblast and immune cell migration (90, 
222, 223), endometrial - blastocyst interactions (224) and spiral artery remodelling (93), we could not demonstrate a clear role for CXCL10 in the placental pathology in preeclampsia since there were no differences between normal and preeclamptic pregnancies (Figure 25c). This does not rule out a role for CXCL10 in the placenta at an earlier stage, and also, aberrant CXCL10 production may occur at the decidual locus.

The finding of CCL22, a chemoattractant for Th2 cells, being present in trophoblasts of first trimester placenta but not in third trimester placenta (Figure 26) suggests also that CCL22 is important in particular in the early placentation. This is corroborated by Freier et al (105), showing expression of CCL22 in trophoblasts in first trimester placentas, but it was not investigated in term placentas. In addition to CCL22, there are other chemokines associated with Th2, in particular CCL17, which would be of interest to study in preeclampsia. In further support of a role for Th2 chemokines in pregnancy complications, an aberrant expression of CCL22, correlating with Treg infiltration, was observed in miscarriage conditions (105). 




Figure 25. Trophoblast expression of CCL18 (a), CCL20 (b) and CXCL10 (c) in placental biopsies from women with preeclampsia (PE) and normal pregnancy (NP) (left panel), and PE, divided into early-onset preeclampsia (EOP) and late-onset preeclampsia (LOP) in the right panel, where also expression in first trimester placentas (T1) is shown. Mann-Whitney U test was used for comparison between two groups, in multiple-group comparisons Kruskal-Wallis $<0.05$ was a prerequisite for two-group comparisons. Lines denote medians. Empty circles indicate vaginal delivery and circles with a dot indicate acute caesarean sectio. 


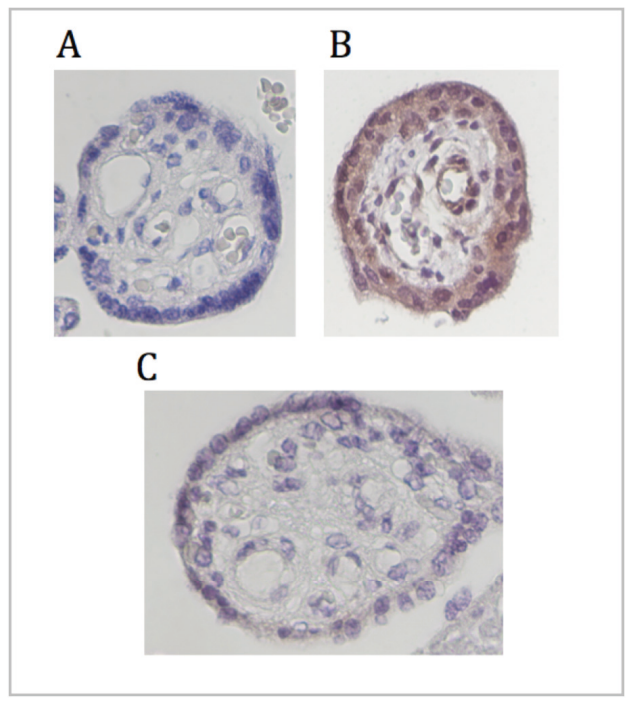

Figure 26. Placental biopsies inoculated with antibodies against CCL22 from a preeclamptic pregnancy (A), a first trimester placenta (B) and a third trimester normal pregnancy $(\mathrm{C})$.

\section{Plasma levels of chemokines}

There were no differences in CCL18 levels in plasma, either between normal pregnant and preeclamptic mothers or between women with EOP and LOP (Table VIII). While CCL20 was not detectable in the majority of samples, detectable CCL20 levels were found significantly more frequently in the preeclampsia $(17.8 \%)$ than in the normal pregnancy (NP) group $(6.5 \% ; \mathrm{p}<0.02)$, particularly for EOP $(28.6 \%$; $\mathrm{p}<0.01)$, while for LOP there was only a trend $(13.7 \% ; \mathrm{p}=0.051)$. Also, the median plasma level was significantly increased in the EOP group compared with normal pregnant women (Table VIII). We could not show any difference in plasma levels between preeclamptic and normal pregnant women for CCL22 (Table VIII, measurements were done in paper II (217)). Plasma levels of CXCL10 were higher in both EOP and LOP compared with normal pregnant women, with similar levels in the EOP and LOP group (Table VIII, measurements were done in paper II (217)). For all four chemokines there were no differences in the EOP group between women treated with corticosteroids before blood sampling $(n=8)$ compared with women who were not treated at the time of sampling $(\mathrm{n}=20)$. There was no correlation between local expression and plasma level for CCL18 $(\mathrm{r}=-0.15 ; \mathrm{p}=0.47)$ or CXCL10 $(\mathrm{r}=-0.22$; $\mathrm{p}=0.23$ ). For CCL22 we did not find any placental expression in the third trimester 
and CCL20 was not detectable in the majority of the plasma samples. Correlation tests were therefore not performed for these chemokines.

The systemic chemokine levels indicate a pro-inflammatory profile with increases in Th1 (CXCL10) and Th17 (CCL20) chemokines in preeclampsia. Our finding of increased CCL20 is in line with a previously reported increase in IL-17A-producing $\mathrm{CD}^{+}$cells in the circulation of preeclamptic women (12). A possible role of CCL20 was also proposed in spontaneous term and preterm labour (term and preterm) (104), although no changes in serum CCL20 levels in women with preterm labour and delivery were reported in one study (102). The role of circulating CCL20 levels in preeclampsia is still uncertain, although increased levels are in line with the general view of systemic inflammation in preeclampsia. The increase in plasma levels of the Th1-associated chemokine CXCL10 in preeclamptic compared to normal pregnant women is in line with a previous study that showed increased serum levels of CXCL10 in preeclamptic women compared with normal pregnant women but also in comparison with mothers who have small for gestational age (SGA) neonates without preeclampsia. Since the increase in CXCL10 levels does not differ between EOP and LOP in our study, but between preeclampsia and IUGR (95), it is more likely to reflect an anti-angiogenic state and an enhanced systemic inflammatory response in the maternal endothelium than a placental insult. This is in line with the fact that we could not show any difference in placental expression of CXCL10 between normal and preeclamptic pregnancies. As shallow placentation with deficient modulation of spiral arteries is a placental insult shared for IUGR and early-onset preeclampsia, it is possible that the increased plasma level of CXCL10 in preeclampsia, but not in IUGR, may contribute to the clinical presentation of preeclampsia due to its proinflammatory and anti-angiogenic properties on maternal endothelium $(95,217)$. Moreover, CXCL10 has been found to be involved in conditions where a Th1/Th2 imbalance is involved (94). The plasma levels of CXCL10 and CCL22 presented in the present paper are the same as presented previously in paper II (217). We chose to show these results also in this study since they allowed us to compare local and systemic levels. Circulating levels of CCL22 have previously been measured only in 
normal pregnancy $(217,225)$, indicating a role for CCL22 in earlier stages of pregnancy.

aim of the study was to establish whether local immunity (in this case related to chemokines) is mirrored systemically. Overall, there were no correlations between local expression and systemic levels of chemokines, indicating that the compartments are not directly inter-related, a finding that is also pertinent to Treg cells (78) and important to keep in mind to avoid misunderstandings and misinterpretations of data. Women with EOP were treated with corticosteroids in two doses shortly after they were diagnosed with preeclampsia, but this was not done for women with LOP. We have previously shown that corticosteroids can affect the frequency and phenotype of Treg cells when administrated in close proximity to blood sampling. In the IHC study, however, placental samples were taken post-partum when most of the effects of corticosteroids could have disappeared. We did not see many differences between EOP and LOP in the IHC study, which may have two explanations: either there was no major effect left of the corticosteroid treatment, or the corticosteroid treatment had dampened the increased inflammation in EOP.

There are several potential imitations of the study. CS versus vaginal delivery can potentially affect immune parameters in the placenta. While all women in the EOP and NP groups were delivered by elective CS (so selected to avoid influence of vaginal delivery), there were three women delivered vaginally and five women delivered by acute CS in the LOP group. However, the findings were similar in this small group, suggesting that mode of delivery did not skew the results. Another weakness is that we do not know if first trimester placenta represent normal pregnancies since the pregnancies were terminated, although this should not have any major influence and is indeed unavoidable. It should be noted that we only studied four chemokines, although they were chosen due to their association with different immune profiles. In addition, we measured expression in trophoblasts but we do not know if that correlates to the amount of secreted chemokines. A strength of the study is that we studied chemokines both in peripheral blood and locally in trophoblasts in the same pregnant women. Another advantage of the study is that women with early 
and late-onset preeclampsia with possibly different pathophysiologies were analysed separately.

Table VIII. Plasma levels of chemokines. Median values with min and max values within brackets. Values for CXCL10 and CCL22 are from a previous study (217).

\begin{tabular}{|lllll|}
\hline Chemokine & $\begin{array}{l}\text { Early-onset } \\
\text { preeclampsia }\end{array}$ & $\begin{array}{l}\text { Late-onset } \\
\text { preeclampsia }\end{array}$ & $\begin{array}{l}\text { Normal } \\
\text { pregnancy }\end{array}$ & Detectable \\
\hline CXCL10 & $86^{* *}$ & $\begin{array}{l}115^{* * * *} \\
(80-161)\end{array}$ & $\begin{array}{l}70 \\
(51-99)\end{array}$ & $100 \%$ \\
& $(62-160)$ & 43282 & 46227 & $100 \%$ \\
\hline CCL18 & $(16115-161120)$ & $(25822-86548)$ & $(22747-128810)$ & \\
& $9.8 * *$ & 8.7 & 6.4 & $12.4 \%$ \\
CCL20 & $(4.9-45.7)$ & $(4.9-207.6)$ & $(4.9-77.1)$ & $100 \%$ \\
\hline CCL22 & 106.6 & 97.5 & 93.4 & \\
& $(72-142)$ & $(67-130)$ & $(68-117)$ & \\
\hline${ }^{*}<<0.05, * * \mathrm{p}<0.01, * * * \mathrm{p}<0.001, * * * \mathrm{p}<0.0001$ & & & \\
& & & & \\
\end{tabular}

In conclusion, systemic and local studies in preeclampsia on CCL18, CCL20, CCL22 and CXCL10, show decreased expression of CCL18 in placentas from preeclamptic compared with normal pregnant women, indicating a defect local tolerance with a skewing of the immune system towards Th1 instead of Th2/Treg in preeclampsia. Increased expression of CCL20 and CCL22 in first trimester placenta suggest that these chemokines are important for implantation and early placentation, while increased third trimester plasma levels of CCL20 and CXCL10 in preeclamptic women mainly seem to mirror the state of maternal systemic increased endothelial inflammation and aberrant angiogenesis typical for preeclampsia. 


\section{Summary and conclusions}

Preeclampsia is still one of the most challenging conditions in obstetrics due to its impact on maternal and foetal morbidity and mortality, and the lack of evidencebased prevention and treatment strategies.

The pathogenesis of preeclampsia is still not clear but there is an increasing amount of data indicating that the condition is a result of uncompensated maternal endothelial systemic inflammatory response to factors from stressed trophoblasts due to either placental insult (extrinsic dysfunction) or villous overcrowding (intrinsic dysfunction). An increasing body of evidence indicates that an involvement of the immune system, including maladaptation and defect tolerance to the conceptus, is an integral part of the pathogenesis, at least in early-onset preeclampsia (EOP), resulting in a shallow placentation with defect trophoblast invasion in the uterine spiral arteries. Based on the hypothesis that sera from patients with preeclampsia could function as a "blueprint" of causative factors, we describe in paper I a serum-based pregnancy-specific mouse model that closely mirrors the human condition, as well as an in vitro predictive assay. We were able to show that a single administration of human preeclampsia serum in pregnant IL-10 $0^{-/-}$mice induced the full spectrum of preeclampsia-like symptoms, caused hypoxic injury in uteroplacental tissues and endotheliosis in maternal kidneys, and also elevated soluble fms-like tyrosine kinase 1(sFlt-1) and soluble endoglin (sEng) in maternal mice serum, markers related to the disease. The same serum samples induced a partial preeclampsia phenotype in wild type mice. Importantly, preeclampsia serum disrupted cross talk between trophoblasts and endothelial cells in an in vitro model of endovascular activity (Tube formation test). Disruption of endovascular activity could be documented in serum samples, after only 12 to 14 weeks of gestation, from patients who subsequently developed preeclampsia. These results indicate that preeclampsia patient sera can be used to understand the pregnancy-specific disease pathology in mice and can predict the disorder.

Although preeclampsia has been associated with increased inflammation, aberrant angiogenesis and activated coagulation, their correlation and relative contributions to 
the pathogenesis are unknown. In paper II we found that markers for increased inflammation, hypercoagulation and aberrant angiogenesis were independently associated with preeclampsia. Cytokines, chemokines, and complement factors seem to be part of a Th1-associated inflammatory reaction in preeclampsia. Most of the differences were more pronounced in EOP than in LOP, suggesting a more homogeneous pathogenesis in EOP, which is in line with findings based on placental pathology. In women giving birth to SGA babies, where a pathologic placentation can be anticipated, we found differences in levels of biomarkers only for sFlt-1 and PlGF compared to mothers with appropriate for gestational age (AGA) babies. Thus, these biomarkers seem to be relevant indicators of placental pathology, while other biomarkers might also indicate maternal endothelial pathology. Chemokines, in contrast to cytokines, may prove to be useful markers in preeclampsia, in addition to established markers.

A deficiency in Treg cells causing reduced immune regulatory capacity has been proposed in preeclampsia. Utilizing recent advances in flow cytometry phenotyping, we found (paper III) no major alterations in circulating Treg numbers in preeclamptic women compared to normal pregnant and non-pregnant women. Instead we found increased proportions of CTLA $-4^{+}$and $\mathrm{CCR} 4^{+}$cells within Treg subpopulations. This is in line with a migratory defect of Treg cells in preeclampsia, potentially associated with a reduced number of suppressive Treg cells at the foetal-maternal interface. As corticosteroid treatment seems to affect the distribution of Treg subpopulations, this variable should be accounted for in studies of Treg cells in preeclampsia.

Chemokines are supposed to be part of the immune adaptation in pregnancy and since they form the immune response by recruiting certain $\mathrm{T}$ helper $(\mathrm{Th})$ cells, they are suitable as markers of different Th-associated immune profiles. We found in paper IV a decreased expression of CCL18, a chemokine associated to Th2/Treg, in trophoblasts from preeclamptic women, as compared to normal pregnancies, indicating a local regulatory defect in preeclampsia, in line with a reported decreased presence of Tregs at the foetomaternal interface in preeclampsia. This is also in accordance with our finding (paper II) of a possible migratory defect of circulating 
Treg cells based on the phenotype. The increased expression of CCL20 and CCL22 in first trimester placenta suggest that these chemokines may be important for implantation and early placentation, while increased circulating levels of CXCL10 and CCL20 in third trimester preeclamptic women probably mirror the state of maternal systemic increased endothelial inflammation and aberrant angiogenesis typical for preeclampsia.

In summary, our data suggest that placental factors in serum from preeclamptic women affect the maternal endothelium, resulting in increased inflammation, activated coagulation and aberrant angiogenesis, in particular for EOP, and that the immune system is involved in the pathogenesis with an unbalanced local and systemic immune profile involving a lack of regulation and a skewing towards Th1/Th17 in preeclampsia. These findings add to the understanding of the pathogenesis in preeclampsia and emphasize that factors in serum are involved in the pathogenesis and may serve as biomarkers for early detection and monitoring of preeclampsia. 


\section{Future perspectives}

This thesis has presented data that further elucidate the complicated pathogenic mechanisms in preeclampsia. The overall objective for research in this area is to find a method for effective prediction and prevention of the condition. From a clinical view the priority must be to predict and prevent EOP and IUGR since these conditions have a significant impact on maternal and foetal morbidity and mortality, as well as on iatrogenic prematurity. This impact is not so pronounced in LOP. Since pathophysiology seems to be, at least in part, different in EOP compared to LOP, prediction of preeclampsia might be more difficult in LOP, which from a clinical perspective is not a big issue since it is much more important to predict and prevent EOP. The placental insult associated with both EOP and IUGR increases the likelihood of finding an effective method of prediction and prevention. An effective prevention method should interact with one or more or the pathogenetic mechanisms described for preeclampsia, including increased inflammation, activated coagulation and aberrant angiogenesis. This is true for the preventive drugs, e.g. aspirin and LMWH, whose use has been suggested, if an effective predictive algorithm can be introduced in the first trimester with acceptable sensibility and specificity. The described Tube formation test in paper I might be a useful tool for testing the potential of such drugs to reverse the adverse effects of serum factors on the formation of capillary tubes. A placental insult causing both IUGR and EOP represents a serious risk for both increased morbidity and mortality in the actual pregnancy but also for an increased future risk of cardiovascular morbidity, and increased risk of developing the metabolic syndrome for the child later in life due to intrauterine malnutrition stress. If an effective prediction and prevention method for EOP and IUGR can be established this may have great benefits for the future health of both mother and child, and may also lead to reduced health care spending due to reduced costs for neonatal care. Even with an effective prediction and prevention method we will still have cases of severe early-onset preeclampsia constituting a threat to both the health of the mother and the child; therefore, treatment of an established preeclamptic condition is also of vital interest. Studies on treatment with 
statins (Pravastatin) are already ongoing. Statins are of interest since they interact with inflammation, coagulation and angiogenesis, and murine studies are promising. Another mechanism described in this thesis is activated coagulation due to low levels of antithrombin, which precedes preeclampsia by several weeks. Studies have shown that it is possible to prolong pregnancies with a debut of severe preeclampsia very early in pregnancy by treatment with antithrombin intravenously, and there are ongoing studies to see if this could be an alternative in certain cases (PRESERVE-1 Trial).

has still not been satisfactory clarified why a placental insult of similar type sometimes results in EOP combined with a placental insufficiency and sometimes only in IUGR without preeclampsia. This is an area for future research. One hypothesis is that impaired placental blood flow without reperfusion causes hypoxia but not oxidative stress, and hence causes IUGR without preeclampsia, but this has not been clarified.

Another new exciting area of research is the association between infection and preeclampsia. Studies have shown that certain chronic and recurrent infections are associated with preeclampsia but the pathophysiologic mechanisms are not clear. Both effects on the placental microbiome leading to changes in the immune profile as well as an influence on inflammatory status of maternal endothelium are possible mechanisms. In the future we might discover that we can avoid preeclampsia by eradication of certain chronic infections such as periodontitis, Helicobacter pylorus positive gastritis, malaria or recurrent urinary tract infections.

Due to a global high maternal mortality in preeclampsia and a major neonatal problem with prematurely delivered babies due to preeclampsia and IUGR there is an urgent need, after decades of research, for an obstetrical breakthrough with establishment of an effective prediction and prevention method for both preeclampsia and IUGR. 


\section{Acknowledgments}

I would like to express my gratitude to all those, who have contributed to this thesis with generous help and never-ending support over these years. In particular, I owe my thankfulness to:

All the women in our region, who have participated in the studies in this thesis, without whom this thesis would not have been possible to implement.

Leif Matthiesen, my main supervisor and my very good and highly appreciated friend and colleague, who have inspired me from the beginning all the way and shared my fascination for both basal clinical obstetrical work and research to advance the knowledge in the area. Also, thanks for many fun times together and a wonderful fellowship at conferences and meetings.

Jan Ernerudh, my co-supervisor, for your invaluable contribution in particular with regard to reviewing, correcting and improving the included manuscripts in this thesis. Moreover, your great knowledge within the area of reproductive immunology has led to many interesting discussions and ideas, not least regarding the planning and direction of the work with this thesis.

Maria Jenmalm, my second co-supervisor, who with an endless energy has very carefully reviewed my manuscripts in detail and thereby contributed to a significant improvement of the quality. You have also teached me a lot in the area of immunology for which I am grateful and also contributed to the planning of this thesis.

Göran Berg, co-supervisor and colleague, who with a lot of experience has contributed with encouragement and valuable advices, which has facilitate the work with this thesis. It has also been a pleasure after many years to reconnect after the previous collegial cooperation.

Surendra Sharma, who in a very generous way made it possible for me to be involved in his succesful research in his laboratory in Providence and allowed me to 
be a part of it. I was received in a very friendly way with great hospitality when I visited Providence for which I am very grateful.

\section{Judith Svensson-Arvelund, Jenny Mjösberg and Maria Hjort who in an} invaluable way contributed to my third paper (with Jenny as shared first author) by laboratory work sometimes even at inconvenient times, interpretation of results, checking the statistics and contribution to the manuscript, always with enthusiasm.

Robert Lindau, for your generous assistance in the laboratory and for your valuable contribution to paper IV.

Heriberto Rodriguez-Martinez for the important role in our immunohistology project, where we could benefit from your great experience and knowledge in that area.

Inger Gustavsson, former midwife in charge of Labour ward at County hospital Ryhov in Jönköping, for your energetic and enthusiastic contribution with the recruitment of patients to our preeclampsia study including the collection of blood samples and placental biopsies. Without your contribution this project had been difficult to realize.

Georgia Papapavlos and Samantha Karlsson, for aiding with a substantial laboratory work, and manuscript writing in my fourth paper.

Staffs at Obstetrical departments at County hospital Ryhov in Jönköping, University hospital in Linköping, Kalmar county hospital and County hospital Vrinnevi in Norrköping for your willingness to assist with blood sampling and preparing placental biopsies.

Staffs at antenatal health care centres in Jönköping and Linköping for your contribution with recruitement of patients and blood sampling.

Laboratory staff at AIR for always supporting me in all my studies in different ways.

Futurum academy for Health and Care Jönköping County Council, Sweden for a very generous support during my entire time as $\mathrm{PhD}$ student, which was a prerequisite for 
me to be able to accomplish this studies and simultaneously maintain my job as a clinically active obstetrician and gynaecologist.

FORSS (Medical Research Council of Southeast Sweden) for supporting all my projects financially very generously.

All my colleagues at Department of Obstetrics and Gynaecology at County hospital Ryhov in Jönköping for accepting without complaints my absence from my clinical work due to the work with this thesis.

My three daughters Therese, Josephine and Cecilia with their families for always encouraging me in my work.

Carin, the one and only woman of my life, for all her support and patience during all years of research and studies. 


\section{References}

1. American College of Obstetricians and gynecologists ibI. Hypertension, Pregnancy-InducedPractice Guideline. 2013.

2. Beck S, Wojdyla D, Say L, Betran AP, Merialdi M, Requejo JH, et al. The worldwide incidence of preterm birth: a systematic review of maternal mortality and morbidity. Bull World Health Organ. 2010;88:31-8.

3. Duley L. The global impact of pre-eclampsia and eclampsia. Semin Perinatol. 2009;33:130-7. 4. Ferrara A, Kahn HS, Quesenberry CP, Riley C, Hedderson MM. An increase in the incidence of gestational diabetes mellitus: Northern California, 1991-2000. Obstet Gynecol. 2004;103:526-33.

5. Raymond D, Peterson E. A critical review of early-onset and late-onset preeclampsia. Obstet Gynecol Surv. 2011;66:497-506.

6. Wikstrom AK, Nash P, Eriksson UJ, Olovsson MH. Evidence of increased oxidative stress and a change in the plasminogen activator inhibitor (PAI)-1 to PAI-2 ratio in early-onset but not lateonset preeclampsia. Am J Obstet Gynecol. 2009;201:597 e1-8.

7. Vatten LJ, Skjaerven R. Is pre-eclampsia more than one disease? BJOG. 2004;111:298-302.

8. Schlembach D. Pre-eclampsia--still a disease of theories. Fukushima J Med Sci. 2003;49:69-115.

9. Redman CW, Sargent IL. Immunology of pre-eclampsia. Am J Reprod Immunol. 2010;63:53443.

10. Borzychowski AM, Croy BA, Chan WL, Redman CW, Sargent IL. Changes in systemic type 1 and type 2 immunity in normal pregnancy and pre-eclampsia may be mediated by natural killer cells. Eur J Immunol. 2005;35:3054-63.

11. Darmochwal-Kolarz D, Leszczynska-Gorzelak B, Rolinski J, Oleszczuk J. T helper 1- and T helper 2-type cytokine imbalance in pregnant women with pre-eclampsia. Eur J Obstet Gynecol Reprod Biol. 1999;86:165-70.

12. Darmochwal-Kolarz D, Kludka-Sternik M, Tabarkiewicz J, Kolarz B, Rolinski J, LeszczynskaGorzelak B, et al. The predominance of Th17 lymphocytes and decreased number and function of Treg cells in preeclampsia. J Reprod Immunol. 2012;93:75-81.

13. Raghupathy R, Makhseed M, Azizieh F, Hassan N, Al-Azemi M, Al-Shamali E. Maternal Th1and Th2-type reactivity to placental antigens in normal human pregnancy and unexplained recurrent spontaneous abortions. Cell Immunol. 1999;196:122-30.

14. Saito S, Nakashima A, Shima T, Ito M. Th1/Th2/Th17 and regulatory T-cell paradigm in pregnancy. Am J Reprod Immunol. 2010;63:601-10.

15. Mjosberg J, Berg G, Jenmalm MC, Ernerudh J. FOXP3+ regulatory T cells and T helper 1, T helper 2, and T helper 17 cells in human early pregnancy decidua. Biol Reprod. 2009;82:698-705. 16. Burton GJ, Charnock-Jones DS, Jauniaux E. Regulation of vascular growth and function in the human placenta. Reproduction. 2009;138:895-902.

17. Tuuli MG, Longtine MS, Nelson DM. Review: Oxygen and trophoblast biology--a source of controversy. Placenta. 2011;32 Suppl 2:S109-18.

18. Lam C, Lim KH, Karumanchi SA. Circulating angiogenic factors in the pathogenesis and prediction of preeclampsia. Hypertension. 2005;46:1077-85.

19. Toal M, Chan C, Fallah S, Alkazaleh F, Chaddha V, Windrim RC, et al. Usefulness of a placental profile in high-risk pregnancies. Am J Obstet Gynecol. 2007;196:363 e1-7.

20. Burton GJ, Jauniaux E. Placental oxidative stress: from miscarriage to preeclampsia. J Soc Gynecol Investig. 2004;11:342-52.

21. Burton GJ. Oxygen, the Janus gas; its effects on human placental development and function. J Anat. 2009;215:27-35.

22. Burton GJ, Woods AW, Jauniaux E, Kingdom JC. Rheological and physiological consequences of conversion of the maternal spiral arteries for uteroplacental blood flow during human pregnancy. Placenta. 2009;30:473-82.

23. Huppertz B, Kingdom JC. Apoptosis in the trophoblast--role of apoptosis in placental morphogenesis. J Soc Gynecol Investig. 2004;11:353-62.

24. Keelan JA, Mitchell MD. Placental cytokines and preeclampsia. Front Biosci. 2007;12:2706-27. 
25. Redman CW, Sargent IL. Placental debris, oxidative stress and pre-eclampsia. Placenta. 2000;21:597-602.

26. Redman CW, Sargent IL, Staff AC. IFPA Senior Award Lecture: making sense of preeclampsia - two placental causes of preeclampsia? Placenta. 2014;35 Suppl:S20-5.

27. Jauniaux E, Watson AL, Hempstock J, Bao YP, Skepper JN, Burton GJ. Onset of maternal arterial blood flow and placental oxidative stress. A possible factor in human early pregnancy failure. Am J Pathol. 2000;157:2111-22.

28. Huppertz B. Placental origins of preeclampsia: challenging the current hypothesis.

Hypertension. 2008;51:970-5.

29. Redman CW, Sargent IL. Immunology of pre-eclampsia. Am J Reprod Immunol.63:534-43.

30. Borzychowski AM, Sargent IL, Redman CW. Inflammation and pre-eclampsia. Semin Fetal Neonatal Med. 2006;11:309-16.

31. Olsson MG, Centlow M, Rutardottir S, Stenfors I, Larsson J, Hosseini-Maaf B, et al. Increased levels of cell-free hemoglobin, oxidation markers, and the antioxidative heme scavenger alpha(1)microglobulin in preeclampsia. Free Radic Biol Med. 2010;48:284-91.

32. Derzsy Z, Prohaszka Z, Rigo J, Jr., Fust G, Molvarec A. Activation of the complement system in normal pregnancy and preeclampsia. Mol Immunol. 2010;47:1500-6.

33. Zhang J. Partner change, birth interval and risk of pre-eclampsia: a paradoxical triangle.

Paediatr Perinat Epidemiol. 2007;21 Suppl 1:31-5.

34. Robertson SA, Guerin LR, Bromfield JJ, Branson KM, Ahlstrom AC, Care AS. Seminal fluid drives expansion of the CD4+CD25+ T regulatory cell pool and induces tolerance to paternal alloantigens in mice. Biol Reprod. 2009;80:1036-45.

35. Dekker G. The partner's role in the etiology of preeclampsia. J Reprod Immunol. 2002;57:20315.

36. Seavey MM, Mosmann TR. Immunoregulation of fetal and anti-paternal immune responses. Immunol Res. 2008;40:97-113.

37. Koopman LA, Kopcow HD, Rybalov B, Boyson JE, Orange JS, Schatz F, et al. Human decidual natural killer cells are a unique NK cell subset with immunomodulatory potential. J Exp Med. 2003; 198:1201-12.

38. Vivier E, Tomasello E, Baratin M, Walzer T, Ugolini S. Functions of natural killer cells. Nat Immunol. 2008;9:503-10.

39. Nagler A, Lanier LL, Cwirla S, Phillips JH. Comparative studies of human FcRIII-positive and negative natural killer cells. J Immunol. 1989;143:3183-91.

40. Cooper MA, Fehniger TA, Caligiuri MA. The biology of human natural killer-cell subsets. Trends Immunol. 2001;22:633-40.

41. Hanna J, Goldman-Wohl D, Hamani Y, Avraham I, Greenfield C, Natanson-Yaron S, et al. Decidual NK cells regulate key developmental processes at the human fetal-maternal interface. Nat Med. 2006;12:1065-74.

42. Kopcow HD, Allan DS, Chen X, Rybalov B, Andzelm MM, Ge B, et al. Human decidual NK cells form immature activating synapses and are not cytotoxic. Proc Natl Acad Sci U S A.

2005;102:15563-8.

43. King A, Balendran N, Wooding P, Carter NP, Loke YW. CD3- leukocytes present in the human uterus during early placentation: phenotypic and morphologic characterization of the CD56++ population. Dev Immunol. 1991;1:169-90.

44. Manaster I, Mandelboim O. The unique properties of uterine NK cells. Am J Reprod Immunol. 2010;63:434-44.

45. Vacca P, Moretta L, Moretta A, Mingari MC. Origin, phenotype and function of human natural killer cells in pregnancy. Trends Immunol. 2011;32:517-23.

46. Moffett A, Hiby SE. How Does the maternal immune system contribute to the development of pre-eclampsia? Placenta. 2007;28 Suppl A:S51-6.

47. Parham P. Influence of KIR diversity on human immunity. Adv Exp Med Biol. 2005;560:47-50. 
48. Lash GE, Naruse K, Robson A, Innes BA, Searle RF, Robson SC, et al. Interaction between uterine natural killer cells and extravillous trophoblast cells: effect on cytokine and angiogenic growth factor production. Hum Reprod. 2011;26:2289-95.

49. Engert S, Rieger L, Kapp M, Becker JC, Dietl J, Kammerer U. Profiling chemokines, cytokines and growth factors in human early pregnancy decidua by protein array. Am J Reprod Immunol. 2007;58:129-37.

50. Kalkunte SS, Mselle TF, Norris WE, Wira CR, Sentman CL, Sharma S. Vascular endothelial growth factor $\mathrm{C}$ facilitates immune tolerance and endovascular activity of human uterine NK cells at the maternal-fetal interface. J Immunol. 2009;182:4085-92.

51. Sargent IL, Borzychowski AM, Redman CW. NK cells and pre-eclampsia. J Reprod Immunol. 2007;76:40-4.

52. Zhang Z, Gong F, Jia L, Chang C, Hou L, Yang R, et al. Studies on activity of NK cells in preeclampsia patients. J Huazhong Univ Sci Technolog Med Sci. 2004;24:473-5.

53. Svensson-Arvelund J, Ernerudh J, Buse E, Cline JM, Haeger JD, Dixon D, et al. The placenta in toxicology. Part II: Systemic and local immune adaptations in pregnancy. Toxicol Pathol.

2014;42:327-38.

54. Mantovani A. MSCs, macrophages, and cancer: a dangerous menage-a-trois. Cell Stem Cell. 2012;11:730-2.

55. Gordon S. Alternative activation of macrophages. Nat Rev Immunol. 2003;3:23-35.

56. Mantovani A, Sica A, Sozzani S, Allavena P, Vecchi A, Locati M. The chemokine system in diverse forms of macrophage activation and polarization. Trends Immunol. 2004;25:677-86.

57. Svensson J, Jenmalm MC, Matussek A, Geffers R, Berg G, Ernerudh J. Macrophages at the fetal-maternal interface express markers of alternative activation and are induced by M-CSF and IL10. J Immunol. 2011;187:3671-82.

58. Svensson-Arvelund J, Mehta RB, Lindau R, Mirrasekhian E, Rodriguez-Martinez H, Berg G, et al. The human fetal placenta promotes tolerance against the semiallogeneic fetus by inducing regulatory T cells and homeostatic M2 macrophages. J Immunol. 2015;194:1534-44.

59. Nagamatsu T, Schust DJ. The immunomodulatory roles of macrophages at the maternal-fetal interface. Reprod Sci. 2010;17:209-18.

60. Svensson-Arvelund J, Ernerudh J. The Role of Macrophages in Promoting and Maintaining Homeostasis at the Fetal-Maternal Interface. Am J Reprod Immunol. 2015;74:100-9.

61. Chen W. Tregs in immunotherapy: opportunities and challenges. Immunotherapy. 2011;3:9114.

62. Miyara M, Yoshioka Y, Kitoh A, Shima T, Wing K, Niwa A, et al. Functional delineation and differentiation dynamics of human CD4+ T cells expressing the FoxP3 transcription factor.

Immunity. 2009;30:899-911.

63. Shevach EM. Regulatory T cells in autoimmmunity*. Annu Rev Immunol. 2000;18:423-49.

64. Baban B, Chandler PR, Sharma MD, Pihkala J, Koni PA, Munn DH, et al. IDO activates

regulatory T cells and blocks their conversion into Th17-like T cells. J Immunol. 2009;183:247583.

65. Nishizawa H, Hasegawa K, Suzuki M, Kamoshida S, Kato T, Saito K, et al. The etiological role of allogeneic fetal rejection in pre-eclampsia. Am J Reprod Immunol. 2007;58:11-20.

66. Tilburgs T, Roelen DL, van der Mast BJ, de Groot-Swings GM, Kleijburg C, Scherjon SA, et al. Evidence for a selective migration of fetus-specific CD4+CD25bright regulatory $\mathrm{T}$ cells from the peripheral blood to the decidua in human pregnancy. J Immunol. 2008;180:5737-45.

67. Mjosberg J, Svensson J, Johansson E, Hellstrom L, Casas R, Jenmalm MC, et al. Systemic reduction of functionally suppressive CD4dimCD25highFoxp3+ Tregs in human second trimester pregnancy is induced by progesterone and 17beta-estradiol. J Immunol. 2009;183:759-69.

68. Aluvihare VR, Kallikourdis M, Betz AG. Regulatory T cells mediate maternal tolerance to the fetus. Nat Immunol. 2004;5:266-71.

69. Sasaki Y, Sakai M, Miyazaki S, Higuma S, Shiozaki A, Saito S. Decidual and peripheral blood CD4+CD25+ regulatory T cells in early pregnancy subjects and spontaneous abortion cases. Mol Hum Reprod. 2004;10:347-53. 
70. Schumacher A, Brachwitz N, Sohr S, Engeland K, Langwisch S, Dolaptchieva M, et al. Human chorionic gonadotropin attracts regulatory $\mathrm{T}$ cells into the fetal-maternal interface during early human pregnancy. J Immunol. 2009;182:5488-97.

71. Dimova T, Nagaeva O, Stenqvist AC, Hedlund M, Kjellberg L, Strand M, et al. Maternal Foxp3 expressing CD4+CD25+ and CD4+ CD25- regulatory T-cell populations are enriched in human early normal pregnancy decidua: a phenotypic study of paired decidual and peripheral blood samples. Am J Reprod Immunol. 2011;66 Suppl 1:44-56.

72. Mjosberg J, Berg G, Jenmalm MC, Ernerudh J. FOXP3+ regulatory T cells and T helper 1, T helper 2, and T helper 17 cells in human early pregnancy decidua. Biol Reprod. 2010;82:698-705. 73. Prins JR, Boelens HM, Heimweg J, Van der Heide S, Dubois AE, Van Oosterhout AJ, et al. Preeclampsia is associated with lower percentages of regulatory T cells in maternal blood. Hypertens Pregnancy. 2009;28:300-11.

74. Hu D, Chen Y, Zhang W, Wang H, Wang Z, Dong M. Alteration of peripheral CD4+CD25+ regulatory $\mathrm{T}$ lymphocytes in pregnancy and pre-eclampsia. Acta Obstet Gynecol Scand.

2008;87:190-4.

75. Paeschke S, Chen F, Horn N, Fotopoulou C, Zambon-Bertoja A, Sollwedel A, et al. Preeclampsia is not associated with changes in the levels of regulatory T cells in peripheral blood. Am J Reprod Immunol. 2005;54:384-9.

76. Saito S, Nakashima A, Ito M, Shima T. Clinical implication of recent advances in our understanding of IL-17 and reproductive immunology. Expert Rev Clin Immunol. 2011;7:649-57. 77. Saito S. Th17 cells and regulatory T cells: new light on pathophysiology of preeclampsia. Immunol Cell Biol. 2010;88:615-7.

78. Ernerudh J, Berg G, Mjosberg J. Regulatory T helper cells in pregnancy and their roles in systemic versus local immune tolerance. Am J Reprod Immunol.66 Suppl 1:31-43.

79. Jones RL, Stoikos C, Findlay JK, Salamonsen LA. TGF-beta superfamily expression and actions in the endometrium and placenta. Reproduction. 2006;132:217-32.

80. Tilburgs T, Scherjon SA, van der Mast BJ, Haasnoot GW, Versteeg VDV-MM, Roelen DL, et al. Fetal-maternal HLA-C mismatch is associated with decidual T cell activation and induction of functional T regulatory cells. J Reprod Immunol. 2009;82:148-57.

81. Komatsu N, Mariotti-Ferrandiz ME, Wang Y, Malissen B, Waldmann H, Hori S. Heterogeneity of natural Foxp3+ T cells: a committed regulatory T-cell lineage and an uncommitted minor population retaining plasticity. Proc Natl Acad Sci U S A. 2009;106:1903-8.

82. Lackie J. "Cytokine" in . A Dictionary of Biomedicine.Oxford University Press. . 2010.

83. Bowen JM, Chamley L, Keelan JA, Mitchell MD. Cytokines of the placenta and extra-placental membranes: roles and regulation during human pregnancy and parturition. Placenta. 2002;23:25773.

84. Jonsson Y, Ruber M, Matthiesen L, Berg G, Nieminen K, Sharma S, et al. Cytokine mapping of sera from women with preeclampsia and normal pregnancies. J Reprod Immunol. 2006;70:83-91. 85. Saito S, Sakai M. Th1/Th2 balance in preeclampsia. J Reprod Immunol. 2003;59:161-73. 86. Chaouat G, Zourbas S, Ostojic S, Lappree-Delage G, Dubanchet S, Ledee N, et al. A brief review of recent data on some cytokine expressions at the materno-foetal interface which might challenge the classical Th1/Th2 dichotomy. J Reprod Immunol. 2002;53:241-56.

87. Le Y, Zhou Y, Iribarren P, Wang J. Chemokines and chemokine receptors: their manifold roles in homeostasis and disease. Cell Mol Immunol. 2004;1:95-104.

88. Rosenkilde MM, Schwartz TW. The chemokine system -- a major regulator of angiogenesis in health and disease. APMIS. 2004;112:481-95.

89. Belperio JA, Keane MP, Arenberg DA, Addison CL, Ehlert JE, Burdick MD, et al. CXC chemokines in angiogenesis. J Leukoc Biol. 2000;68:1-8.

90. Nagaoka K, Sakai A, Nojima H, Suda Y, Yokomizo Y, Imakawa K, et al. A chemokine, interferon (IFN)-gamma-inducible protein $10 \mathrm{kDa}$, is stimulated by IFN-tau and recruits immune cells in the ovine endometrium. Biol Reprod. 2003;68:1413-21. 
91. Loetscher M, Gerber B, Loetscher P, Jones SA, Piali L, Clark-Lewis I, et al. Chemokine receptor specific for IP10 and mig: structure, function, and expression in activated T-lymphocytes. J Exp Med. 1996;184:963-9.

92. Sallusto F, Lenig D, Mackay CR, Lanzavecchia A. Flexible programs of chemokine receptor expression on human polarized T helper 1 and 2 lymphocytes. J Exp Med. 1998;187:875-83.

93. Wallace AE, Cartwright JE, Begum R, Laing K, Thilaganathan B, Whitley GS. Trophoblastinduced changes in $\mathrm{C}$-x-C motif chemokine 10 expression contribute to vascular smooth muscle cell dedifferentiation during spiral artery remodeling. Arterioscler Thromb Vasc Biol. 2013;33:e93e101.

94. Goldberg SH, van der Meer P, Hesselgesser J, Jaffer S, Kolson DL, Albright AV, et al. CXCR3 expression in human central nervous system diseases. Neuropathol Appl Neurobiol. 2001;27:12738.

95. Gotsch F, Romero R, Friel L, Kusanovic JP, Espinoza J, Erez O, et al. CXCL10/IP-10: a missing link between inflammation and anti-angiogenesis in preeclampsia? J Matern Fetal Neonatal Med. 2007;20:777-92.

96. Lee J, Romero R, Chaiworapongsa T, Dong Z, Tarca AL, Xu Y, et al. Characterization of the fetal blood transcriptome and proteome in maternal anti-fetal rejection: evidence of a distinct and novel type of human fetal systemic inflammatory response. Am J Reprod Immunol. 2013;70:26584.

97. Zhang Z, Kaptanoglu L, Haddad W, Ivancic D, Alnadjim Z, Hurst S, et al. Donor T cell activation initiates small bowel allograft rejection through an IFN-gamma-inducible protein-10dependent mechanism. J Immunol. 2002;168:3205-12.

98. Islam SA, Ling MF, Leung J, Shreffler WG, Luster AD. Identification of human CCR8 as a CCL18 receptor. J Exp Med. 2013;210:1889-98.

99. Gustafsson C, Mjosberg J, Matussek A, Geffers R, Matthiesen L, Berg G, et al. Gene expression profiling of human decidual macrophages: evidence for immunosuppressive phenotype. PLoS One. 2008;3:e2078.

100. Tranquilli AL, Landi B, Corradetti A, Giannubilo SR, Sartini D, Pozzi V, et al. Inflammatory cytokines patterns in the placenta of pregnancies complicated by HELLP (hemolysis, elevated liver enzyme, and low platelet) syndrome. Cytokine. 2007;40:82-8.

101. Schutyser E, Struyf S, Menten P, Lenaerts JP, Conings R, Put W, et al. Regulated production and molecular diversity of human liver and activation-regulated chemokine/macrophage inflammatory protein-3 alpha from normal and transformed cells. J Immunol. 2000;165:4470-7. 102. Laudanski P, Lemancewicz A, Pierzynski P, Akerlund M, Laudanski T. Decreased serum level of macrophage inflammatory chemokine-3beta/CCL19 in preterm labor and delivery. Eur J Obstet Gynecol Reprod Biol. 2006;124:23-6.

103. Huang SJ, Chen CP, Schatz F, Rahman M, Abrahams VM, Lockwood CJ. Pre-eclampsia is associated with dendritic cell recruitment into the uterine decidua. J Pathol. 2008;214:328-36.

104. Hamill N, Romero R, Gotsch F, Kusanovic JP, Edwin S, Erez O, et al. Exodus-1 (CCL20): evidence for the participation of this chemokine in spontaneous labor at term, preterm labor, and intrauterine infection. J Perinat Med. 2008;36:217-27.

105. Freier CP, Kuhn C, Rapp M, Endres S, Mayr D, Friese K, et al. Expression of CCL22 and Infiltration by Regulatory T Cells are Increased in the Decidua of Human Miscarriage Placentas. Am J Reprod Immunol. 2015;74:216-27.

106. Holtan SG, Chen Y, Kaimal R, Creedon DJ, Enninga EA, Nevala WK, et al. Growth modeling of the maternal cytokine milieu throughout normal pregnancy: macrophage-derived chemokine decreases as inflammation/counterregulation increases. J Immunol Res. 2015;2015:952571. 107. Sacks G, Sargent I, Redman C. An innate view of human pregnancy. Immunol Today. 1999;20:114-8.

108. Redman CW, Sacks GP, Sargent IL. Preeclampsia: an excessive maternal inflammatory response to pregnancy. Am J Obstet Gynecol. 1999;180:499-506.

109. Redman CW. Immunology of preeclampsia. Semin Perinatol. 1991;15:257-62. 
110. Mincheva-Nilsson L, Baranov V. Placenta-derived exosomes and syncytiotrophoblast microparticles and their role in human reproduction: immune modulation for pregnancy success. Am J Reprod Immunol. 2014;72:440-57.

111. Mincheva-Nilsson L, Baranov V. The role of placental exosomes in reproduction. Am J Reprod Immunol. 2010;63:520-33.

112. Germain SJ, Sacks GP, Sooranna SR, Sargent IL, Redman CW. Systemic inflammatory priming in normal pregnancy and preeclampsia: the role of circulating syncytiotrophoblast microparticles. J Immunol. 2007;178:5949-56.

113. Dekel N, Gnainsky Y, Granot I, Mor G. Inflammation and implantation. Am J Reprod Immunol. 2010;63:17-21.

114. Redman CW, Sargent IL. Pre-eclampsia, the placenta and the maternal systemic inflammatory response--a review. Placenta. 2003;24 Suppl A:S21-7.

115. Wolf M, Kettyle E, Sandler L, Ecker JL, Roberts J, Thadhani R. Obesity and preeclampsia: the potential role of inflammation. Obstet Gynecol. 2001;98:757-62.

116. Salmon JE, Heuser C, Triebwasser M, Liszewski MK, Kavanagh D, Roumenina L, et al. Mutations in complement regulatory proteins predispose to preeclampsia: a genetic analysis of the PROMISSE cohort. PLoS Med. 2011;8:e1001013.

117. Lynch AM, Murphy JR, Gibbs RS, Levine RJ, Giclas PC, Salmon JE, et al. The interrelationship of complement-activation fragments and angiogenesis-related factors in early pregnancy and their association with pre-eclampsia. BJOG. 2010;117:456-62.

118. Burwick RM, Feinberg BB. Eculizumab for the treatment of preeclampsia/HELLP syndrome. Placenta. 2013;34:201-3.

119. Bremme KA. Haemostatic changes in pregnancy. Best Pract Res Clin Haematol. 2003;16:15368.

120. Cerneca F, Ricci G, Simeone R, Malisano M, Alberico S, Guaschino S. Coagulation and fibrinolysis changes in normal pregnancy. Increased levels of procoagulants and reduced levels of inhibitors during pregnancy induce a hypercoagulable state, combined with a reactive fibrinolysis. Eur J Obstet Gynecol Reprod Biol. 1997;73:31-6.

121. Savelieva GM, Efimov VS, Grishin VL, Shalina RI, Kashezheva AZ. Blood coagulation changes in pregnant women at risk of developing preeclampsia. Int J Gynaecol Obstet. 1995;48:3-8.

122. Gilabert J, Reganon E, Vila V, Baamonde A, Villa P, Aznar J, et al. Congenital hypofibrinogenemia and pregnancy, obstetric and hematological management. Gynecol Obstet Invest. 1987;24:271-6.

123. Aharon A, Brenner B, Katz T, Miyagi Y, Lanir N. Tissue factor and tissue factor pathway inhibitor levels in trophoblast cells: implications for placental hemostasis. Thromb Haemost. 2004;92:776-86.

124. Drake TA, Morrissey JH, Edgington TS. Selective cellular expression of tissue factor in human tissues. Implications for disorders of hemostasis and thrombosis. Am J Pathol. 1989;134:1087-97.

125. Mackman N. Mouse models in haemostasis and thrombosis. Thromb Haemost. 2004;92:440-3.

126. Li M, Huang SJ. Innate immunity, coagulation and placenta-related adverse pregnancy outcomes. Thromb Res. 2009;124:656-62.

127. VanWijk MJ, Boer K, Berckmans RJ, Meijers JC, van der Post JA, Sturk A, et al. Enhanced coagulation activation in preeclampsia: the role of APC resistance, microparticles and other plasma constituents. Thromb Haemost. 2002;88:415-20.

128. Heit JA. Thrombophilia: common questions on laboratory assessment and management. Hematology Am Soc Hematol Educ Program. 2007:127-35.

129. Hellgren M. Hemostasis during normal pregnancy and puerperium. Semin Thromb Hemost. 2003;29:125-30.

130. Esmon CT. Inflammation and thrombosis. J Thromb Haemost. 2003;1:1343-8.

131. Esmon CT. Coagulation and inflammation. J Endotoxin Res. 2003;9:192-8.

132. Dizon-Townson DS, Nelson LM, Easton K, Ward K. The factor V Leiden mutation may predispose women to severe preeclampsia. Am J Obstet Gynecol. 1996;175:902-5. 
133. Kupferminc MJ, Eldor A, Steinman N, Many A, Bar-Am A, Jaffa A, et al. Increased frequency of genetic thrombophilia in women with complications of pregnancy. N Engl J Med. 1999;340:913.

134. Mustonen T, Alitalo K. Endothelial receptor tyrosine kinases involved in angiogenesis. J Cell Biol. 1995;129:895-8.

135. Park JE, Chen HH, Winer J, Houck KA, Ferrara N. Placenta growth factor. Potentiation of vascular endothelial growth factor bioactivity, in vitro and in vivo, and high affinity binding to Flt-1 but not to Flk-1/KDR. J Biol Chem. 1994;269:25646-54.

136. Shweiki D, Itin A, Soffer D, Keshet E. Vascular endothelial growth factor induced by hypoxia may mediate hypoxia-initiated angiogenesis. Nature. 1992;359:843-5.

137. Ahmad S, Ahmed A. Elevated placental soluble vascular endothelial growth factor receptor-1 inhibits angiogenesis in preeclampsia. Circ Res. 2004;95:884-91.

138. Mayhew TM, Wijesekara J, Baker PN, Ong SS. Morphometric evidence that villous development and fetoplacental angiogenesis are compromised by intrauterine growth restriction but not by pre-eclampsia. Placenta. 2004;25:829-33.

139. Hagmann H, Thadhani R, Benzing T, Karumanchi SA, Stepan H. The promise of angiogenic markers for the early diagnosis and prediction of preeclampsia. Clin Chem. 2012;58:837-45.

140. Yuan HT, Haig D, Ananth Karumanchi S. Angiogenic factors in the pathogenesis of preeclampsia. Curr Top Dev Biol. 2005;71:297-312.

141. Maynard S, Epstein FH, Karumanchi SA. Preeclampsia and angiogenic imbalance. Annu Rev Med. 2008;59:61-78.

142. Stepan H, Herraiz I, Schlembach D, Verlohren S, Brennecke S, Chantraine F, et al. Implementation of the sFlt-1/P1GF ratio for prediction and diagnosis of pre-eclampsia in singleton pregnancy: implications for clinical practice. Ultrasound Obstet Gynecol. 2015;45:241-6.

143. Poon LC, Nicolaides KH. Early prediction of preeclampsia. Obstet Gynecol Int. 2014;2014:297397.

144. Bujold E, Roberge S, Lacasse Y, Bureau M, Audibert F, Marcoux S, et al. Prevention of preeclampsia and intrauterine growth restriction with aspirin started in early pregnancy: a metaanalysis. Obstet Gynecol. 2010;116:402-14.

145. Henderson JT, Whitlock EP, O'Connor E, Senger CA, Thompson JH, Rowland MG. Low-dose aspirin for prevention of morbidity and mortality from preeclampsia: a systematic evidence review for the U.S. Preventive Services Task Force. Ann Intern Med. 2014;160:695-703.

146. Roberge S, Demers S, Nicolaides KH, Bureau M, Cote S, Bujold E. Prevention of preeclampsia by low-molecular-weight heparin in addition to aspirin: a meta-analysis. Ultrasound Obstet Gynecol. 2016;47:548-53.

147. Roberge S, Nicolaides K, Demers S, Hyett J, Chaillet N, Bujold E. The role of aspirin dose on the prevention of preeclampsia and fetal growth restriction: systematic review and meta-analysis. Am J Obstet Gynecol. 2016.

148. Ramma W, Ahmed A. Therapeutic potential of statins and the induction of heme oxygenase-1 in preeclampsia. J Reprod Immunol. 2014;101-102:153-60.

149. Costantine MM, Cleary K, Eunice Kennedy Shriver National Institute of Child H, Human Development Obstetric--Fetal Pharmacology Research Units N. Pravastatin for the prevention of preeclampsia in high-risk pregnant women. Obstet Gynecol. 2013;121:349-53.

150. Kobayashi T, Terao T, Ikenoue T, Sameshima H, Nakabayashi M, Kajiwara Y, et al.

Treatment of severe preeclampsia with antithrombin concentrate: results of a prospective feasibility study. Semin Thromb Hemost. 2003;29:645-52.

151. Paidas MJ, Sibai BM, Triche EW, Frieling J, Lowry S, Group P-S. Exploring the role of antithrombin replacement for the treatment of preeclampsia: a prospective randomized evaluation of the safety and efficacy of recombinant antithrombin in very preterm preeclampsia (PRESERVE-1). Am J Reprod Immunol. 2013;69:539-44.

152. Bulletins--Obstetrics ACoP. ACOG practice bulletin. Diagnosis and management of preeclampsia and eclampsia. Number 33, January 2002. Obstet Gynecol. 2002;99:159-67. 
153. Festing S, Wilkinson R. The ethics of animal research. Talking Point on the use of animals in scientific research. EMBO Rep. 2007;8:526-30.

154. Foëx B. The ethics of animal experimentation. : EMJ. 2007;24(11):.

doi:10.1136/emj.2007.050146. Emergency Medicine Journal 2007;24:750-1.

155. Sechzer JA. Historical issues concerning animal experimentation in the United States. Soc Sci Med F. 1981;15:13-7.

156. Weatherall D. Animal research: the debate continues. Lancet. 2007;369:1147-8.

157. Ghasemi M, Dehpour AR. Ethical considerations in animal studies. J Med Ethics Hist Med. 2009;2:12.

158. Benirschke K. House mouse (Mus musculus) - Comparative Placentation. 2002.

159. Rossant J, Cross JC. Placental development: lessons from mouse mutants. Nat Rev Genet. 2001;2:538-48.

160. Kalkunte S, Lai Z, Tewari N, Chichester C, Romero R, Padbury J, et al. In vitro and in vivo evidence for lack of endovascular remodeling by third trimester trophoblasts. Placenta.

2008;29:871-8.

161. Tewari N, Kalkunte S, Murray DW, Sharma S. The water channel aquaporin 1 is a novel molecular target of polychlorinated biphenyls for in utero anomalies. J Biol Chem.

2009;284:15224-32.

162. Lequin RM. Enzyme immunoassay (EIA)/enzyme-linked immunosorbent assay (ELISA). Clin Chem. 2005;51:2415-8.

163. Burgos-Ramos E M-MG, Argente J BV. Multiplexed Bead Immunoassays:

Advantages and Limitations in Pediatrics www intechopencom. 2012.

164. Vignali DA. Multiplexed particle-based flow cytometric assays. J Immunol Methods.

2000;243:243-55.

165. Liu MY, Xydakis AM, Hoogeveen RC, Jones PH, Smith EO, Nelson KW, et al. Multiplexed analysis of biomarkers related to obesity and the metabolic syndrome in human plasma, using the Luminex-100 system. Clin Chem. 2005;51:1102-9.

166. Martos-Moreno GA, Burgos-Ramos E, Canelles S, Argente J, Barrios V. Evaluation of a multiplex assay for adipokine concentrations in obese children. Clin Chem Lab Med. 2010;48:143946.

167. Leng SX, McElhaney JE, Walston JD, Xie D, Fedarko NS, Kuchel GA. ELISA and multiplex technologies for cytokine measurement in inflammation and aging research. J Gerontol A Biol Sci Med Sci. 2008;63:879-84.

168. Ormerod M. Flow cytometry -- A Basic Introduction. 2008.

169. O'Neill K, Aghaeepour N, Spidlen J, Brinkman R. Flow cytometry bioinformatics. PLoS Comput Biol. 2013;9:e1003365.

170. Jahan-Tigh RR, Ryan C, Obermoser G, Schwarzenberger K. Flow cytometry. J Invest Dermatol. 2012;132:e1.

171. Ramos-Vara JA, Miller MA. When tissue antigens and antibodies get along: revisiting the technical aspects of immunohistochemistry--the red, brown, and blue technique. Vet Pathol. 2014;51:42-87.

172. Matos LL, Trufelli DC, de Matos MG, da Silva Pinhal MA. Immunohistochemistry as an important tool in biomarkers detection and clinical practice. Biomark Insights. 2010;5:9-20.

173. Zhou CC, Ahmad S, Mi T, Abbasi S, Xia L, Day MC, et al. Autoantibody from women with preeclampsia induces soluble Fms-like tyrosine kinase-1 production via angiotensin type 1 receptor and calcineurin/nuclear factor of activated T-cells signaling. Hypertension. 2008;51:1010-9.

174. Zhou CC, Zhang Y, Irani RA, Zhang H, Mi T, Popek EJ, et al. Angiotensin receptor agonistic autoantibodies induce pre-eclampsia in pregnant mice. Nat Med. 2008;14:855-62.

175. Gaber LW, Spargo BH, Lindheimer MD. Renal pathology in pre-eclampsia. Baillieres Clin Obstet Gynaecol. 1994;8:443-68.

176. Romero R, Nien JK, Espinoza J, Todem D, Fu W, Chung H, et al. A longitudinal study of angiogenic (placental growth factor) and anti-angiogenic (soluble endoglin and soluble vascular 
endothelial growth factor receptor-1) factors in normal pregnancy and patients destined to develop preeclampsia and deliver a small for gestational age neonate. J Matern Fetal Neonatal Med.

2008;21:9-23.

177. Venkatesha S, Toporsian M, Lam C, Hanai J, Mammoto T, Kim YM, et al. Soluble endoglin contributes to the pathogenesis of preeclampsia. Nat Med. 2006;12:642-9.

178. Roberts JM, Hubel CA. The two stage model of preeclampsia: variations on the theme. Placenta. 2009;30 Suppl A:S32-7.

179. Koch CJ, Lord EM, Shapiro IM, Clyman RI, Evans SM. Imaging hypoxia and blood flow in normal tissues. Adv Exp Med Biol. 1997;428:585-93.

180. Hung TH, Skepper JN, Charnock-Jones DS, Burton GJ. Hypoxia-reoxygenation: a potent inducer of apoptotic changes in the human placenta and possible etiological factor in preeclampsia. Circ Res. 2002;90:1274-81.

181. Nevo O, Soleymanlou N, Wu Y, Xu J, Kingdom J, Many A, et al. Increased expression of sFlt1 in in vivo and in vitro models of human placental hypoxia is mediated by HIF-1. Am J Physiol Regul Integr Comp Physiol. 2006;291:R1085-93.

182. Caniggia I, Mostachfi H, Winter J, Gassmann M, Lye SJ, Kuliszewski M, et al. Hypoxiainducible factor-1 mediates the biological effects of oxygen on human trophoblast differentiation through TGFbeta(3). J Clin Invest. 2000;105:577-87.

183. Rajakumar A, Whitelock KA, Weissfeld LA, Daftary AR, Markovic N, Conrad KP. Selective overexpression of the hypoxia-inducible transcription factor, HIF-2alpha, in placentas from women with preeclampsia. Biol Reprod. 2001;64:499-506.

184. Mestas J, Hughes CC. Of mice and not men: differences between mouse and human immunology. J Immunol. 2004;172:2731-8.

185. Bowen RS, Gu Y, Zhang Y, Lewis DF, Wang Y. Hypoxia promotes interleukin-6 and -8 but reduces interleukin-10 production by placental trophoblast cells from preeclamptic pregnancies. $\mathrm{J}$ Soc Gynecol Investig. 2005;12:428-32.

186. Royle C, Lim S, Xu B, Tooher J, Ogle R, Hennessy A. Effect of hypoxia and exogenous IL-10 on the pro-inflammatory cytokine TNF-alpha and the anti-angiogenic molecule soluble Flt-1 in placental villous explants. Cytokine. 2009;47:56-60.

187. Gu Y, Lewis DF, Wang Y. Placental productions and expressions of soluble endoglin, soluble fms-like tyrosine kinase receptor-1, and placental growth factor in normal and preeclamptic pregnancies. J Clin Endocrinol Metab. 2008;93:260-6.

188. Haeger M, Unander M, Bengtsson A. Complement activation in relation to development of preeclampsia. Obstet Gynecol. 1991;78:46-9.

189. Rampersad R, Barton A, Sadovsky Y, Nelson DM. The C5b-9 membrane attack complex of complement activation localizes to villous trophoblast injury in vivo and modulates human trophoblast function in vitro. Placenta. 2008;29:855-61.

190. Guven MA, Coskun A, Ertas IE, Aral M, Zencirci B, Oksuz H. Association of maternal serum CRP, IL-6, TNF-alpha, homocysteine, folic acid and vitamin B12 levels with the severity of preeclampsia and fetal birth weight. Hypertens Pregnancy. 2009;28:190-200.

191. Madazli R, Aydin S, Uludag S, Vildan O, Tolun N. Maternal plasma levels of cytokines in normal and preeclamptic pregnancies and their relationship with diastolic blood pressure and fibronectin levels. Acta Obstet Gynecol Scand. 2003;82:797-802.

192. Tosun M, Celik H, Avci B, Yavuz E, Alper T, Malatyalioglu E. Maternal and umbilical serum levels of interleukin-6, interleukin-8, and tumor necrosis factor-alpha in normal pregnancies and in pregnancies complicated by preeclampsia. J Matern Fetal Neonatal Med. 2010;23:880-6.

193. Stumpf C, Auer C, Yilmaz A, Lewczuk P, Klinghammer L, Schneider M, et al. Serum levels of the Th1 chemoattractant interferon-gamma-inducible protein (IP) 10 are elevated in patients with essential hypertension. Hypertens Res. 2011;34:484-8.

194. Sandberg M, Frykman A, Ernerudh J, Berg G, Matthiesen L, Ekerfelt C, et al. Cord blood cytokines and chemokines and development of allergic disease. Pediatr Allergy Immunol.

2009;20:519-27. 
195. Pease JE, Williams TJ. Chemokines and their receptors in allergic disease. J Allergy Clin Immunol. 2006;118:305-18; quiz 19-20.

196. Kronborg CS, Gjedsted J, Vittinghus E, Hansen TK, Allen J, Knudsen UB. Longitudinal measurement of cytokines in pre-eclamptic and normotensive pregnancies. Acta Obstet Gynecol Scand. 2011;90:791-6.

197. Hayashi M, Ueda Y, Ohkura T, Inaba N. Interleukin-6 concentrations in the placenta and blood in normal pregnancies and preeclampsia. Horm Metab Res. 2005;37:419-24.

198. Djurovic S, Clausen T, Wergeland R, Brosstad F, Berg K, Henriksen T. Absence of enhanced systemic inflammatory response at 18 weeks of gestation in women with subsequent pre-eclampsia. BJOG. 2002;109:759-64.

199. Noori M, Donald AE, Angelakopoulou A, Hingorani AD, Williams DJ. Prospective study of placental angiogenic factors and maternal vascular function before and after preeclampsia and gestational hypertension. Circulation. 2010;122:478-87.

200. Wikstrom AK, Larsson A, Eriksson UJ, Nash P, Norden-Lindeberg S, Olovsson M. Placental growth factor and soluble FMS-like tyrosine kinase-1 in early-onset and late-onset preeclampsia. Obstet Gynecol. 2007;109:1368-74.

201. Varughese B, Bhatla N, Kumar R, Dwivedi SN, Dhingra R. Circulating angiogenic factors in pregnancies complicated by pre-eclampsia. Natl Med J India. 2010;23:77-81.

202. Jiang TT, Chaturvedi V, Ertelt JM, Kinder JM, Clark DR, Valent AM, et al. Regulatory T cells: new keys for further unlocking the enigma of fetal tolerance and pregnancy complications. J Immunol. 2014;192:4949-56.

203. Miyara M, Gorochov G, Ehrenstein M, Musset L, Sakaguchi S, Amoura Z. Human FoxP3+ regulatory T cells in systemic autoimmune diseases. Autoimmun Rev. 2011;10:744-55.

204. Navarro J, Aristimuno C, Sanchez-Ramon S, Vigil D, Martinez-Gines ML, Fernandez-Cruz E, et al. Circulating dendritic cells subsets and regulatory T-cells at multiple sclerosis relapse:

differential short-term changes on corticosteroids therapy. J Neuroimmunol. 2006;176:153-61.

205. Karagiannidis C, Akdis M, Holopainen P, Woolley NJ, Hense G, Ruckert B, et al.

Glucocorticoids upregulate FOXP3 expression and regulatory T cells in asthma. J Allergy Clin Immunol. 2004;114:1425-33.

206. Dimeloe S, Nanzer A, Ryanna K, Hawrylowicz C. Regulatory T cells, inflammation and the allergic response-The role of glucocorticoids and Vitamin D. J Steroid Biochem Mol Biol.

2010;120:86-95.

207. Chen X, Oppenheim JJ, Winkler-Pickett RT, Ortaldo JR, Howard OM. Glucocorticoid amplifies IL-2-dependent expansion of functional FoxP3(+)CD4(+)CD25(+) T regulatory cells in vivo and enhances their capacity to suppress EAE. Eur J Immunol. 2006;36:2139-49.

208. Moraes-Fontes MF, Rebelo M, Caramalho I, Zelenay S, Bergman ML, Coutinho A, et al. Steroid treatments in mice do not alter the number and function of regulatory T cells, but amplify cyclophosphamide-induced autoimmune disease. J Autoimmun. 2009;33:109-20.

209. Santner-Nanan B, Peek MJ, Khanam R, Richarts L, Zhu E, Fazekas de St Groth B, et al. Systemic increase in the ratio between Foxp3+ and IL-17-producing CD4+ T cells in healthy pregnancy but not in preeclampsia. J Immunol. 2009;183:7023-30.

210. Sasaki Y, Darmochwal-Kolarz D, Suzuki D, Sakai M, Ito M, Shima T, et al. Proportion of peripheral blood and decidual CD4(+) CD25(bright) regulatory T cells in pre-eclampsia. Clin Exp Immunol. 2007;149:139-45.

211. Steinborn A, Haensch GM, Mahnke K, Schmitt E, Toermer A, Meuer S, et al. Distinct subsets of regulatory T cells during pregnancy: is the imbalance of these subsets involved in the pathogenesis of preeclampsia? Clin Immunol. 2008;129:401-12.

212. Toldi G, Saito S, Shima T, Halmos A, Veresh Z, Vasarhelyi B, et al. The frequency of peripheral blood CD4+ CD25high FoxP3+ and CD4+ CD25- FoxP3+ regulatory T cells in normal pregnancy and pre-eclampsia. Am J Reprod Immunol. 2012;68:175-80.

213. Hsu P, Santner-Nanan B, Dahlstrom JE, Fadia M, Chandra A, Peek M, et al. Altered decidual DC-SIGN+ antigen-presenting cells and impaired regulatory T-cell induction in preeclampsia. Am J Pathol. 2012;181:2149-60. 
214. Toldi G, Svec P, Vasarhelyi B, Meszaros G, Rigo J, Tulassay T, et al. Decreased number of FoxP3+ regulatory T cells in preeclampsia. Acta Obstet Gynecol Scand. 2008;87:1229-33.

215. Ilekis JV, Reddy UM, Roberts JM. Preeclampsia--a pressing problem: an executive summary of a National Institute of Child Health and Human Development workshop. Reprod Sci.

2007;14:508-23.

216. Quinn KH, Lacoursiere DY, Cui L, Bui J, Parast MM. The unique pathophysiology of earlyonset severe preeclampsia: role of decidual T regulatory cells. J Reprod Immunol. 2011;91:76-82.

217. Boij R, Svensson J, Nilsson-Ekdahl K, Sandholm K, Lindahl TL, Palonek E, et al. Biomarkers of coagulation, inflammation, and angiogenesis are independently associated with preeclampsia. Am J Reprod Immunol.68:258-70.

218. Boij R, Mjosberg J, Svensson-Arvelund J, Hjorth M, Berg G, Matthiesen L, et al. Regulatory T-cell Subpopulations in Severe or Early-onset Preeclampsia. Am J Reprod Immunol. 2015;74:36878.

219. Jianjun Z, Yali H, Zhiqun W, Mingming Z, Xia Z. Imbalance of T-cell transcription factors contributes to the Th1 type immunity predominant in pre-eclampsia. Am J Reprod Immunol. 2010;63:38-45.

220. Fu B, Tian Z, Wei H. TH17 cells in human recurrent pregnancy loss and pre-eclampsia. Cell Mol Immunol. 2014;11:564-70.

221. Wu HX, Jin LP, Xu B, Liang SS, Li DJ. Decidual stromal cells recruit Th17 cells into decidua to promote proliferation and invasion of human trophoblast cells by secreting IL-17. Cell Mol Immunol. 2014;11:253-62.

222. Imakawa K, Nagaoka K, Nojima H, Hara Y, Christenson RK. Changes in immune cell distribution and IL-10 production are regulated through endometrial IP-10 expression in the goat uterus. Am J Reprod Immunol. 2005;53:54-64.

223. Nagaoka K, Nojima H, Watanabe F, Chang KT, Christenson RK, Sakai S, et al. Regulation of blastocyst migration, apposition, and initial adhesion by a chemokine, interferon gamma-inducible protein $10 \mathrm{kDa}$ (IP-10), during early gestation. J Biol Chem. 2003;278:29048-56.

224. Dominguez F, Martinez S, Quinonero A, Loro F, Horcajadas JA, Pellicer A, et al. CXCL10 and IL-6 induce chemotaxis in human trophoblast cell lines. Mol Hum Reprod. 2008;14:423-30. 225. Abelius MS, Lempinen E, Lindblad K, Ernerudh J, Berg G, Matthiesen L, et al. Th2-like chemokine levels are increased in allergic children and influenced by maternal immunity during pregnancy. Pediatr Allergy Immunol. 2014;25:387-93. 



\section{Papers}

The articles associated with this thesis have been removed for copyright reasons. For more details about these see:

http://urn.kb.se/resolve?urn=urn:nbn:se:liu:diva-132446 